\title{
1 Passive flow control for aerodynamic performance enhancement of airfoil with its application in Wells turbine - under oscillating flow condition
}

3

\author{
Ahmed S. Shehata ${ }^{1,2 *}$, Qing Xiao ${ }^{1}$, Khalid M. Saqr ${ }^{3}$, Ahmed Naguib ${ }^{2}$, Day Alexander ${ }^{1}$ \\ 1) Department of Naval Architecture, Ocean and Marine Engineering, University of \\ Strathclyde, Glasgow G4 OLZ, U.K
}

2) Marine Engineering Department, College of Engineering and Technology, Arab Academy for Science Technology and Maritime Transport, P.O. 1029 AbuQir,

Alexandria, EGYPT

3) Mechanical Engineering Department, College of Engineering and Technology, Arab Academy for Science Technology and Maritime Transport, P.O. 1029 AbuQir,

Alexandria, EGYPT

* Corresponding Author: Ahmed S. Shehata, E-mail address: ahmed.mohamed-ahmed-shehata@strath.ac.uk

\begin{abstract}
In this work, the passive flow control method was applied to improve the performance of symmetrical airfoil section in the stall regime. In addition to the commonly used first law analysis, the present study utilized an entropy generation minimization method to examine the impact of the flow control method on the entropy generation characteristics around the turbine blade. This work is performed using a time-dependent CFD model of isolated NACA airfoil, which refers to the turbine blade, under sinusoidal flow boundary conditions, which emulates the actual operating conditions. Wells turbine is one of the most proper applications that can be applied by passive flow control method because it is subjected to early stall. Additionally, it consists of a number of blades that have a symmetrical airfoil section subject to the wave condition. It is deduced that with the use of passive flow control, torque coefficient of blade increases by more than $40 \%$ within stall regime and by more than $17 \%$ before the stall happens. A significantly delayed stall is also observed.
\end{abstract}


1 Keywords: Sinusoidal flow; Wells turbine; Passive flow control method; Entropy generation;

2 Stall regime; Large Eddy Simulation.

\section{Nomenclature}

\begin{tabular}{|ll|}
\hline A & The total blade area $\left(\mathrm{m}^{2}\right)$ \\
$C_{D}$ & Blade chord $(\mathrm{m})$ \\
$C_{L}$ & Drag force coefficient \\
$C_{T}$ & Lift force coefficient \\
D & Torque coefficient \\
$D_{S S}$ & The fluid domain \\
$f$ & Suction slot diameter $(\mathrm{m})$ \\
$F_{D}$ & Cycle frequency $(\mathrm{Hz})$ \\
$\mathrm{G}$ & In-line force acting on cylinder $(\mathrm{N})$ \\
$K E$ & The filter function \\
$L_{S S}$ & Kinetic Energy $(\mathrm{J})$ \\
$K$ & Suction slot location from leading edge in chord percentage $\%$ \\
$\Delta \mathrm{p}$ & Turbulent kinetic energy $(\mathrm{J} / \mathrm{kg})$ \\
$R_{m}$ & Pressure difference across the turbine $\left(\mathrm{N} / \mathrm{m}^{2}\right)$ \\
$S_{g e n}$ & Mean rotor radius $(\mathrm{m})$ \\
$S_{G}$ & Local entropy generation rate $\left(\mathrm{W} / \mathrm{m}^{2} \mathrm{~K}\right)$ \\
$S_{i j}$ & Global entropy generation rate $(\mathrm{W} / \mathrm{K})$ \\
$S_{t}$ & Mean strain rate $(1 / \mathrm{s})$ \\
$S_{V}$ & Thermal entropy generation rate $\left(\mathrm{W} / \mathrm{m}^{2} \mathrm{~K}\right)$ \\
$T_{o}$ & Viscous entropy generation rate $\left(\mathrm{W} / \mathrm{m}^{2} \mathrm{~K}\right)$ \\
\hline & Reservoir temperature $(\mathrm{K})$ \\
&
\end{tabular}




\begin{tabular}{|ll|}
\hline$U$ & Moving frame velocity $(\mathrm{m} / \mathrm{s})$ \\
$\bar{u}_{i}$ & Reynolds Averaged velocity component in i direction $(\mathrm{m} / \mathrm{s})$ \\
$V$ & Volume of a computation cell $\left(\mathrm{m}^{3}\right)$ \\
$V_{a}$ & Instantaneous Velocity $(\mathrm{m} / \mathrm{s})$ \\
$V_{a m}$ & Highest speed of axial direction $(\mathrm{m} / \mathrm{s})$ \\
$V_{o}$ & Initial velocity for computation $(\mathrm{m} / \mathrm{s})$ \\
$V_{r}$ & Relative velocity $(\mathrm{m} / \mathrm{s})$ \\
$\dot{W}$ & The net-work transfer rate $(\mathrm{W} / \mathrm{s})$ \\
$\dot{W}_{r e v}$ & Reversible work transfer rate $(\mathrm{W} / \mathrm{s})$ \\
$\eta_{F}$ & The efficiency in first law of thermodynamics \\
$\eta_{S}$ & The second law efficiency \\
$\mu$ & Viscosity (kg/ms) \\
$\mu_{t}$ & Turbulent viscosity (N.s $/ \mathrm{m} 2)$ \\
$\rho$ & Density (kg/m $)$ \\
$\bar{\emptyset}$ & Flow coefficient \\
$\omega$ & Rotor angular speed $(\mathrm{rad} / \mathrm{s})$ \\
\hline$\left.\rho u_{i}^{\prime} u_{j}^{\prime}\right)$ & \\
\hline
\end{tabular}

\section{List of Abbreviations}

CFD Computational Fluid Dynamics

NACA National Advisory Committee for Aeronautics

OWC Oscillating Water Column

2D Two Dimensional

3D Three Dimensional 


\section{Introduction}

2 The techniques developed to maneuver the boundary layer, either for the purpose of increasing 3 the lift or decreasing the drag, are classified under the general heading of boundary layer 4 control or flow control. In order to achieve separation postponement, methods of flow control 5 lift enhancement and drag reduction have been considered. It is important to note that flow 6 control can be defined as a process used to alter a natural flow state or development path 7 (transient between states) into a more desired state (or development path; e.g. laminar, 8 smoother, faster transients) [1]. Moreover, it could be more precisely defined as modifying the 9 flow field around the airfoil to increase lift and decrease drag. This could be achieved by using 10 different flow control techniques such as blowing and suction, morphing wing, plasma 11 actuators, and changing the shape of the airfoil [2]. All the techniques essentially do the same 12 job, i.e. reduce flow separation so that the flow is attached to the airfoil and, thus, reduce drag 13 and increase lift. In regards to flow control techniques, they can be broadly classified as active 14 and passive flow control which can be further classified into more specific techniques [3]. The 15 terms "active" or "passive" do not have any clearly accepted definitions, but nonetheless are 16 frequently used. Typically, the classification is based on energy addition, either on the 17 possibility of finding parameters and modifying them after the system is built, or on the 18 steadiness of the control system; whether it is steady or unsteady. Such studies have 19 demonstrated that suction slot can modify the pressure distribution over an airfoil surface and 20 have a substantial effect on lift and drag coefficients [4-9]. A wide variety of different studies

21 have been conducted on flow control techniques. In actual fact, in 1904, Prandtl [10] was the 22 first scientist who employed boundary layer suction on a cylindrical surface to delay boundary 23 layer separation. The earliest known experimental works on boundary layer suction for wings 24 were conducted in the late 1930s and the 1940s [11-13]. Huang et al. [14] studied the suction 25 and blowing flow control techniques on a NACA0012 airfoil. The combination of jet location 26 and angle of attack showed a remarkable difference concerning lift coefficient as perpendicular 27 suction at the leading edge increased in comparison to the case in other suction situations. 28 Moreover, the tangential blowing at downstream locations was found to lead to the maximum 29 increase in the lift coefficient value. Rosas in [15] numerically studied flow separation control 
1 through oscillatory fluid injection, in which lift coefficient increased. The authors in [16] 2 examined the optimization of synthetic jet parameters on a NACA0015 airfoil in different 3 angles of attack to increase the lift to drag ratio. Their results revealed that the optimum jet 4 location moved toward the leading edge and the optimum jet angle incremented as the angle of 5 attack increased. The CFD method has been increasingly used to investigate boundary layer 6 control. Many flow control studies by CFD approaches [17-20] have been conducted to 7 investigate the effects of blowing and suction jets on the aerodynamic performance of airfoils.

8 The major challenge facing oscillating water column ocean energy extraction systems is to find 9 an efficient and economical means of converting flow kinetic energy to unidirectional rotary 10 motion for driving electrical generators [21-25], as seen in Figure 1. The energy conversion 11 from the oscillating air column [26, 27] can be achieved by using a self-rectifying air turbine 12 such as Wells turbine which was invented by A. A. Wells in 1976, see Figure 2 [28-33]. Wells 13 turbine consists of a number of blades that have symmetrical airfoil section. This airfoil section 14 under different conditions with various geometric parameters was investigated by other 15 researchers in consideration of improving the overall system performance. In order to achieve 16 this purpose, different methods were used, such as experimental, analytical and numerical 17 simulation. The main disadvantage of Wells turbine is the stall condition [34]. Aerodynamic 18 bodies subjected to pitching motions or oscillations exhibit a stalling behavior different from 19 that observed when the flow over a wing at a fixed angle of attack separates. The latter 20 phenomenon is referred to as static stall, since the angle of attack is fixed. In the case of a 21 dynamically pitching body, such as an airfoil with large flow rates and a large angle of attack, 22 the shear layer near the leading edge rolls up to form a leading-edge vortex which provides 23 additional suction over the upper airfoil surface as it convects downstream. This increased 24 suction leads to performance gains in lift and stall delay, but the leading-edge vortex quickly 25 becomes unstable and detaches from the airfoil. As soon as it passes behind the trailing edge, 26 however, the leading-edge vortex detachment is accompanied by a dramatic decrease in lift and 27 a significant increase in drag. This phenomenon is called dynamic stall. From Figure 3 it can be 28 noted that Wells turbine can extract power at low air flow rate, when other turbines would be 29 inefficient[35, 36]. Also, the aerodynamic efficiency increases with the increase of the flow 
1 coefficient (angle of attack) up to a certain value, after which it decreases. Thus, most of the 2 past studies aimed to 1) improve the torque coefficient (the turbine output) and 2) improve the 3 turbine behavior under the stall condition. In a number of previous studies [37-39], it was 4 concluded that the delay of stall onset contributes to improving Wells turbine performance. 5 This delay can be achieved by setting guide vanes on the rotor's hub [37, 40, 41]. It was found 6 that a multi-plane turbine without guide vanes was less efficient (approximately 20\%) than the 7 one with guide vanes. A comparison between Wells turbines having 2D guide vanes and 3D 8 guide vanes was investigated [42,43] by testing a Wells turbine model under steady flow 9 conditions, and using the computer simulation (quasi-steady analysis. It demonstrated that, the $103 \mathrm{D}$ case has superior characteristics in the running and starting characteristics. Concerning 11 Wells turbine systems which operate at high pressure values, a multi plane (usually tow stage) 12 turbine configuration can be used. Such a concept avoids the use of guide vanes and, therefore, 13 the turbine would require less maintenance and repairs [37]. The performance of a biplane 14 Wells turbine is dependent on the gap between the planes as it is shown in [37]. A gap-to-chord 15 ratio between the planes of 1.0 was recommended. Experimental results in [44] showed that 16 the use of two twin rotors rotating in the opposite direction to each other was an efficient means 17 of recovering the swirl kinetic energy without the use of guide vanes. The overall performance 18 of several types of Wells turbine design have been investigated in [45] and, a semi-empirical 19 method for predicting the performance has been used in [46]. Similar comparisons were 20 undertaken using experimental measurement in [47]. It can be observed that the contra-rotating 21 turbine had an operational range which was similar to that of the monoplane turbine with guide 22 vanes and it achieved similar peak efficiency as well. However, the flow performed was better 23 than the latter in the post-stall regime. In order to improve the performance of the Wells 24 turbine, the effect of end plate on the turbine characteristics has been investigated in [48, 49]. 25 Using an experimental model and a CFD method it was shown that the optimum plate position 26 was a forward type. The peak efficiency increases approximately $4 \%$ as compared to the Wells 27 turbine without an endplate. The calculations of the blade sweeps for the Wells turbine with a 28 numerical code by [50] and experimentally with quasi-steady analysis in [51]. As a result, it 29 was concluded that the performance of the Wells turbines was influenced by the blade sweep 30 area. 
1 Exergy analysis is performed using the numerical simulation for steady state biplane Wells 2 turbines [52] where the upstream rotor has a design point second law efficiency of $82.3 \%$ 3 although the downstream rotor second law efficiency equals $60.7 \%$. The entropy generation, 4 due to viscous dissipation, around different 2D airfoil sections for Wells turbine was recently 5 examined by the authors in $[53,54]$. When Reynolds number was increased from $6 \times 10^{4}$ to $61 \times 10^{5}$ the total entropy generation increased more than two folds for both airfoils 7 correspondingly. However, when Reynolds number was increased further to $2 \times 10^{5}$, the total 8 entropy generation exhibited unintuitive values ranging from $25 \%$ less to $20 \%$ higher than the corresponding value at Reynolds number $=1 \times 10^{5}$. The efficiency for four different airfoils in

10 the compression cycle is higher than the suction cycle at 2 degree angle of attack. Although, 11 when the angle of attack increases, the efficiency for the suction cycle increases much more 12 than the compression one. This study suggested that a possible existence of critical Reynolds 13 number for the operating condition at which viscous irreversibilities takes minimum values. A 14 comparison between total entropy generation of a suggested design (with variable chord) and a 15 constant chord of Wells turbine was presented in [55]. The detailed results demonstrate an 16 increase in static pressure difference around a new blade and a $26.02 \%$ average decrease in 17 total entropy generation throughout the full operating range. Most of the researchers studied the performance of different airfoils design and different operational conditions where analyzing the problem was only based on the parameter of first law of thermodynamics. In order to form a 20 deeper understanding, it is necessary to look at the second law of thermodynamics since it has 21 shown very promising result in many applications, such as wind turbine in [56-61], and gas 22 turbine in [62-67].

23 Wells turbine consists of a number of blades that have symmetrical airfoil section. This airfoil 24 section under different conditions with various geometric parameters was investigated by other researchers to improve the overall system performance. Different methods were used to achieve 26 this purpose, such as experimental, analytical and numerical simulation. In this work the CFD 27 analysis is used to investigate and analyze the flow around the isolated NACA airfoil, which refers to the turbine blade, under sinusoidal flow boundary conditions, which emulates the actual operating conditions. The force coefficients, such as torque coefficient and the entropy 
1 generation value, are calculated and compared under different conditions with various design

2 parameters by analyzing the flow around the airfoil section using CFD software, where the

3 force coefficients are referring to the first law analysis and the entropy generation value is

4 referring to the second law analysis. The objective of the present work is to demonstrate that

5 the performance of airfoil section, which refers to the Wells turbine blade at stall and near-stall

6 conditions, can be radically improved by using passive flow control method such as suction or

7 blowing slot. Therefore, a typical slot is created in the airfoil section, normal to the chord, and

8 due to the pressure difference between the two surfaces. Consequently, a suction effect occurs

9 which delays the stall. Accordingly, there is no need to generate any specific active suction or

10 blowing within the airfoil or the slot. Along with this design, there are two new aspects here.

11 The first is improving the performance of airfoil section for Wells turbine in near-stall

12 conditions. The second is to study the effect of slot in oscillating (i.e. sinusoidal) flow, which is

13 newly compared to the unidirectional flow as in aerodynamics applications. Apart from that, an

14 entropy generation minimization method is used to conduct the second-law analysis as recently

15 reported by the authors in [53,54]. An investigation on the entropy generation, due to viscous

16 dissipation, around turbine airfoils in two-dimensional unsteady flow configurations, will be

17 carried out. In reference to the literature, no specific unsteady CFD study of the slot effect with

18 sinusoidal flow on the entropy generation rate has been performed for airfoil section of Wells 19 turbine.

\section{Mathematical Model and Numerical Approach}

21 The governing equations employed for Large Eddy Simulation (LES) are obtained by filtering 22 the time-dependent Navier-Stokes equations. The filtering process effectively filters out eddies 23 whose scales are smaller than the filter width or grid spacing used in the computations. The 24 resulting equations thus govern the dynamics of large eddies. A filtered variable (denoted by an 25 over-bar) is defined by [68]:

$26 \bar{\phi}(x)=\int_{D} \phi\left(x^{\prime}\right) G\left(x, x^{\prime}\right) d x^{\prime}$ 
1 where $\mathrm{D}$ is the fluid domain, and $\mathrm{G}$ is the filter function that determines the scale of the 2 resolved eddies. In FLUENT, the finite-volume discretization itself implicitly provides the 3 filtering operation[69]:

$4 \bar{\phi}(x)=\frac{1}{V} \int_{V} \phi\left(x^{\prime}\right) d x^{\prime}, x^{\prime} \in V$

5 where $V$ is the volume of a computational cell. The filter function, $G\left(x, x^{\prime}\right)$, implied here is

6 then

$7 \quad G\left(x, x^{\prime}\right)=\left\{\begin{array}{c}1 / V \text { for } x^{\prime} \in V \\ 0 \text { otherwise }\end{array}\right.$

9 The LES model will be applied to essentially incompressible (but not necessarily constant-

10 density) flows. By filtering the incompressible Navier-Stokes equations, one obtains [70]

$11 \frac{\partial \rho}{\partial t}+\frac{\partial \rho \bar{u}_{i}}{\partial x_{i}}=0$

$12 \frac{\partial}{\partial t}\left(\rho \bar{u}_{i}\right)+\frac{\partial}{\partial x_{j}}\left(\rho \bar{u}_{i} \bar{u}_{j}\right)=\frac{\partial}{\partial x_{j}}\left(\mu \frac{\partial \bar{u}_{i}}{\partial x_{j}}\right)-\frac{\partial \bar{\rho}}{\partial x_{i}}-\frac{\partial \tau_{i j}}{\partial x_{j}}$

13 Where $\tau_{i j}$ is the sub-grid-scale stress defined by

$14 \tau_{i j}=\rho \overline{u_{i} u_{j}}-\rho \overline{u_{i}} \overline{u_{j}}$

15 The sub-grid-scale stresses resulting from the filtering operation are unidentified, and require

16 modeling. The majority of sub-grid-scale models are eddy viscosity models of the following 17 form [71]:

$18 \tau_{i j}-\frac{1}{3} \tau_{k k} \sigma_{i j}=-2 \mu_{t} \bar{S}_{i j}$

19 Where $\bar{S}_{i j}$ is the rate-of-strain tensor for the resolved scale defined by:

$20 \quad \bar{S}_{i j}=\frac{1}{2}\left(\frac{\partial \bar{u}_{i}}{\partial x_{j}}+\frac{\partial \bar{u}_{j}}{\partial x_{i}}\right)$

21 and $\mu_{t}$ is the sub-grid-scale turbulent viscosity, which the Smagorinsky-Lilly model is used for 22 it [72]. The most basic of sub-grid-scale models for "Smagorinsky-Lilly model" was proposed 23 by Smagorinsky [73] and was further developed by Lilly [74]. In the Smagorinsky-Lilly model, 24 the eddy viscosity is modeled by:

$25 \mu_{t}=\rho L_{s}^{2}|\bar{S}|$ 
1 where $L_{s}$ is the mixing length for sub-grid-scale models and $|\bar{S}|=\sqrt{2 \bar{S}_{i j} \bar{S}_{i j}}$. The $L_{s}$ is

2 computed using:

$3 \quad L_{s}=\min \left(k d, C_{s} V^{1 / 3}\right)$

4 Where $C_{s}$ is the Smagorinsky constant, $k=0.42, d$ is the distance to the closest wall, and $V$ is

5 the volume of the computational cell. Lilly derived a value of 0.23 for $C_{s}$ from homogeneous

6 isotropic turbulence. However, this value was found to cause excessive damping of large-scale

7 fluctuations in the presence of mean shear or in transitional flows. $C_{s}=0.1$ has been found to

8 yield the best results for a wide range of flows.

10 For the first law of thermodynamics, the lift and drag coefficient $C_{L}$ and $C_{D}$ are computed from

11 the post processing software. The average value for lift and drag coefficient was used to

12 calculate one value for torque coefficient for each angle of attack. Afterwards, the torque

13 coefficient can then be expressed as [39, 46, 75]:

$14 C_{T}=\left(C_{L} \sin \alpha-C_{D} \cos \alpha\right)$

15 The flow coefficient $\bar{\phi}$ relating tangential and axial velocties of the rotor is difined as

$16 \bar{\phi}=\frac{V_{a}}{\omega * R_{m}}$

17 where the $\alpha$ angle of attack equal to

$18 \alpha=\tan ^{-1} \frac{V_{a}}{\omega R_{m}}$

19 and the torque as:

$20 \quad$ Torque $=\frac{1}{2} \rho\left(V_{a}^{2}+\left(\omega R_{m}\right)^{2}\right) A R_{m} C_{T}$

21 the efficiency in the first law of thermodynamics $\left(\eta_{F}\right)$ is defined as:

$22 \eta_{F}=\frac{\text { Torque* } \omega}{\Delta P * Q}$

23 The transport equations of such models can be found in turbulence modeling texts such as [76].

24 The second law of thermodynamic defines the network transfer rate $\dot{W}$ as [77]:

$25 \dot{W}_{r e v}-\dot{W}=T_{o} S_{g e n}$ 
2 Which has been known for most of this century in engineering as the Gouy-Stodola 3 theorem[78].

4 It is possible to express the irreversible entropy generation in terms of the derivatives of 5 local flow quantities in the absence of phase changes and chemical reactions. The two 6 dissipative mechanisms in viscous flow are the strain-originated dissipation and the thermal

7 dissipation which correspond to a viscous and a thermal entropy generation respectively [79].

8 Thus, it can be written,

$9 S_{g e n}=S_{V}+S_{t h}$

10 In incompressible isothermal flow, such as the case in hand, the thermal dissipation 11 term vanishes. The local viscous irreversibilities therefore can be expressed as:

$12 S_{V}=\frac{\mu}{T_{o}} \phi$

13 where $\phi$ is the viscous dissipation term, that is expressed in two dimensional Cartesian 14 coordinates as [79]:

$15 \phi=2\left[\left(\frac{\partial u}{\partial x}\right)^{2}+\left(\frac{\partial v}{\partial y}\right)^{2}\right]+\left(\frac{\partial u}{\partial y}+\frac{\partial v}{\partial x}\right)^{2}$

16 Equations 18 and 19 were used to create the UDF file, which is used to calculate the local 17 entropy form the FLUENT software. Then, the global entropy generation rate is hence 18 expressed as:

$19 S_{G}=\iint_{x y} S_{V} d y d x$

20 Which is also calculated from the FLUENT software by integral the global value,

21 The next equation is defining the exergy value, which can be written as [80]:

22 Exergy $=K E+S_{G}$

23 and finally the second law efficiency is defined as [56]:

$24 \quad \eta_{s}=\frac{K E}{\text { Exergy }}$ 
1 Where $K E=\frac{1}{2} V^{2}$

2 From the above equation we can come up with a number of conclusions. On the one hand, that

3 the torque coefficient indicates to the first law efficiency and the global entropy generation rate

4 indicates to the second law and efficiency, in which the increase in torque coefficient leads to

5 increase in the first law efficiency. On the other hand, the decrease in the global entropy

6 generation rate leads to an increase in the second law efficiency.

\section{3. CFD Approach}

\subsection{Computational model, solver details and boundary conditions}

Two-dimensional numerical models for NACA0015 airfoils were built and validated against experimental measurements under unsteady flow conditions with both non-oscillating 11 velocity, and sinusoidal inlet velocity. The computational domain is discretized to Cartesian 12 structured finite volume cells using GAMBIT code. The application of such boundary 13 condition types [81-84] matches the Green-Gauss cell based evaluation method for the gradient 14 terms used in the solver (ANSYS FLUENT). Numerous tests accounting for different 15 interpolation schemes were used to compute cell face values of the flow field variables. The 16 variables of governing equation which are velocity and pressure, as well as convergence tests 17 have been undertaken. The second order upwind [85] interpolation scheme was used in this 18 work in which it yields results which are approximately similar to such yielded by third order 19 MUSCL scheme in the present situation. In addition, in some cases of the third order MUSCL 20 scheme was given high oscillatory residual during the solution. Figure 4 demonstrates the 21 dimensions of the whole computational domain and the location of airfoil, and it also shows the 22 grid distribution near the wall of the airfoil. Furthermore, the near views of slot mesh can be 23 determined from Figure 5 for different slot diameter. The Quad-Pave meshing scheme 24 (Structured Grid) is used in this work. It was also detected that the solution reaches 25 convergence when the scaled residuals approaches $1 \times 10^{-5}$. See Figure 6 for the convergence 26 criteria in the non-oscillating flow and sinusoidal flow inlet velocity. At such limit, the flow 27 field variables holds constant values with the application of consecutive iterations. 
The axial flow of Wells Turbine is modeled as a sinusoidal wave in this simulation.

2 Therefore, Inlet boundary conditions are set to change as time. In order to apply the inlet

3 boundary condition, inlet velocity with periodic function (see Figure 7) is generated as follows.

$4 \quad V_{a}=V_{o}+V_{a m} \sin (\sin 2 \pi f t)$

5 Where $t$ is time period, 6 seconds are set as one period in this simulation considering to 6 the literature survey [84, 86-88]. Time step is set as 0.000296721 seconds in order to satisfy

7 CFL (Courant Friedrichs Lewy) [89] condition equal to 1. The sinusoidal wave condition create 8 various Reynolds number up to $2 \times 10^{4}$ according to the reference [83].

\subsection{Grid sensitivity test}

11 In order to ensure that the numerical produces results are minimally dependent on the grid size, 12 several grids were tested to estimate the number of grid cells required to establish a reliable 13 model. The grid sensitivity test is performed where 4 grids with different mesh sizes ranging 14 from 112603 up to 446889 cells are investigated. This test shows that for grids with mesh sizes 15 of 312951 cells, gives good result within reasonable computation time (more details about this 16 result in [53]. Therefore, it was selected to conduct the analysis presented hereafter.

17 Figure 8 show the grid sensitivity analysis with respect to cell number across the slot section

18 for one, two, four and eight cells in the transversal direction. It can be noted that the results for 19 the four grids A, B, C and D are approximately the same. On the other hand, by increase the 20 number of cells in the transversal direction, the cells number for the total domain is increase for 21 the four grids A, B, C and D by 312951, 350662, 388637 and 413665 respectively. Therefore, 22 the grid A was selected in order to immunize the solution time of the different cases without 23 impacting on the quality and accuracy of the results.

\section{$24 \quad$ 3.3. LES resolution quality assessment}

25 In the most common practice, in LES, the filter length depends on the resolution of spatial 26 discretization (i.e. grid) in a specified problem. The implication of the filtering technique, 27 which is the backbone of LES, is the question about the resolution of the resolved scales in 
1 comparison with the total turbulence spectrum in the flow. An assortment of several attempts 2 were made to propose and index of LES quality [90, 91]. The most established index of LES 3 quality was proposed by Pope [92]. Such quality index can be expressed mathematically as a 4 function $M(x, t)$ of space and time [93] as:

$$
M(x, t)=\frac{K_{R e s}}{K_{R e s}+K_{S G S}}
$$
where $K_{\text {Res }}$ and $K_{S G S}$ are the resolved and subgrid modeled turbulent kinetic energy scalars,

7 respectively. In the present work, $K_{R e s}$ can be calculated as: $K_{R e S}=\frac{1}{2}\left(\tilde{u}^{2}+\tilde{v}^{2}\right)$ and $K_{S G S}$ can 8 be calculated as $K_{S G S}=\frac{v_{t}^{2}}{(C \Delta)^{2}}$ where $v_{t}$ is the subgrid modeled turbulent kinematic viscosity as 9 calculated in the Smagorinsky model as: $v_{t}=L_{s}^{2}|\bar{S}|$, where $L_{S}$ is the mixing length for subgrid scales as calculated in equation (10) and $\Delta$ is the filter length [94]. Pope [92] has evidently 11 shown that when $M(x, t) \geq 80 \%$ the LES is sufficiently resolved and the flow field is properly 12 resolved. Literature records support Pope's proposition in numerous and variant flows as 13 reported in [95-98]. In the present work, the quality index $M(x, t)$ was calculated for the 14 computational domain and plotted against LES filter length as in Figure (9). It is shown that $15 M(x, t) \geq 80 \%$ for filter lengths in the range $\Delta \geq 0.01$. In Figure (10) a histogram of the filter 16 length shows that approximately $98 \%$ of the grid has values of $M(x, t)$ larger than $90 \%$ which 17 satisfies Pope's criteria for fully resolved LES.

18 Since one of the work main objectives is to study the stall regime, therefore, an accurate 19 simulation for the stall must be done. The following Figure (Figure 11) illustrates that a 20 comparison between different models to simulate two dimensional NACA0015 in an unsteady 21 flow with stall angle (13.6 degrees) for NACA0015 with Reynolds number equals to $2 \times 10^{5}$ 22 from experimental data $[83,99]$ was presented. The comparison uses only the stall angle to 23 identify which model can present it. The Large Eddy Simulation model (LES) gives good 24 results for the torque coefficient value, while, other models cannot predict the stall angle. The 25 LES model has shown high disturbance for the path line of the flow stream and the pressure 26 distribution at the upper surface, which leads to the stall condition. The larger turbulent 27 separated zone of the LES may be a reason for the lower value of the lift force [100]. The LES 
1 has shown that some vortexes were formed and caused to appear a fluctuation behavior of 2 pressure distribution on the upper surface of the airfoil, whereas other models were not able to 3 predict it [101]. On the other hand, the unsteady RANS turbulence modeling has shown a quite

4 dissipative character that attenuates the instabilities and the vortex structures related to the 5 dynamic stall [102]. Therefore, the LES model will be used to investigate the stall behavior.

6 Large Eddy Simulation model was used to model the flow around NACA0015 airfoil in order 7 to give the best agreement with experimental data adopted from[83, 99] and [103]. The Large 8 Eddy Simulation model gives excellent results when they are used to simulate the airfoil in stall 9 condition, according to literature survey [70, 100, 104-110].

10 Although LES is a 3D model by definition, there have been numerous successful attempts to 11 use it in 2D applications. For example, flow over obstacles[111], hump[112], block[113], 12 airfoils[109, 114, 115] and Hills[116]. Other two dimension model applications include the 13 problems dealing with, dam-break [117], mechanism of pollutant[118, 119], heat transfer[120, 14 121], turbulent Convection [122] and Parallel Blade Vortex[123]. The flow under investigation 15 occurs due to sinusoidal velocity signal in the XY plane, with no other velocity signals in other 16 domains. Hence, all the main flow phenomena of interest occurs in the XY plane except for the 17 vortex stretching and secondary shedding which occur in the $\mathrm{XZ}$ and $\mathrm{YZ}$ planes. The authors 18 have reviewed the 2D assumption of the flow under consideration in their recent extensive 19 review paper [34] and concluded that the 2D assumptions are not influential in the flow 20 structure nor the aerodynamic performance of the airfoil under oscillating flow. Hence, the 21 governing equations were reduced to two dimensional form, and solved accordingly. 22 Consequently, and given the fact that this reduction is physically valid, the method of solution 23 of the governing equation (i.e. LES) must follow the coordinate formalism of the governing 24 equations, hence it was solved as two-dimensional problem. In this work two sets of 25 experimental data were used to validate the numerical model from references. First, 26 experimental data from references [83, 99, 124] are used to simulate and validate the stall 27 condition. Details of the first validation case, where Wells turbine prototype are under 28 investigation, is characterized by the following parameters: hub radius, is equal to101 $\mathrm{mm}$; tip 29 radius, equal to $155 \mathrm{~mm}$; NACA0015 blade profile with constant chord length, equal to $74 \mathrm{~mm}$; 
1 and number of blades, equal to 7. Therefore, the hub-to-tip ratio, and the solidity, is equal to

20.65 and 0.64 , respectively. The uncertainty in the measurements is $5 \%$. The blades have been

3 produced with composite material reinforced by carbon fiber with suited attachment. Second,

4 experimental data from reference [103] is adopted to simulate and validate the unsteady

5 sinusoidal wave inlet velocity. Details of the second validation case, where experimental data

6 for unsteady forces $\left(F_{D}\right)$ acting on a square cylinder in oscillating flow with nonzero mean

7 velocity are measured. The oscillating air flows are generated by a unique AC servomotor wind

8 tunnel. The generated velocity histories are almost exact sinusoidal waves.

9 For unsteady flow with non-oscillating velocity, Figure 12 shows a very good agreement 10 between the measured torque coefficient from reference $[83,99]$ and the calculated torque 11 coefficient from CFD result at Reynolds number of 200000. It can be noted that the 12 computational model has approximately the same stall condition value as the reference. The 13 comparison between those results and the percentage of error are listed in Table 1. 14 Furthermore, for an unsteady flow with sinusoidal inlet velocity, Figure 13 and 14 show a good 15 agreement between measured drag force from reference [103] and predicted drag force from 16 CFD at two different frequencies $(2 \mathrm{~Hz}$ and $1 \mathrm{~Hz}$ ). It can be shown from Figure 13 and 14 that 17 the computational model has almost the same behavior of oscillating flow condition as the 18 reference; see also the error percentage in Table 2 for the two frequencies. Finally, Figure 15 19 displays the results of computational model under sinusoidal inlet flow velocity with 20 experimental data from $[83,99]$ and an excellent agreement is achieved. The comparison of 21 these results and the percentage of error are summarized in Table 3. The Large Eddy 22 Simulation computational model has approximately the same stall condition value as the 23 reference.

\section{4. Results and Discussion}

25 A slot with certain diameter at various locations from the leading edge was created with a shape of NACA0015 from reference [83, 99], see Figure 16. The diameter and location for the slot were changed in order to obtain an optimum value. During the compression cycle, this slot suctions the flow from lower surface (high pressure) and blows it to the upper 
surface (low pressure), see Figure 17. Where, Figure $17 \mathrm{~A}$ is for the accelerating flow at 1.3 second and $\mathrm{B}$ is for the decelerating flow at 1.65 second with Reynolds number equal to 190000. Furthermore, this pressure difference affecting on the velocity vector direction, as it can be noted in Figure 17 for the velocity vector of the velocity magnitude. On the other hand, during the suction cycle in Figure $17 \mathrm{C}$ (4.35 second) and D (4.6 second), the slot suctions the flow from the upper surface (high pressure) and blows it to the lower surface (low pressure) in both the accelerating and decelerating flow at Reynolds number equal to 190000. It can be also noted that the pressure difference affecting on the velocity vector direction, which it refer to the flow direction. Therefore, it can be concluded that the factor affecting determination of the slot velocity direction is the pressure difference. The slot will be defined as a suction slot in the analysis and results which were presented henceforth. The test cases investigated are under 1) unsteady flow with non-oscillating velocity and 2) sinusoidal wave condition.

\subsection{Unsteady flow with non-oscillating velocity}

The effect of suction slots in the airfoils behavior will be shown in the following three sections.

\subsubsection{Torque coefficient and Stall angle}

Figure 18 demonstrates the effect of varying $D_{s s}$ on the torque coefficient at the stall angle (13.6 Degree) from Figure 11 for reference [83, 99]. All suction slots have $L_{s s}$ up to $65 \%$. It can be remarked that the suction slot with $D_{s S}$ of $0.001 \mathrm{~m}$ gives a higher torque coefficient than others. The torque coefficient increases about $26 \%$ than the airfoil without suction slot.

Figure 19 exemplifies the effect of $L_{s s}$ on the torque coefficient at the stall angle (13.6 Degree) with $D_{s S}$ equal to $0.001 \mathrm{~m}$. It can be discerned that, the $L_{s s}$ equal to $45 \%$, gives a higher torque coefficient than other $L_{s s}$. Where, the torque coefficient increases about $42 \%$ than the airfoil without suction slot.

Figure 20 reveals the effect of suction slot with optimum $L_{s S}$ and optimum $D_{S S}$ on the torque coefficient at different angles. It is clearly noted that the improvement of torque coefficient at different angles (from $7 \%$ to $19 \%$ ), especially at stall regime (from $44 \%$ to $45 \%$ ), which is 
1 caused by the delay in stall angle. For more details about the value of improvement in torque

2 coefficient, see Table 4.

\subsubsection{Flow field around the airfoil section}

4 Figure 21 shows path lines colored by mean velocity magnitude at maximum value of torque 5 coefficient and stall condition. In addition, it also shows the effect of suction slot on the 6 boundary layer and flow field around the airfoil. Also, it highlights the amount of the difference 7 between the effects of suction slot before and after the stall condition. This difference is clearly 8 indicated between Figures a, b for 12.3 (Degree) and Figures c, d for 13.6 (Degree). The effect 9 of suction slot on the separation layer at the end of blade in Figures a, b was small. This is due 10 to the fact that the tow Figures did not have the stall condition yet. On the other hand, the effect 11 of suction slot on the separation layer in Figures $\mathrm{c}$ and $\mathrm{d}$ is significant because Figure $\mathrm{c}$ 12 represents the data in the stall condition however, Figure d does not. As for Figures e and f, the 13 two airfoils are in stall regime. Figures 22 and 23 clarify the pressure distribution around the 14 upper and lower surface of airfoil at maximum velocity $(2.92 \mathrm{~m} / \mathrm{s})$ with different angles of 15 attack. It can be shown that the low pressure area at the trailing edge was increased with the 16 increase in angle of attack for the airfoil without slots. From Figure 23 A), C) and E) it can be 17 noted that the low pressure zones and disturbances at the trailing edge for the upper surface was 18 created the layer separation at the trailing edge and it was also increased by the increase in 19 angle of attack. The effect of the suction slot was very clear at the pressure distribution around 20 the airfoil, where it was more significant after the stall angles (13.6 and 14.4 degrees) than that 21 before the stall (12.3 degrees). The difference between the pressure value for the upper and 22 lower surface at the trailing edge was decreased by adding suction slot to the airfoil especially 23 at the stall angles.

Figure 24 shows that the suction slot has a negative effect on the second law efficiency, where 26 the global entropy generation rate increases at all angles from (14\% to $41 \%)$. The 10.6 degree 27 angle of attack (before the stall) has the highest difference in global entropy generation rate by $2841 \%$ due to suction slot. On the other hand, 8.7 (before the stall) and 13.6 (after the stall) 
1 degree angle of attack have the lowest difference in global entropy generation rate by $14 \%$ due

2 to suction slot. Otherwise, the 10.1, 11.27, 11.74 and 12.3 (before the stall) degree have the

3 same difference in global entropy generation rate by $21.5 \%$ due to suction slot. Also, the 14.4

4 (after the stall) degree has a difference in the global entropy generation rate by $30 \%$. This

5 phenomenon suggests that the change in velocity gradient due to the suction slot has a direct

6 impact on the entropy generation.

$7 \quad$ 4.2. Sinusoidal wave

$8 \quad$ 4.2.1. Torque coefficient and Stall angle

9 Figure 25 a) clarifies the instantaneous torque coefficient at compression cycle for different $L_{s s}$,

10 while Figure $25 \mathrm{~b}$ ) shows the average value of torque coefficient. These values are at citrine

11 angle of attack of 13.6 (Degree) and citrine $D_{s s}$ equal to $0.001 \mathrm{~m}$. The $L_{s s}$ equal to $45 \%$, gives a

12 higher torque coefficient value than other $L_{s s}$. This result is consistent with the result from

13 previous section. Figure 26 shows the effect of $L_{s s}$ with $45 \%$ and $D_{s s}$ equal to $0.001 \mathrm{~m}$, on

14 torque coefficient at different angles. The improvement of torque coefficient is clearly noted

15 before the stall regime (from $11 \%$ to $26 \%$ ) and at stall regime (from $32 \%$ to $53 \%$ ). Table 5

16 shows more details about the value of improvement in torque coefficient.

17 Figure 27 explains the hysteretic behavior due to the reciprocating flow, the performance of the

18 Wells turbine has a hysteretic loop in which the values of torque coefficient in the accelerating

19 flow is smaller than in the decelerating flow. The hysteretic behavior was studied

20 experimentally and numerically in the references of [51, 69, 84, 86-88, 125-129]. By a

21 numerical simulation using a quasi-steady analysis, it can be that the only study which

22 simulated the hysteretic behavior after the stall is [51]. Moreover, Figure 27 highlights the

23 hysteretic behavior after adding the suction slot to the airfoil which has the same behavior.

24 Furthermore, it delays the stall regime in addition the torque coefficient. The torque

25 coefficients at compression cycle for different angles of attack are shown in Figure 28. It can be

26 observed that for all angles, the suction slot increases the torque coefficient. Figures d) and e)

27 have the highest increase value in comparison to other Figures. Whereas, the torque coefficient

28 was increased by (approximately) $26 \%$ in Figure 28 a), 16\% in Figure 28 b) and 11\% in Figure 
$128 \mathrm{c}$ ). The stall regime was delayed in Figure $28 \mathrm{~d}$ ), in addition, the torque coefficient was

2 increased by (approximately) 53\% and by (approximately) 32\% in Figure 28 e). Furthermore,

3 the behavior of torque coefficient with the suction slot curve was more stable than that without

4 suction slot which is increased from the amount of highest value, as it see in Figure d) and e).

\subsubsection{Flow field around the airfoil section}

7 The flow structures over the NACA0015 airfoil in oscillating flow was shown in Figure 29 and 8 Figure 30. Figure 29 accentuates the contour of velocity magnitude at maximum velocity and 9 angle of attack equal to 12.3 degree (before the stall). The improvement effect of the suction 10 slot on flow structures is clear when compared between Figure a) and b), especially in, the 11 separated layer regime at the end of airfoil. The same behavior occurs in Figure 30 a) and b) for 12 the contour of velocity magnitude, and also in Figure c) and d) for mean velocity magnitude 13 from unsteady statistics. Figure 30 emphasize the improvement effect of the suction slot on 14 flow structures at maximum velocity and angle of attack equal to 13.6 degree (after the stall).

15 The suction slot has a direct effect on the flow structures at the end of blade, which leads to an 16 improvement in the separation regime.

17 The path-lien colored by means of velocity magnitude highlight the improvement effect of the 18 suction slot on the separation layers in Figures 31 and 32. It can be noted that by adding the 19 suction slot in the airfoil, this suction slot was decreased from the separation layer at the end of 20 airfoil. By comparing Figure 31 (before the stall) and Figure 32 (after the stall), it can be also 21 noted that, the improvement effect of suction slot on separation layers was increased in the stall 22 regime. The pressure distribution around the upper and lower surface at 12.3 degrees before the 23 stall (Figure 33) and 13.6 degrees after the stall (Figure 34) were presented. The effect of the 24 suction slot on the trailing edge area was appearing through the decrease from the low pressure 25 area that cause disturbances in the path line at the trailing edge area and it extends to the area 26 beyond the trailing edge. The pressure distribution after suction slot location $\left(L_{S S}=45 \%\right)$ at 27 the upper surface has a direct effect in its value before and after the stall. The difference in 28 pressure value between the upper and lower surface after the slot location (Figure 34) was 
1 decreased due to the slot effect. This decrease made the pressure distribution behavior similar

2 to the pressure distribution for the upper surface of the airfoil before the stall (Figure 33) which

3 led to a delay on the stall condition.

\subsubsection{Second law analysis}

5 The numerical simulations are used to obtain local entropy viscosity predictions of the different 6 angle of attack. Figure 35 and 36 highlight the suction slot effect in the entropy behavior when

7 a flow is accelerating and decelerating in compression cycle. Consequently, the entropy 8 generations rate varies with the Reynolds number. The change of Reynolds number values 9 results as a consequence to using sinusoidal wave boundary conditions. Suction slot have 10 negative effect on the entropy behavior in both accelerating and decelerating flow. Otherwise,

11 at some Reynolds numbers, the suction slot decreased from the entropy generation. As an 12 illustration, Figure 35 e) at Reynolds number is less than 100000 in accelerating flow. Also, 13 Figure 36 a) at Reynolds number is equal to 160000 in decelerating flow. The airfoil with the 14 suction slot at 11.3 degree has an average increase in the entropy generation rate by $22 \%$ than 15 that without the suction slot for the accelerating flow. Whereas, on the one hand, the maximum 16 difference in the entropy generation rate was found at Reynolds number to be equal to 193000 17 and 200000 by $36 \%$ than that without the suction slot. On the other hand, the minimum 18 difference in the entropy generation rate was found at Reynolds number from 50000 to 100000 19 by $11 \%$ than that without the suction slot; see Figure 35 a). For decelerating flow at 11.3 20 degree, it can be noted that the maximum increase in the entropy generation rate due to the 21 suction slot was 35\% at Reynolds number equal to 55000. Additionally, on one hand, the 22 entropy generation rate was decreased than that without the suction slot by $-23 \%$ at 160000 23 Reynolds number. This increase and decrease in the entropy generation rate for the airfoil with 24 the suction slot gives an average value equal to $0 \%$ at decelerating flow, see Figure 36 a). From 25 Figure $35 \mathrm{~b}$ ), it can be noted that the maximum increase in the entropy generation rate is $39 \%$ 26 due to the suction slot for accelerating flow at 198000 Reynolds number. On the other hand, the 27 minimum increase in the entropy generation rate is $11 \%$ at Reynolds number from 78000 to 28100000 , with an average percentage $22 \%$ for the 11.7 degree. For decelerating flow at 11.7 29 degree, the maximum increase in the entropy generation rate is $31 \%$ at 30000 Reynolds number 
1 and the minimum value is $-14 \%$ at 175000 Reynolds number, due to the decrease of the entropy 2 generation rate than that without the suction slot. This increase and decrease in the entropy 3 generation rate for the airfoil with the suction slot gives an average value equal to $14 \%$ at 4 decelerating flow, see Figure $36 \mathrm{~b}$ ). The 12.3 degree at accelerating flow gives maximum 5 increase by $35 \%$ at 200000 Reynolds number and minimum increase by $6 \%$ Reynolds number 6 from 78000 to 100000 with an average percentage 21\%, see Figure 35 c). Otherwise, Figure 36

7 c) shows the maximum increase by $34 \%$ at 80000 Reynolds number and minimum increase by $83 \% 160000$ Reynolds number with an average percentage $18 \%$.

9 The airfoil with the suction slot at 13.6 degree has an average increase in the entropy 10 generation rate by $51 \%$ than that without the suction slot for the accelerating flow. Whereas, 11 the maximum different in the entropy generation rate was found at Reynolds number to be 12 equal to 28400 by $152 \%$ than that without suction slot. On the other hand, the minimum 13 difference in the entropy generation rate was found at 160000 Reynolds number by $17 \%$ than 14 that without the suction slot, see Figure 35 d). For decelerating flow at 13.6 degree, the 15 maximum increase in the entropy generation rate is $36 \%$ at 160000 Reynolds number and the 16 minimum value is $-5 \%$ at 80000 Reynolds number, due to the decrease of the entropy 17 generation rate than that without the suction slot. This increase and decrease in the entropy 18 generation rate for the airfoil with the suction slot gives an average value equal to $19 \%$ at 19 decelerating flow, see Figure $36 \mathrm{~d}$ ). The 14.4 degree at accelerating flow gives maximum 20 increase by $26 \%$ at 185000 and 198000 Reynolds number, and minimum increase by $-30 \%$ 21 Reynolds number from 54000 to 80000 due to the decrease of the entropy generation rate than 22 that without suction slot. This increase and decrease in the entropy generation rate for the 23 airfoil with the suction slot gives an average value equal to $3 \%$ at accelerating flow, see Figure 2435 e). Otherwise, Figure 36 e) shows the maximum increase by $46 \%$ at 80000 and 143000 25 Reynolds number, and minimum increase by $0 \% 100000$ Reynolds number with an average 26 percentage $21 \%$.

27 Furthermore, as an average value for the compression cycle, the suction slot was increased 28 from the global entropy generation rate, see Figure 37. This led to a decrease in the second law 29 efficiency, see Figure 38. From Figure 37 and 38, it is deducted that the minimum value for the 
1 global entropy generation rate and maximum second law efficiency occurs at 11.7 degree for

2 airfoil without the suction slot. On the other hand, the minimum value for the global entropy

3 generation rate and maximum second law efficiency occurs at 11.3 degree for airfoil with the

4 suction slot.

\section{5. Conclusions}

6 A two-dimensional incompressible unsteady flow is simulated for airfoil under different 7 conditions to investigate the effect of airfoil with a suction slot on the torque coefficient and a 8 stall condition as well as the entropy generation due to viscous dissipation. The modeling 9 results show that $D_{S S}$ and $L_{S S}$ have different effects on the torque coefficient and stall 10 condition. Therefore, not all the parameters tested in the present study achieve a positive effect 11 in terms of improved blade torque. In general, it can be concluded that the decrease in $D_{s s}$ 12 comes with an increase in torque coefficient. The smallest tested $D_{S S}$ is $0.001 \mathrm{~m}$, since any 13 smaller value would not be practical in real industries. Also, the best $L_{S S}$ is locating 14 (approximately) at $45 \%$ from the leading edge (at 13.6 Degree). By applying these conditions 15 we can achieve a 53\% increase in the torque coefficient at stall regime (13.6 Degree). The 16 increase in torque coefficient, due to the suction slot, ranges from $11 \%$ to $26 \%$ before the stall 17 regime. Hence, the regime after the stall increases in torque coefficient varying from $32 \%$ to $1853 \%$. The main reason behind this observation is due to the delay of the stall condition. The 19 suction slot increases the torque coefficient and delays the stall angle which further leads to an 20 increase of first law efficiency. On the other hand, it decreases the second law efficiency. Thus, 21 if the turbine operates under high flow coefficient (angle of attack), it is strongly suggested to 22 use the suction slot to improve the performance at the stall condition. Otherwise, it may not be 23 effective. Future research should focus on improving the first law efficiency with a minimize 24 entropy generation, by using numerical algorism and experimental test, in order to enhance the 25 overall Wells turbine performance under flow control method. Furthermore, it should 26 investigate the suction slot and its location in the third direction ( $\mathrm{Z}$ axis) via three-dimensional 27 simulation. 


\section{Acknowledgements}

2 The authors would like to acknowledge the support provided by the Department of Naval 3 Architecture, Ocean and Marine Engineering at Strathclyde University, UK and the Department

4 of Marine Engineering at Arab Academy for Science, Technology and Maritime Transport.

\section{References}

6 1. Collis, S., et al., Issues in active flow control: theory, control, simulation and 7 experiment. Progress in Aerospace Sciences, 2004. 40(4-5): p. 237-289.

8 2. Katam, V., Simulation of low-Re flow over a modified NACA 4415 airfoil with 9 oscillating camber. 2005, University of Kentucky: Master's thesis.

10 3. Gad-el-Hak, Pollard, and Bonnet, Flow Control: Fundamentals and Practices. 1998: 11 Springer-Verlag Berlin Heidelberg.

12 4. Yousefi, K., R. Saleh, and P. Zahedi, Numerical study of blowing and suction slot 13 geometry optimization on NACA 0012 airfoil. Journal of Mechanical Science and 14 Technology, 2014. 28(4): p. 1297-1310.

15 5. Chapin, V.G. and E. Benard, Active Control of a Stalled Airfoil Through Steady or 16 Unsteady Actuation Jets. Journal of Fluids Engineering, 2015. 137(9): p. 091103.

17 6. Schatz, M., B. G"unther, and F. Thiele, Computational Investigation of Separation 18 Control for High-Lift Airfoil Flows. Active Flow Control, ed. P.D.R. King. Vol. 95. 2007, Berlin, Germany. 173-189.

7. Chawla, J.S., et al., Efficiency improvement study for small wind turbines through flow control. Sustainable Energy Technologies and Assessments, 2014. 7: p. 195-208.

8. Fernandez, E., R. Kumar, and F. Alvi, Separation Control on a Low-Pressure Turbine Blade using Microjets. Journal of Propulsion and Power, 2013. 29(4): p. 867-881.

9. Volino, R.J., O. Kartuzova, and M.B. Ibrahim, Separation Control on a Very High Lift Low Pressure Turbine Airfoil Using Pulsed Vortex Generator Jets. Journal of Turbomachinery, 2011. 133(4): p. 041021.

10. Schlichting, H., Boundary layer theory. McGraw-Hill, New York, USA, 1968: p. 347362. 
1 11. Richards, E.J. and C.H. Burge, An airfoil designed to give laminar flow over the surface 2 with boundary layer suction. Aeronautical Research Council, R\&M 2263, 1943.

3 12. Walker, S.W. and W.G. Raymer, Wind tunnel test on the 30 percent symmetrical griffth 4 aerofoil with ejection of air. Aeronautical Research Council, R\&M 2475, 1946.

5 13. Braslow, A.L., A history of suction type laminar flow control with emphasis on flight 6 research, NASA History Division. Monograph in Aerospace History, 1999. 13.

7 14. Huang, L., P.G. Huang, and R.P. LeBeau, Numerical study of blowing and suction 8 control mechanism on NACA0012 airfoil. Journal of Aircraft, 2004. 41(5): p. 1005-

10 15. C. R. Rosas, Numerical simulation of flow separation control by oscillatort fluid 11 injection. 2005, A\&M University: Texas

12 16. Akcayoz, E. and I.H. Tuncer, Numerical investigation of flow control over an airfoil 13 using synthetic jets and its optimization. International Aerospace Conference, Turkey, 142009.

15 17. Kim, S.H. and C. Kim, Separation control on NACA23012 using synthetic jet.

17 18. Genc, M.S., U. Keynak, and H. Yapici, Performance of transition model for predicting low re aerofoil flows without/with single and simultaneous blowing and suction. European Journal of Mechanics B/Fluids, 2011. 30(2): p. 218-235.

19. Rumsey, C.L. and T. Nishino, Numerical study comparing RANS and LES approaches on a circulation control airfoil. International Journal of Heat and Fluid Flow, 2011. 32(5): p. 847-864.

20. B. Yagiz, O. Kandil, and Y.V. Pehlivanoglu, Drag minimization using active and passive flow control techniques. Aerospace Science and Technology, 2012. 17(1): p. 21-31.

21. Rosa, A.V.d., Fundamentals of Renewable Energy Processes. Third Edition ed. 2012, United States of America: Elsevier Academic Press. 908.

22. Curran, R. and M. Folley Air turbine design for OWCs, in Ocean Wave Energy, i.J. Cruz, Editor. 2008: Springer, Berlin. . p. 189-219. 
1 23. Falcao, A.F.d.O.J., P.A.P., OWC wave energy devices with air flow control. Ocean $2 \quad$ Engineering, 1999. 26(12): p. 1275-1295.

3 24. Falcao, A.F.d., Stochastic Modelling in wave power-equipment optimisation: maximum 4 energy production versus maximum profit. Ocean Engineering, 2004. 31(2004): p. 5 1407-1421.

$625 . \quad$ Torres, F.R., P.R.F. Teixeira, and E. Didier, Study of the turbine power output of an 7 oscillating water column device by using a hydrodynamic - Aerodynamic coupled 8 model. Ocean Engineering, 2016. 125: p. 147-154.

9 26. Boccotti, P., Comparison between a U-OWC and a conventional OWC. Ocean $10 \quad$ Engineering, 2007. 34: p. 799-805.

11 27. Boccotti, P., Caisson breakwaters embodying an OWC with a small opening-Part I: 12 Theory. Ocean Engineering, 2007. 34(5-6): p. 806-819.

13 28. Raghunathan, S., Theory and Performance of Wells Turbine. Queen's University of 14 Belfast, 1980. Rept. WE/80/13R.

15 29. Hitoshi Hotta, Y.W., V-5 A study on the matching between the air turbine and phase 16 control for the OWC wave power generator. Ocean Engineering, 1985. 12(6): p. 58517586.

18 30. Masahiro Inoue, K.K., Toshiaki Setoguchi, Katsumi Shimamoto, II-2 On the starting 19 and quasi-steady characteristics of wells turbine under oscillating flow condition. Ocean $20 \quad$ Engineering, 1985. 12(6): p. 563.

21 31. Masami Suzuki, C.A., Tetsuo Tagori, II-4 Fundamental studies on oscillating water

24 32. Yukihisa Washio, H.H., Takeaki Miyazaki, Yoshio Masuda, II-3 Full-scale column wave power generator with wells turbine. Ocean Engineering, 1985. 12(6): p. 565. performance tests on tandem wells turbine. Ocean Engineering, 1985. 12(6): p. 564.

33. Folley, M., R. Curran, and T. Whittaker, Comparison of LIMPET Contra-rotating Wells Turbine with Theoretical and Model Test Predictions. Ocean Engineering, 2006. 33(89): p. 1056-1069.

34. Shehata, A.S., et al., Wells turbine for wave energy conversion: a review. International journal of energy research, 2017. 41(1): p. 6-38. 
1 35. Liu, Z., et al., Numerical study on a modified impulse turbine for OWC wave energy 2 conversion. Ocean Engineering, 2016. 111: p. 533-542.

3 36. Okuhara, S., et al., Wells Turbine for Wave Energy Conversion - Improvement of the 4 Performance by Means of Impulse Turbine for Bi-Directional Flow. Open Journal of $5 \quad$ Fluid Dynamics, 2013. 03(02): p. 36-41.

6 37. Raghunathan, S., The Wells Air Turbine for Wave Energy Conversion. Progress 7 Aerospace Sciences, 1995. 31: p. 335-386.

8 38. Dixon, S.L., Fluid Mechanics, Thermodynamics of Turbomachinery. 1998: Pergamon

39. Sheldahl, R.E. and P.C. Klimas, Aerodynamic Characteristics of Seven Symmetrical Airfoil Sections Through 180-Degree Angle of Attack for Use in Aerodynamic Analysis of Vertical Axis Wind Turbines, in Sandia National Laboratories energy report. 1981: the United States of America. p. 118.

40. Raghunathan, S., A methodology for Wells turbine design for wave energy conversion. ARCHIVE: Proceedings of the Institution of Mechanical Engineers, Part A: Journal of Power and Energy 1990-1996 (vols 204-210), 1995. 209(31): p. 221-232.

41. Brito-Melo, A., L.M.C. Gato, and A.J.N.A. Sarmento, Analysis of Wells turbine design parameters by numerical simulation of the OWC performance. Ocean Engineering, 2002. 29: p. 1463-1477.

42. Setoguchi, T., et al., Effect of Guide Vane Shape on the Performance of a Wells Turbine. Renewable Energy, 2001. 23: p. 1-15.

43. Takao, M., et al., The Performance of a Wells Turbine with 3D Guide Vanes. International Journal of Offshore and Polar Engineering, 2001. 11(1): p. 72-76.

44. Gato, L.M.C. and R. Curran, Performance of the Contrarotating Wells Turbine. International Journal of Offshore and Polar Engineering, 1996. 6(1): p. 68-75.

45. Raghunathan, S. and W.C. Beattie, Aerodynamic performance of contra-rotating Wells turbine for wave energy conversion. ARCHIVE: Proceedings of the Institution of Mechanical Engineers, Part A: Journal of Power and Energy 1990-1996 (vols 204-210), 1996. 210(61): p. 431-447. 
1 46. Curran, R., et al., Performance Prediction of Contrarotating Wells Turbines for Wave 2 Energy Converter Design. Journal of Energy Engineering, 1998. 124(2): p. 35-53.

3 47. Gato, L.M.C. and R. Curran, The Energy Conversion Performance of Several Types of 4 Wells Turbine Designs. Proceedings of the Institution of Mechanical Engineers, Part A: 5 Journal of Power and Energy, 1997. 211(2): p. 133-145.

6 48. Mamun, M., et al., Improvement af the Performance of the Wells Turbine by using a $7 \quad$ Very Thin Elongated Endplate at the Blade Tip, in the 3rd BSME-ASME International 8 Conference on Thermal Engineering. 2006, ASME: Dhaka, Bangladesh.

9 49. Takao, M., et al., Wells Turbine with End Plates for Wave Energy Conversion. Ocean 10 Engineering, 2007. 34(11-12): p. 1790-1795.

11 50. Kim, T.H., et al., Numerical investigation on the effect of blade sweep on the 12 performance of Wells turbine. Renewable Energy, 2002. 25: p. 235-248.

13 51. Setoguchi, T., et al., Effect of Rotor Geometry on the Performance of Wells Turbine, in 14 The Thirteenth International Offshore and Polar Engineering Conference. 2003, The

17 52. Shaaban, S., Insight Analysis of Biplane Wells Turbine Performance. Energy 18 Conversion and Management, 2012. 59: p. 50-57.

19 53. Shehata, A.S., et al., Entropy Generation Due to Viscous Dissipation around a Wells Turbine Blade: A Preliminary Numerical Study. Energy Procedia, 2014. 50: p. 808-816.

54. Shehata, A.S., et al., Performance Analysis of Wells Turbine Blades Using the Entropy Generation Minimization Method. Renewable Energy, 2016. 86: p. 1123-1133.

55. Soltanmohamadi, R. and E. Lakzian, Improved design of Wells turbine for wave energy conversion using entropy generation. Meccanica, Springer Netherlands., 2015. 51(8): p. 1713-1722.

56. Pope, K., I. Dincer, and G.F. Naterer, Energy and Exergy Efficiency Comparison of Horizontal and Vertical Axis Wind Turbines. Renewable Energy, 2010. 35(9): p. 21022113. 
1 57. Baskut, O., O. Ozgener, and L. Ozgener, Effects of Meteorological Variables on 2 Exergetic Efficiency of Wind Turbine Power Plants. Renewable and Sustainable Energy 3 Reviews, 2010. 14(9): p. 3237-3241.

4 58. Redha, A.M., I. Dincer, and M. Gadalla, Thermodynamic Performance Assessment of $5 \quad$ Wind Energy Systems: An Application. Energy, 2011. 36(7): p. 4002-4010.

6 59. Ozgener, O. and L. Ozgener, Exergy and Reliability Analysis of Wind Turbine $7 \quad$ Systems: A Case Study. Renewable and Sustainable Energy Reviews, 2007. 11(8): p. 8 1811-1826.

9 60. Baskut, O., O. Ozgener, and L. Ozgener, Second Law Analysis of Wind Turbine Power 10 Plants: Cesme, Izmir Example. Energy, 2011. 36(5): p. 2535-2542.

11 61. Mortazavi, S.M., M.R. Soltani, and H. Motieyan, A Pareto optimal multi-objective optimization for a horizontal axis wind turbine blade airfoil sections utilizing exergy analysis and neural networks. Journal of Wind Engineering and Industrial Aerodynamics, 2015. 136: p. 62-72.

62. Şöhret, Y., et al., Advanced exergy analysis of an aircraft gas turbine engine: Splitting exergy destructions into parts. Energy, 2015. 90: p. 1219-1228.

63. Ghazikhani, M., I. Khazaee, and E. Abdekhodaie, Exergy analysis of gas turbine with air bottoming cycle. Energy, 2014. 72: p. 599-607.

64. Sue, D.-C. and C.-C. Chuang, Engineering design and exergy analyses for combustion gas turbine based power generation system. Energy, 2004. 29(8): p. 1183-1205.

65. Kim, K.H. and K. Kim, Exergy Analysis of Overspray Process in Gas Turbine Systems. Energies, 2012. 5(12): p. 2745-2758.

66. Jubeh, N.M., Exergy Analysis and Second Law Efficiency of a Regenerative Brayton Cycle with Isothermal Heat Addition. Entropy, 2005. 7(3): p. 172.

67. Lugo-Leyte, R., et al., Parametric Analysis of a Two-Shaft Aeroderivate Gas Turbine of 11.86 MW. Entropy, 2015. 17(8): p. 5829-5847.

68. SB., P., Turbulent flows. Cambridge University Press, 2000.

69. Mamun, M., The Study on the Hysteretic Characteristics of the Wells Turbine in a Deep Stall Condition, in Energy and Material Science Graduate School of Science and Engineering. 2006, Saga University: Japan. p. 141. 
70. DAHLSTROM, S., LARGE EDDY SIMULATION OF THE FLOW AROUND A 2 HIGH-LIFT AIRFOIL, in Department of Thermo and Fluid Dynamics. 2003, CHALMERS UNIVERSITY OF TECHNOLOGY: Goteborg, Sweden. p. 62.

4 71. Moin P, S.K., Cabot W, Lee S., A dynamic subgrid-scale model for compressible 5 turbulence and scalar transport. Physics Fluids A, 1991. 3(11): p. 2746-57.

6 72. DK., L., A proposed modification of the Germano subgrid-scale closure method. $7 \quad$ Physics Fluids A, 1992. 4(3): p. 633-5.

8 73. Hinze, J.O., Turbulence. 1975, New York: McGraw-Hill Publishing Co.

9 74. Launder, B.E. and D.B. Spalding, Lectures in Mathematical Models of Turbulence. 101972 , London, England: Academic Press.

11 75. Whittaker, T.J.T., T.P. Stewart, and R. Curran, Design synthesis of oscillating water 12 column wave energy converters: performance matching. Proceedings of the Institution 13 of Mechanical Engineers, Part A: Journal of Power and Energy, 1997. 211(6): p. 48914505 .

15 76. Hirsch, C., Numerical Computation of Internal and External Flows: The Fundamentals

17 77. Bejan, A., Entropy Generation Minimization- The New Thermodynamics of Finite-Size 18 Devices and Finite-Time Processes. Applied Physics Reviews, 1996. 79(3): p. 1191-

78. A. Stodola, Steam and Gas Turbines (McGraw-Hill, New York). 1910.

79. Iandoli, C.L., 3-D Numerical Calculation of the Local Entropy Generation Rates in a Radial Compressor Stage. International journal of thermodynamics, 2005. 8: p. 83-94.

80. Bejan, A., Entropy Generation Minimization: The Method of Thermodynamic Optimization of Finite-Size Systems and Finite-Time Processes. 1995: Taylor \& Francis.

81. Starzmann, R. and T. Carolus, Model-Based Selection of Full-Scale Wells Turbines for Ocean Wave Energy Conversion and Prediction of their Aerodynamic and Acoustic Performances. Proceedings of the Institution of Mechanical Engineers, Part A: Journal of Power and Energy, 2013. 228(1): p. 2-16. 
1 82. Mohamed, M.H. and S. Shaaban, Optimization of Blade Pitch Angle of an Axial 2 Turbine Used for Wave Energy Conversion. Energy, 2013. 56: p. 229-239.

3 83. Torresi, M., S.M. Camporeale, and G. Pascazio, Detailed CFD Analysis of the Steady $4 \quad$ Flow in a Wells Turbine Under Incipient and Deep Stall Conditions. Journal of Fluids $5 \quad$ Engineering, 2009. 131(7): p. 071103.

6 84. Mamun, M., et al., Hysteretic Flow Characteristics of Biplane Wells Turbine. Ocean 7 Engineering, 2004. 31(11-12): p. 1423-1435.

8 85. Smagorinsky, J., General Circulation Experiments with the Primitive Equations. I. The 9 Basic Experiment. Month. Wea. Rev., 1963. 91: p. pp.99-164.

10 86. Setoguchi, T., et al., Hysteretic Characteristics of Wells Turbine for Wave Power 11 Conversion. Renewable Energy, 2003. 28(13): p. 2113-2127.

12 87. Kinoue, Y., et al., Mechanism of Hysteretic Characteristics of Wells Turbine for Wave 13 Power Conversion. Journal of Fluids Engineering, 2003. 125(2): p. 302.

14 88. Kinoue, Y., et al., Hysteretic Characteristics of Monoplane and Biplane Wells Turbine 15 for Wave Power Conversion. Energy Conversion and Management, 2004. 45(9-10): p. $16 \quad 1617-1629$.

17 89. DE Moura, C.A.K., Carlos S., The Courant-Friedrichs-Lewy (CFL) Condition: 80 18 Years After Its Discovery. 1 ed. 2013, Boston: Birkhäuser Basel.

19 90. Saqr, K., Large eddy simulation: the demand for a universal measure of resolution. CFD 20 Letters. 2010: issres.net.

21 91. Celik, I., Z. Cehreli, and I. Yavuz, Index of resolution quality for large eddy

23 92. Pope, S.B., Ten questions concerning the large-eddy simulation of turbulent flows. New $24 \quad$ journal of Physics, 2004. 6(1): p. 35.

25 93. Saqr, K.M., M. Wahid, and M.M. Sies. Highly-resolved large eddy simulation of the 26 nonreacting flow in an asymmetric vortex combustor. in THE 4TH INTERNATIONAL MEETING OF ADVANCES IN THERMOFLUIDS (IMAT 2011). 2012. AIP Publishing. 
1 94. Eldrainy, Y., et al., Large eddy simulation and preliminary modeling of the flow 2 downstream a variable geometry swirler for gas turbine combustors. ... 3 Communications in Heat ..., 2011.

4 95. Mazzei, L., et al., Impact of Swirl Flow on Combustor Liner Heat Transfer and 5 Cooling: A Numerical Investigation With Hybrid Reynolds-Averaged Navier-Stokes 6 Large Eddy Simulation Models. Journal of Engineering for Gas Turbines and Power, 7 2016. 138(5): p. 051504.

8 96. Fureby, C., Challenges for Large Eddy Simulation of Engineering Flows, in Whither 9 Turbulence and Big Data in the 21st Century? 2017, Springer. p. 375-400.

10 97. Georgiadis, N.J., D.P. Rizzetta, and C. Fureby, Large-eddy simulation: current 11 capabilities, recommended practices, and future research. AIAA journal, 2010. 48(8): p. 12 1772-1784.

13 98. Eldrainy, Y.A., et al., Large eddy simulation and preliminary modeling of the flow 14 downstream a variable geometry swirler for gas turbine combustors. International

99. Torresi, M., S. Camporeale, and G. Pascazio, Experimental and Numerical Investigation on the Performance of a Wells Turbine Prototype, in Seventh European Wave and Tidal Energy Conference. 2007: Porto, Portugal

100. Richez, F., et al., Zonal RANS/LES coupling simulation of a transitional and separated flow around an airfoil near stall. Theoretical and Computational Fluid Dynamics, 2007. 22(3-4): p. 305-315.

101. Rezaei, F., E. Roohi, and M. Pasandideh-Fard, Stall simulation of flow around an airfoil using LES model and comparison of RANS models at low angles of attack, in 15th Conference on Fluid Dynamics. 2013: The University of Hormozgan, Bandar Abbas, Iran. p. 1-10.

102. Martinat, G., et al., Turbulence modeling of the flow past a pitching NACA0012 airfoil at $10^{5}$ and $10^{6}$ Reynolds number, . Journal of Fluids and Structures, 2008. 24: p. 12941303. 
1 103. Nomura, T., et al., Aerodynamic Forces on a Square Cylinder in Oscillating Flow with 2 Mean Velocity. Journal of Wind Engineering and Industrial Aerodynamics, 2003. 91: p. 3 199-208.

4 104. Kawai, S. and K. Asada, Wall-modeled large-eddy simulation of high Reynolds number 5 flow around an airfoil near stall condition. Computers \& Fluids, 2013. 85: p. 105-113.

6 105. Alferez, N., I. Mary, and E. Lamballais, Study of Stall Development Around an Airfoil 7 by Means of High Fidelity Large Eddy Simulation. Flow, Turbulence and Combustion, 8 2013.91(3): p. 623-641.

9 106. Kim, Y., I.P. Castro, and Z.T. Xie, Large-Eddy Simulations for Wind Turbine Blade: 10 Dynamic Stall and Rotational Augmentation. 2015. 20: p. 369-375.

11 107. AlMutairi, J., I. AlQadi, and E. ElJack, Large Eddy Simulation of a NACA-0012 Airfoil 12 Near Stall. 2015. 20: p. 389-395.

13 108. Armenio, V., B. Geurts, and J. Fröhlich, Large Eddy Simulation of Flow Around an $14 \quad$ Airfoil Near Stall. 2010. 13: p. 541-545.

15 109. Hitiwadi, M., et al., Large Eddy Simulations of 2D and Open-tip Airfoils Using Voxel

17 110. Bromby, D.Y.a.W., Large-Eddy Simulation of Unsteady Separation Over a Pitching Airfoil at High Reynolds Number, in Seventh International Conference on Computational Fluid Dynamics (ICCFD7). 2012: Big Island, Hawaii.

111. SKYLLINGSTAD, E.D. and H.W. WIJESEKERA, Large-Eddy Simulation of Flow over Two-Dimensional Obstacles: High Drag States and Mixing. Journal of physical oceanography, 2004. 34: p. 94-112.

112. Avdis, A., S. Lardeau, and M. Leschziner, Large Eddy Simulation of Separated Flow over a Two-dimensional Hump with and without Control by Means of a Synthetic Slotjet. Flow, Turbulence and Combustion, 2009. 83(3): p. 343-370.

113. Cheng, W.-C. and F. Porté-Agel, Evaluation of subgrid-scale models in large-eddy simulation of flow past a two-dimensional block. International Journal of Heat and Fluid Flow, 2013. 44: p. 301-311. 
1 114. Christian Tenaud and L.T. Phuoc, Large eddy simulation of unsteady, compressible, 2 separated flow around NACA 0012 airfoil, in Fifteenth International Conference on 3 Numerical Methods in Fluid Dynamics. 1997. p. pp 424-429.

4 115. Shehata, A.S., et al., Comparative analysis of different wave turbine designs based on 5 conditions relevant to northern coast of Egypt. Energy, 2016. $6 \quad$ http://dx.doi.org/10.1016/j.energy.2016.11.091.

7 116. Ashvinkumar Chaudhari, et al., Large Eddy Simulation of Boundary-Layer Flows over 8 Two-Dimensional Hills, in Industrial Mathematics at ECMI 2012. 2012, Springer

117. Özgökmen, T.M., et al., Large eddy simulation of stratified mixing in two-dimensional dam-break problem in a rectangular enclosed domain. Ocean Modelling, 2007. 16(1-2): p. $106-140$.

118. Michioka, T., et al., Large-Eddy Simulation for the Mechanism of Pollutant Removal from a Two-Dimensional Street Canyon. Boundary-Layer Meteorology, 2010. 138(2): p. $195-213$.

119. Chung, T.N.H. and C.-H. Liu, On the Mechanism of Air Pollutant Removal in TwoDimensional Idealized Street Canyons: A Large-Eddy Simulation Approach. BoundaryLayer Meteorology, 2013. 148(1): p. 241-253.

120. Andrej Horvata, I.K., Jure Marnb, Two dimensional large eddy simulation of turbulent natural convection due to internal heat generation. international journal of heat and mass transfer, 2001. 44(21): p. 3985-3995.

121. Matos, A.d., F.A.A. Pinho, and A. Silveira!Neto, Large-eddy simulation of turbulent ow over a two! dimensional cavity with temperature uctuations. International Journal of Heat and Mass Transfer, 1999. 42: p. 3848.

122. Chen, Q. and G.A. Glatzmaier, Large eddy simulations of two-dimensional turbulent convection in a density-stratified fluid. Geophysical \& Astrophysical Fluid Dynamics, 2005. 99(5): p. 355-375.

123. Liu, Y., et al., Numerical Simulation of Two-Dimensional Parallel Blade-Vortex Interactions Using Large Eddy Simulation. Procedia Engineering, 2012. 31: p. 703-707. 
1 124. Torresi, M., S. Camporeale, and G. Pascazio, Performance of a Small Prototype of a High Solidity Wells Turbine, in Seventh European Conference on Turbomachinery Fluid Dynamics and Thermodynamics. 2007: Athens, Greece

4 125. Kim, T.H., et al., Hysteretic Characteristics of Wells Turbine for Wave Power 5 Conversion, in The Twelfth International Offshore and Polar Engineering Conference. 2002, The International Society of Offshore and Polar Engineers: Kitakyushu, Japan. p.

8 126. Kinoue, Y., et al., Comparison of Performances of Turbines for Wave Energy Conversion. Journal of Thermal Science, 2003. 12(4): p. 323-328.

10 127. Setoguchi T, T.M., Kaneko K., Hysteresis on Wells Turbine Characteristics in 11 Reciprocating Flow. International Journal of Rotating Machinery, 1998. 4(1): p. 17-24.

12 128. Thakker, A. and R. Abdulhadi, The Performance of Wells Turbine Under Bi13 Directional Airflow. Renewable Energy, 2008. 33(11): p. 2467-2474.

14 129. Thakker, A. and R. Abdulhadi, Effect of Blade Profile on the Performance of Wells 15 Turbine under Unidirectional Sinusoidal and Real Sea Flow Conditions. International Journal of Rotating Machinery, 2007. 2007: p. 1-9. 


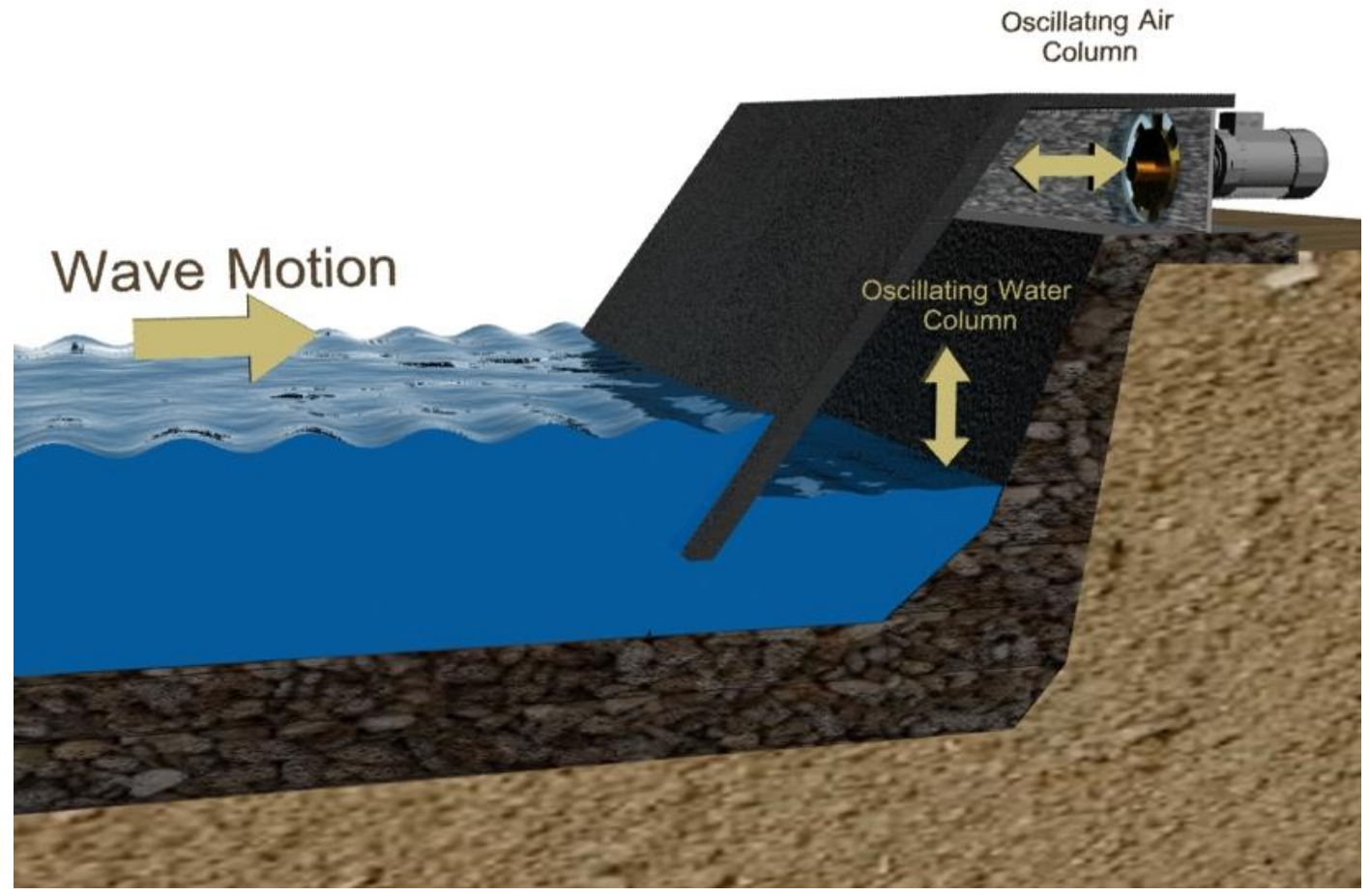

Figure 1 An illustration of the principle of operation of OWC system, where the wave motion is used to drive a turbine through the oscillation of air column [43].

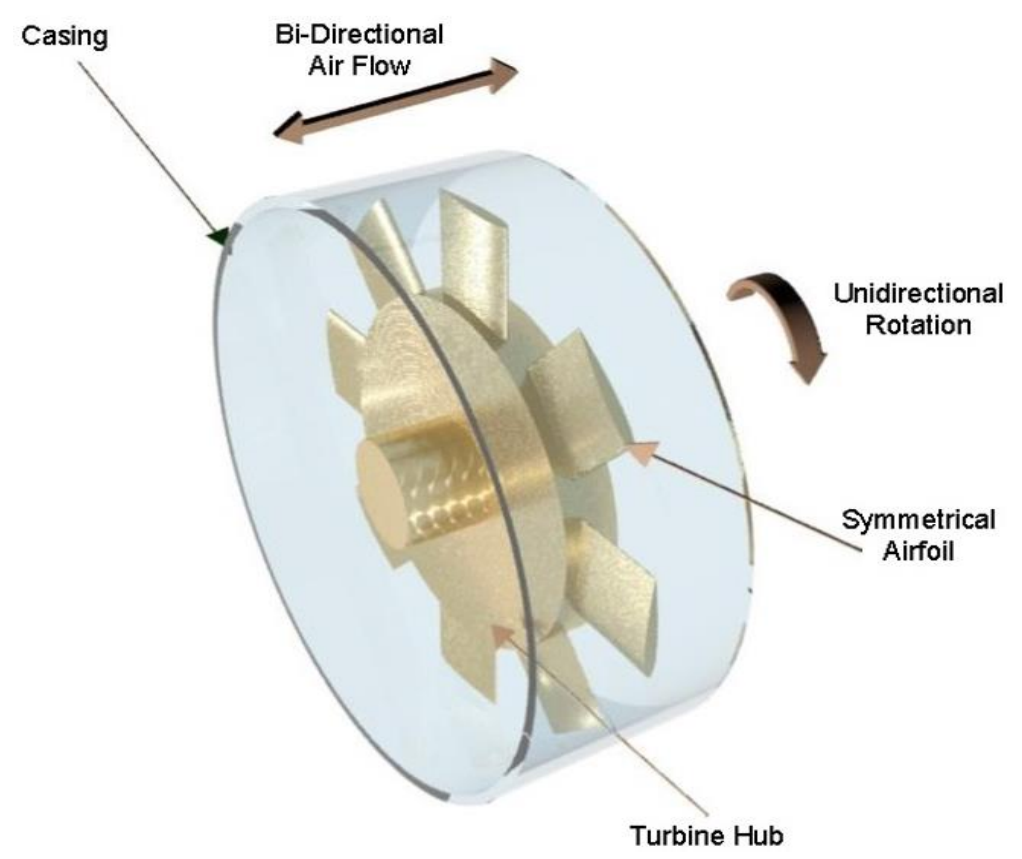

Figure 2 Typical structure of Wells turbine rotor [43]. 


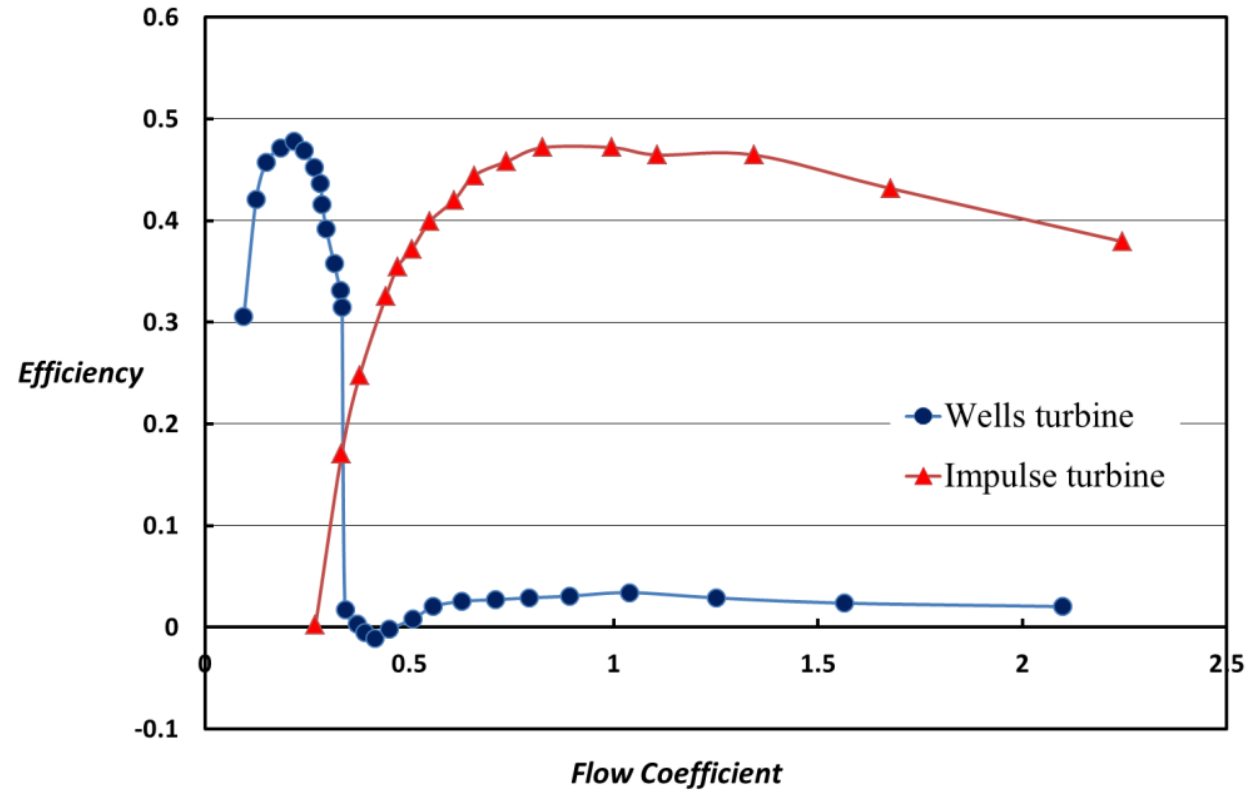

Figure 3 Turbines characteristic under steady flow conditions: Flow coefficient variation with the efficiency [16]. 

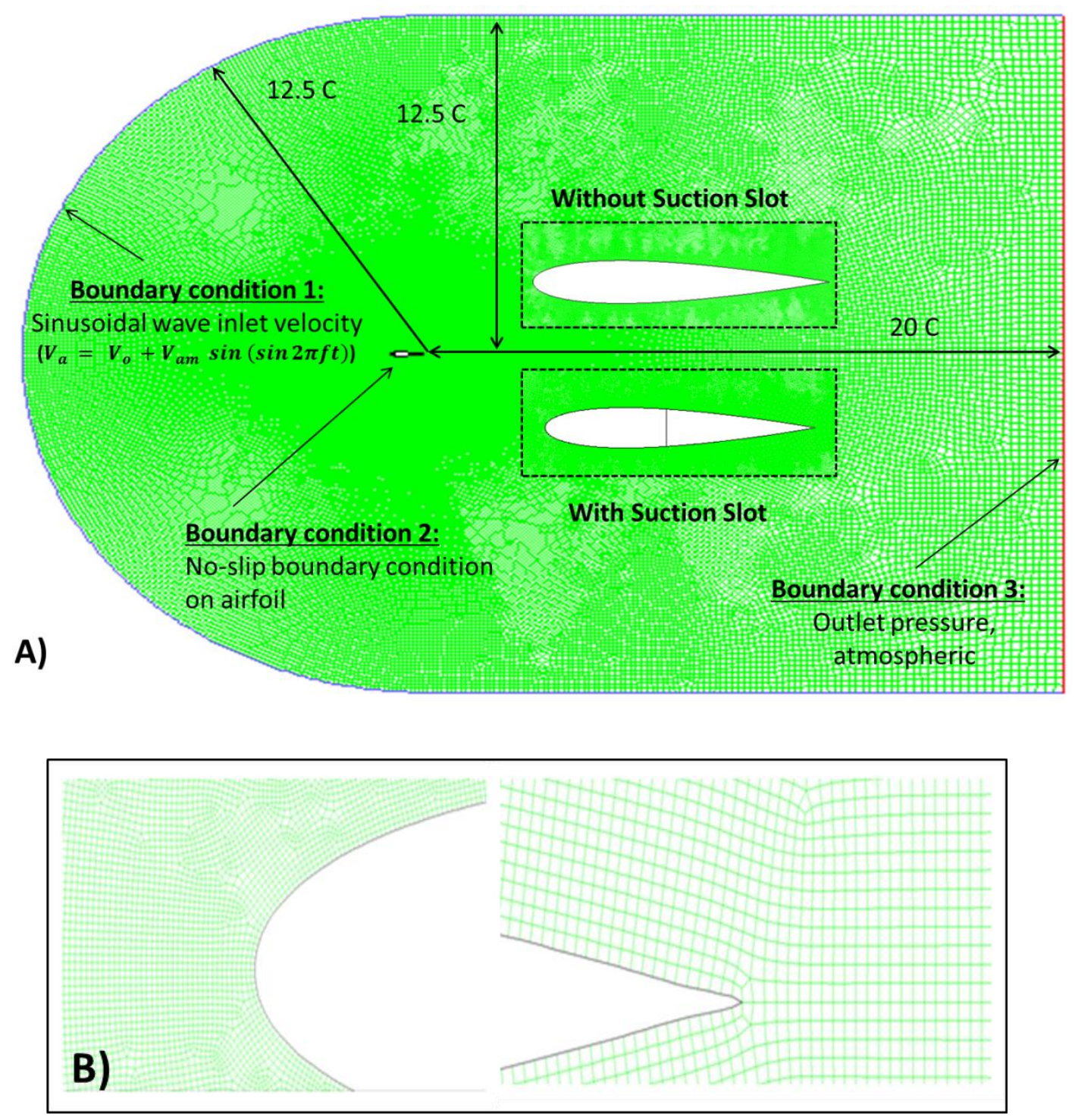

Figure 4 Computational model and boundary conditions A) Dimensions of whole computational domain and location of airfoil B) Computational grid near the wall of the airfoil 


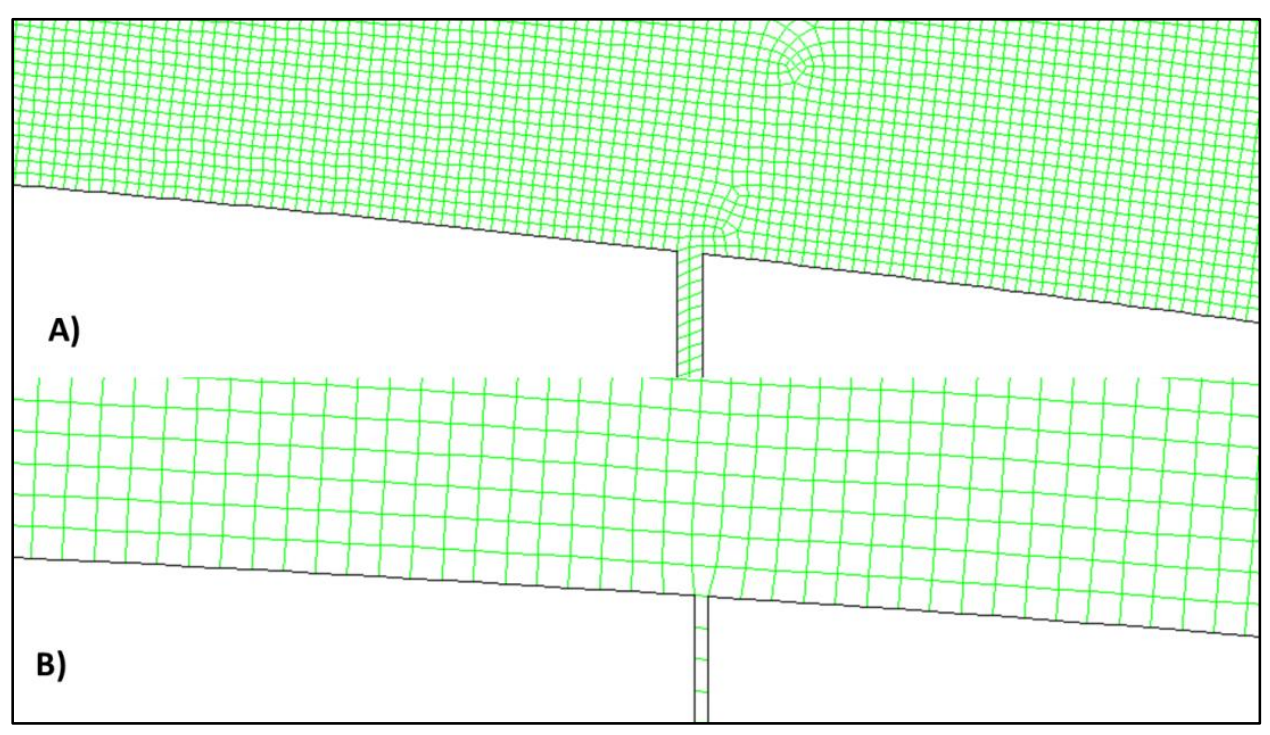

Figure 5 The near views of slot mesh A) $D_{S S}=0.005 \mathrm{~m} \mathrm{~B}$ ) $D_{s S}=0.001 \mathrm{~m}$ 


\begin{tabular}{|c|}
\hline Residuals \\
continuity \\
x-velocity \\
y-velocity \\
\hline
\end{tabular}

A)

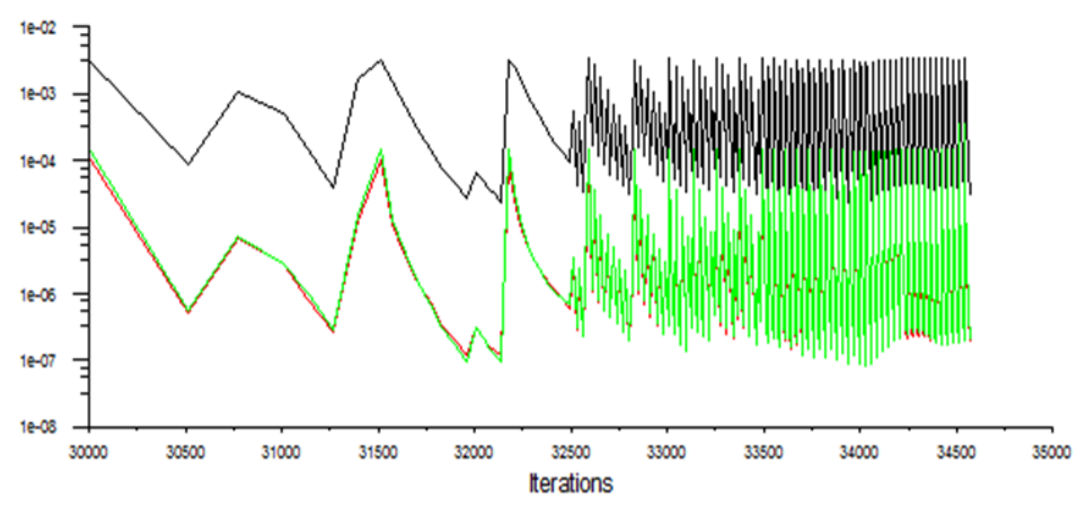

Scaled Residuals (Time $=8.0000 \mathrm{e}+00$ )

ANSYS Fluent 14.5 (2d, pbns, LES, transient)

\begin{tabular}{c}
\hline Residuals \\
\hline continuity \\
\hline$x$-velocity \\
\hline$y$-velocity \\
\hline
\end{tabular}

B)

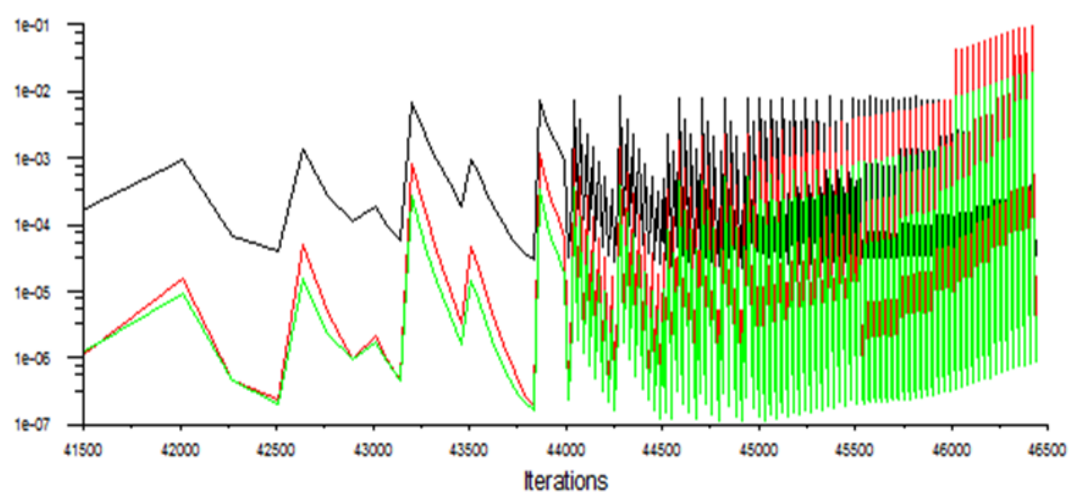

Figure 6 Convergence criteria A) non-oscillating flow B) sinusoidal flow 


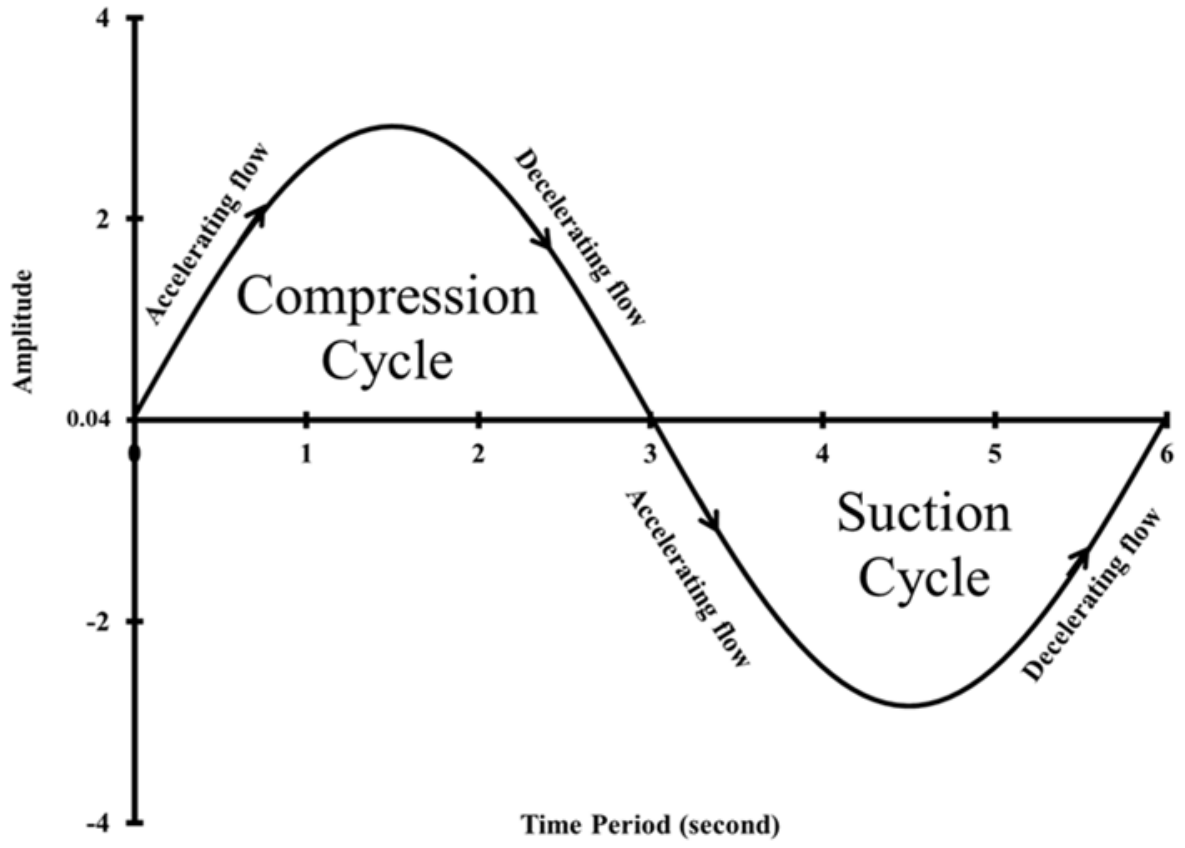

Figure 7 The sinusoidal wave boundary condition, which represents a regular oscillating water column

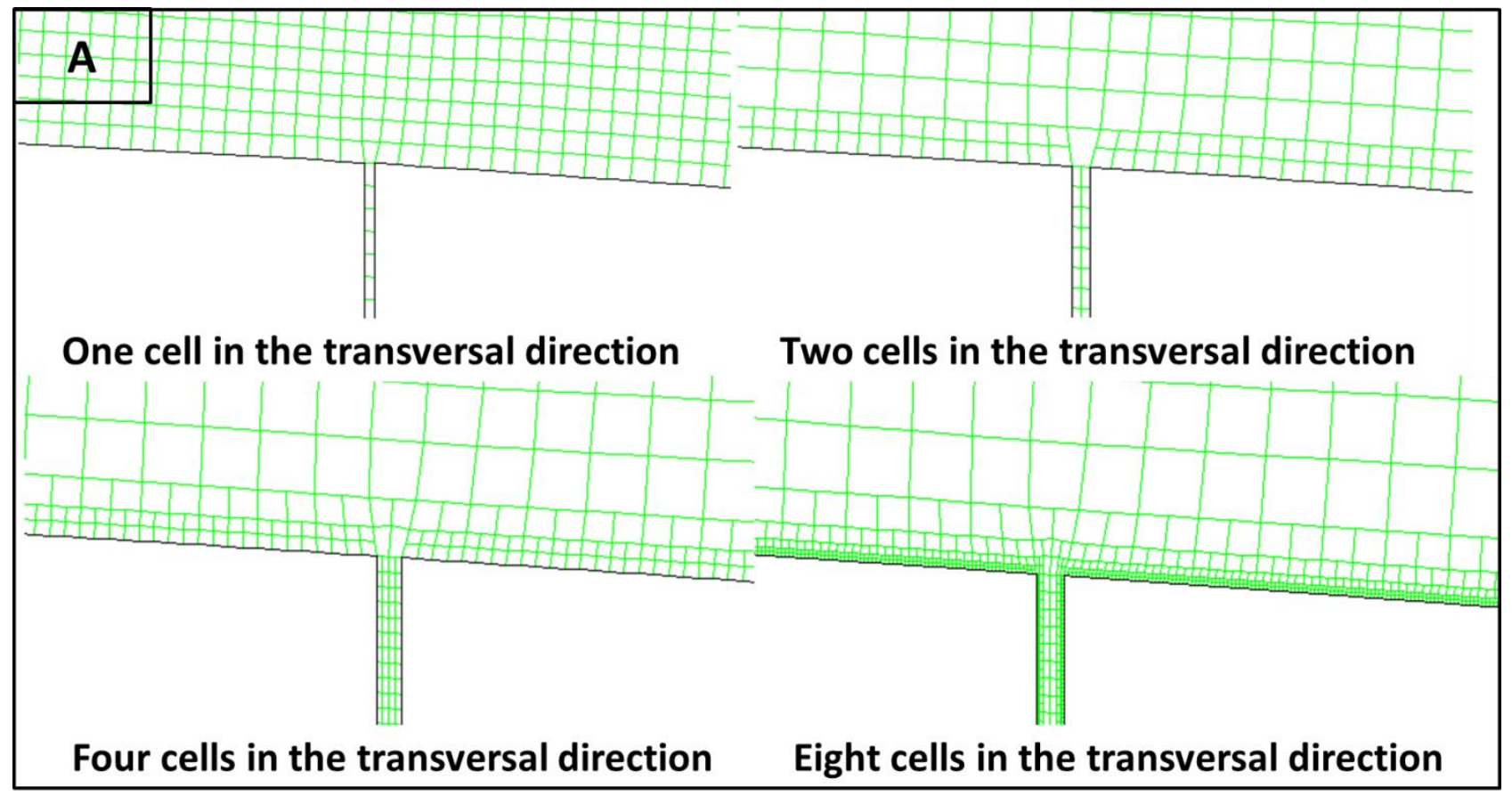




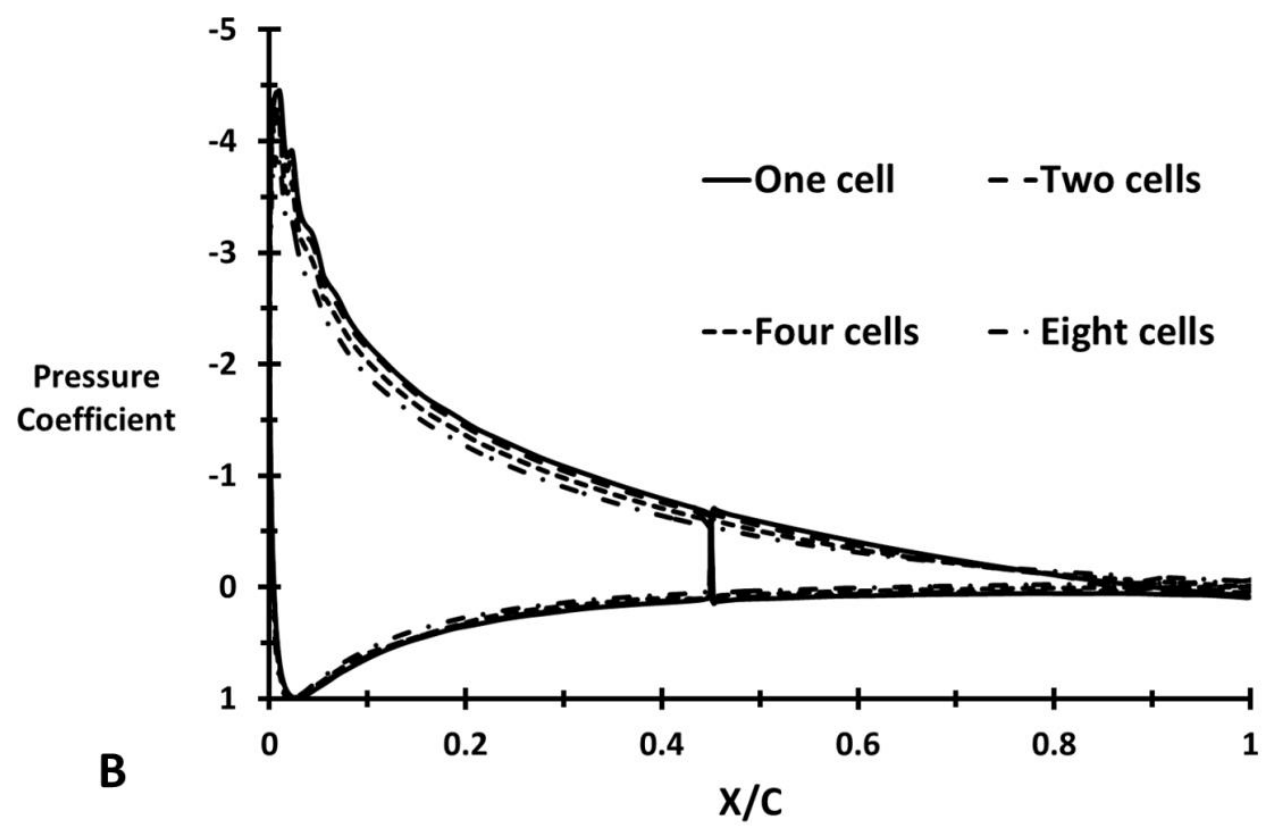

Figure 8 A grid sensitivity analysis with respect to cell number across the slot section A) One, two, four and eight cells in the transversal direction B) Pressure coefficient plotted on the normalized aerofoil cord at different grid resolutions

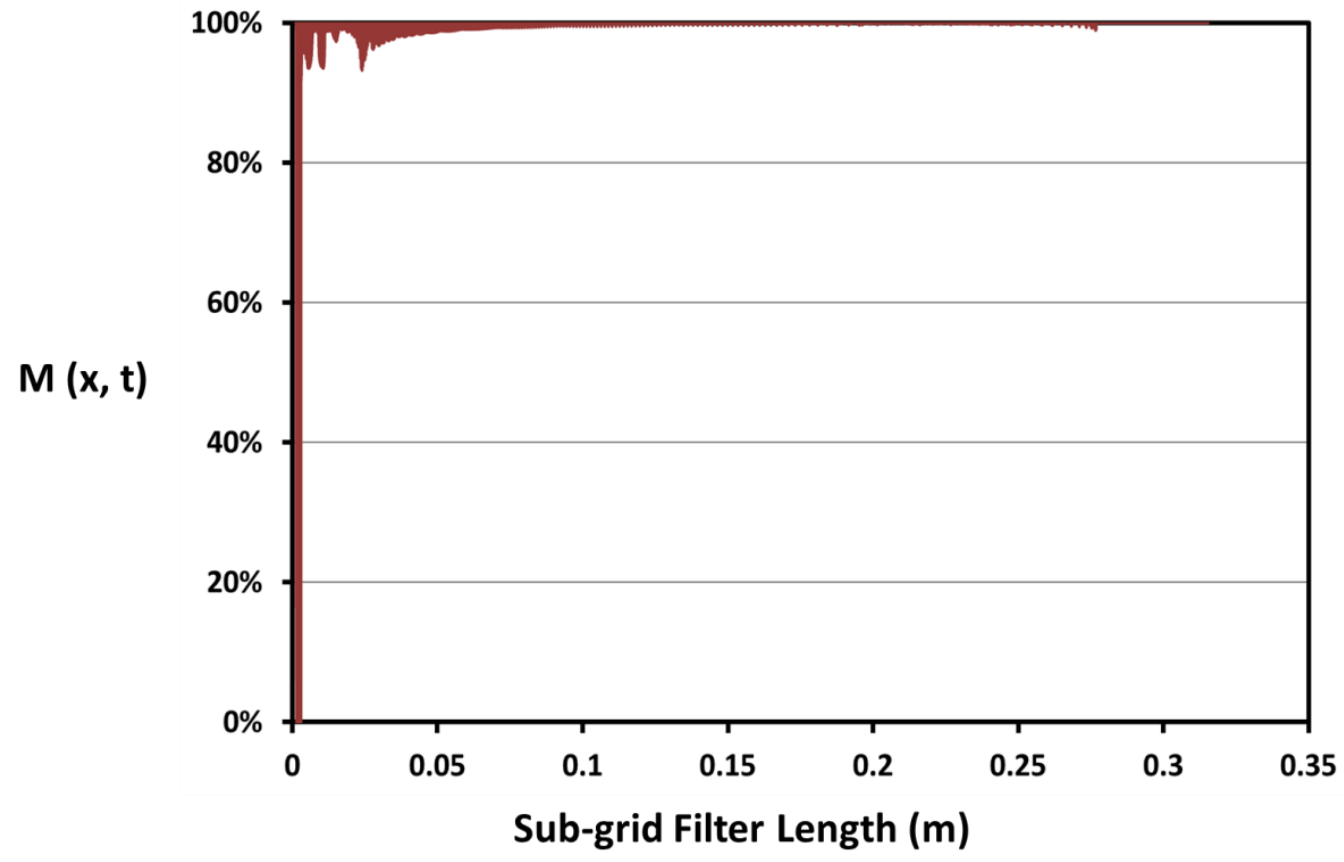

Figure 9 The measure of LES quality by M (x, t) with the Sub-grid Filter Length 


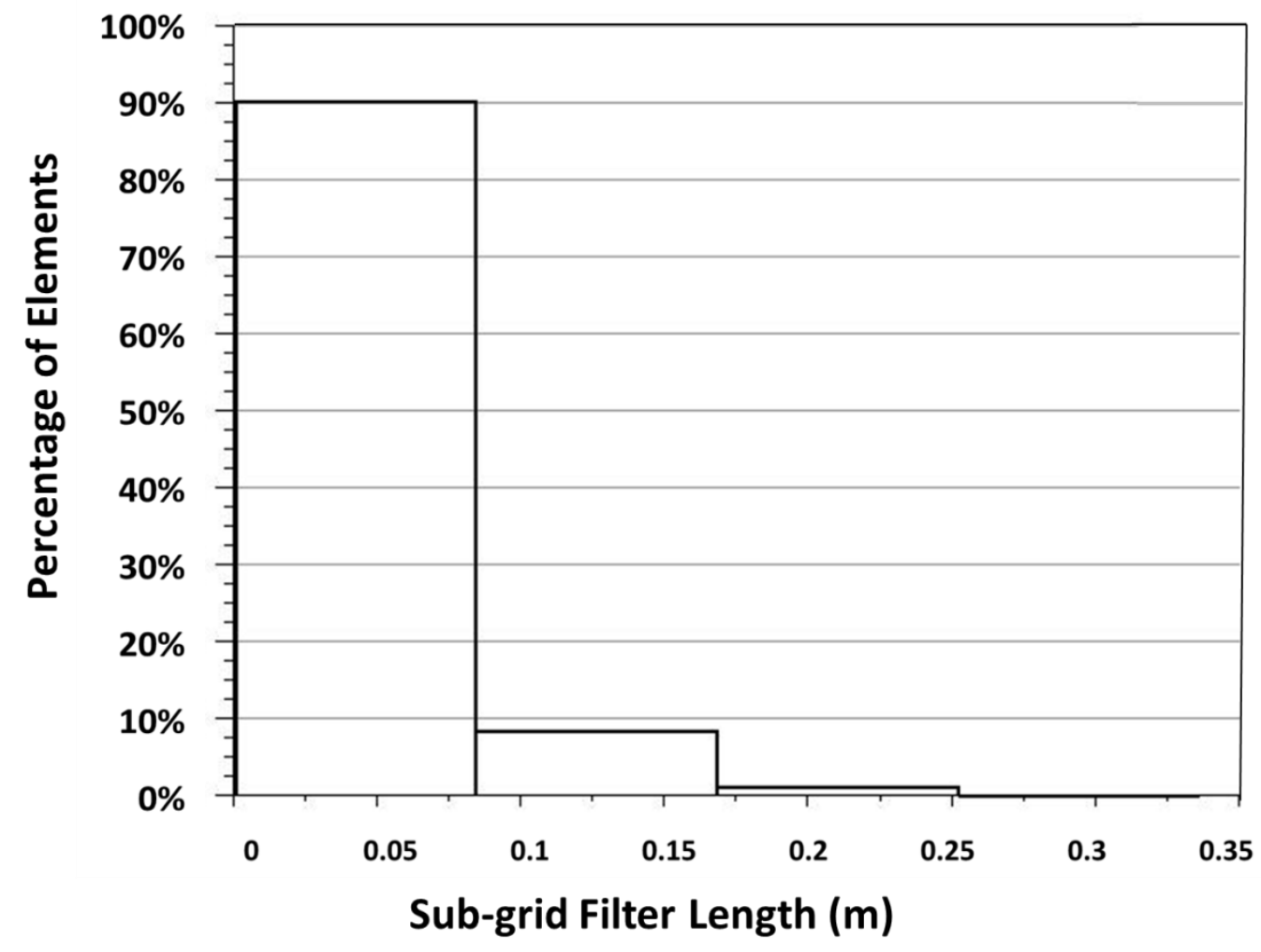

Figure 10 A histogram of Number of Elements for the Sub-grid Filter Length 


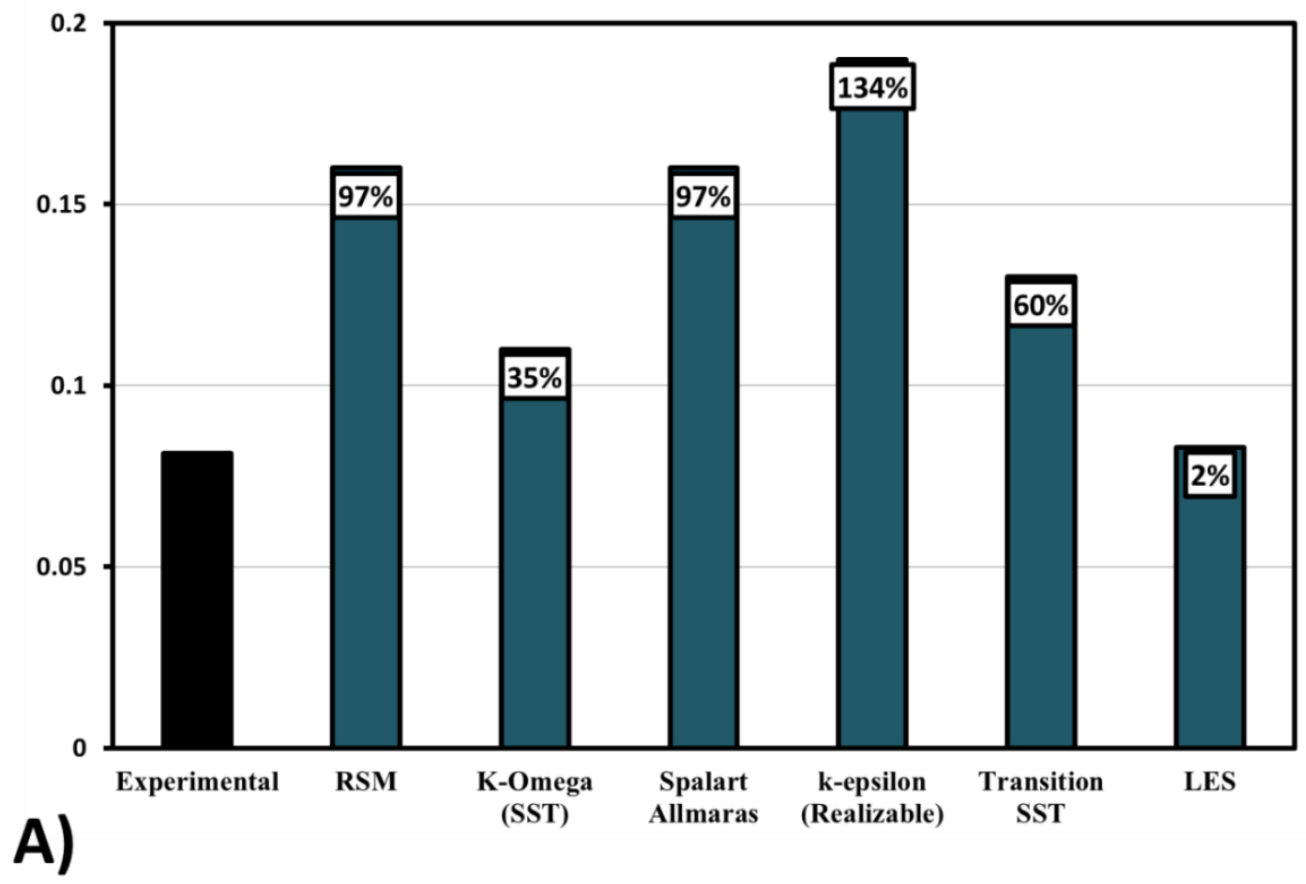

Flow direction

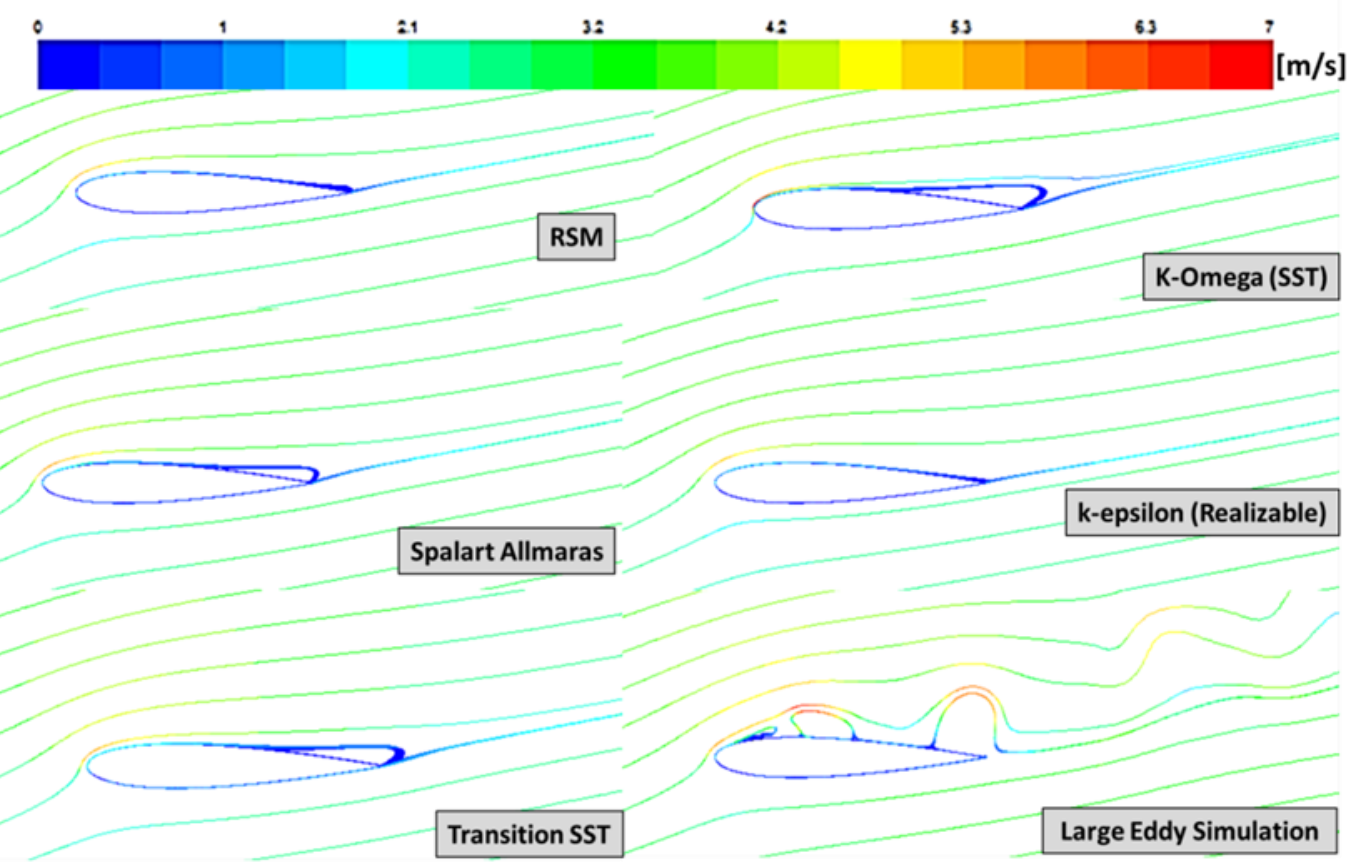

B) 


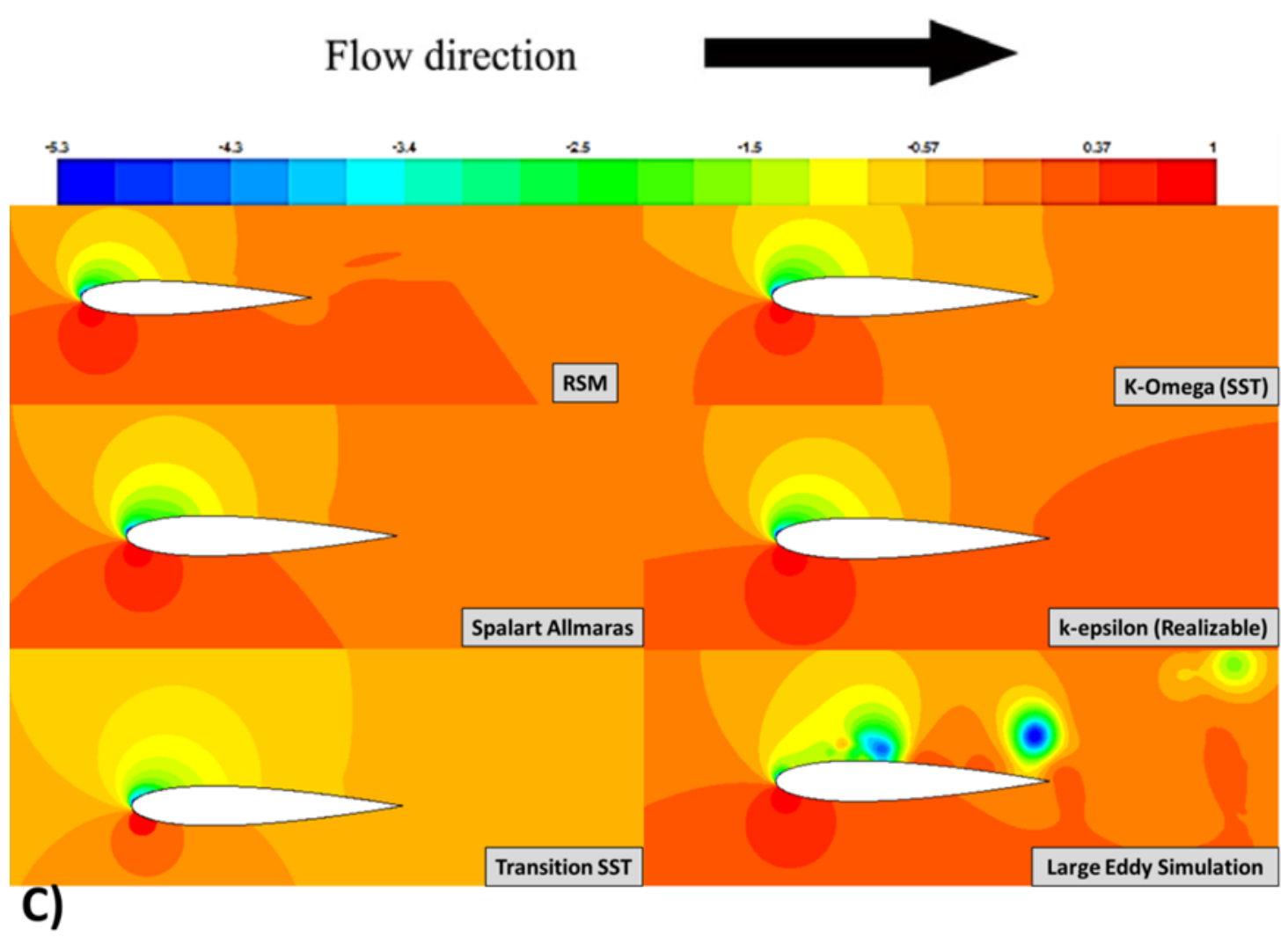



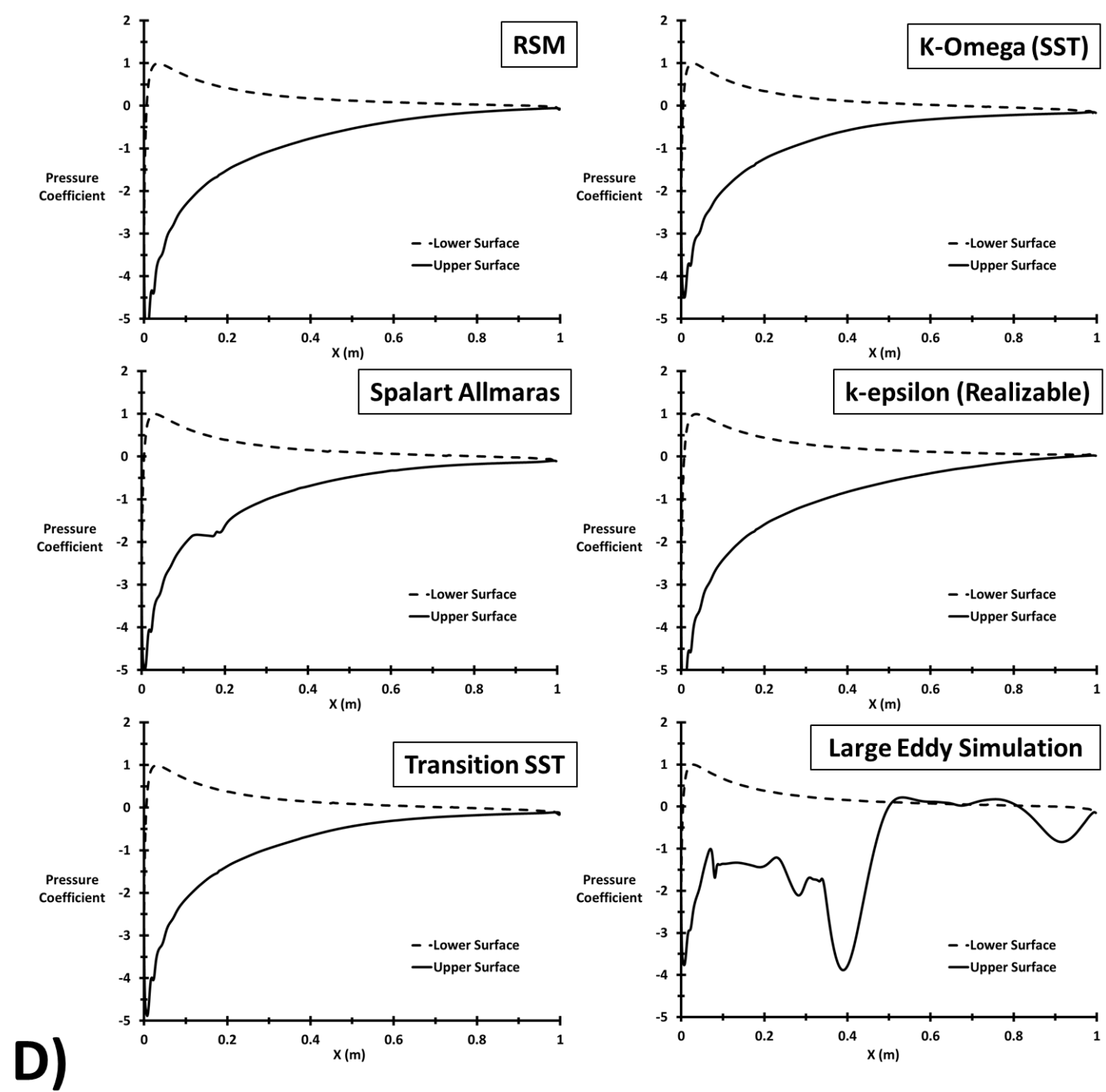

Figure 11 Comparison between different models to simulate the stall angle from experimental data A) Torque coefficient B) Path-line colored by the velocity magnitude C) Contours of pressure distribution D) Pressure distribution at upper and lower surface 


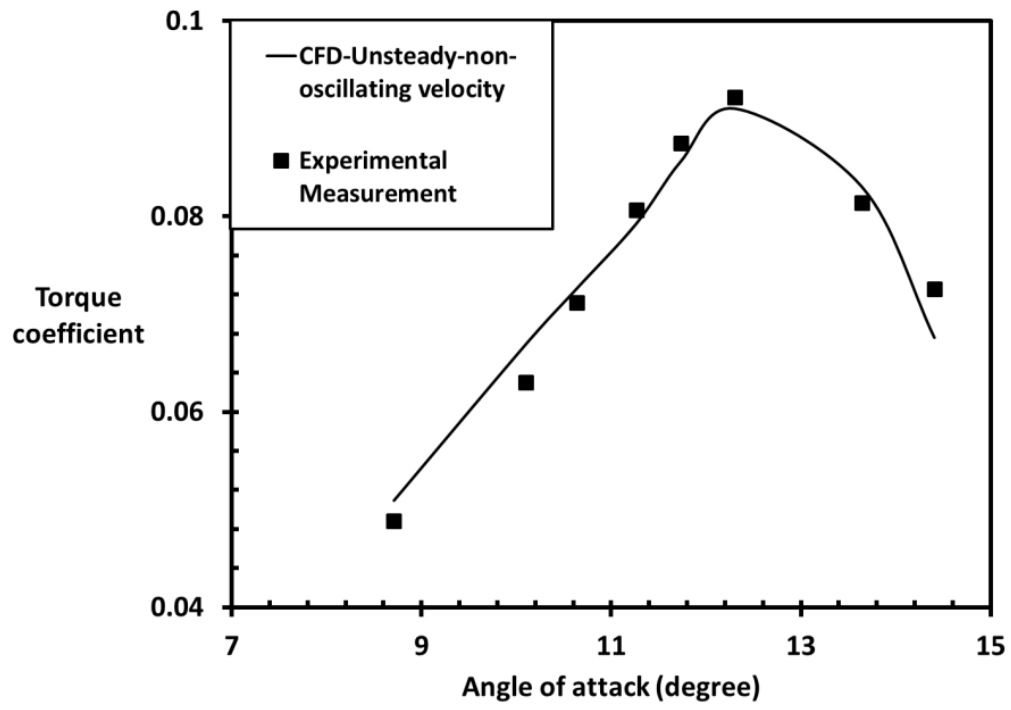

Figure 12 Measured torque coefficient from reference (Torresi, Camporeale et al. 2007, Torresi, Camporeale et al. 2007, Torresi, Camporeale et al. 2009) and calculated torque coefficient from present CFD unsteady flow with non-oscillating velocity

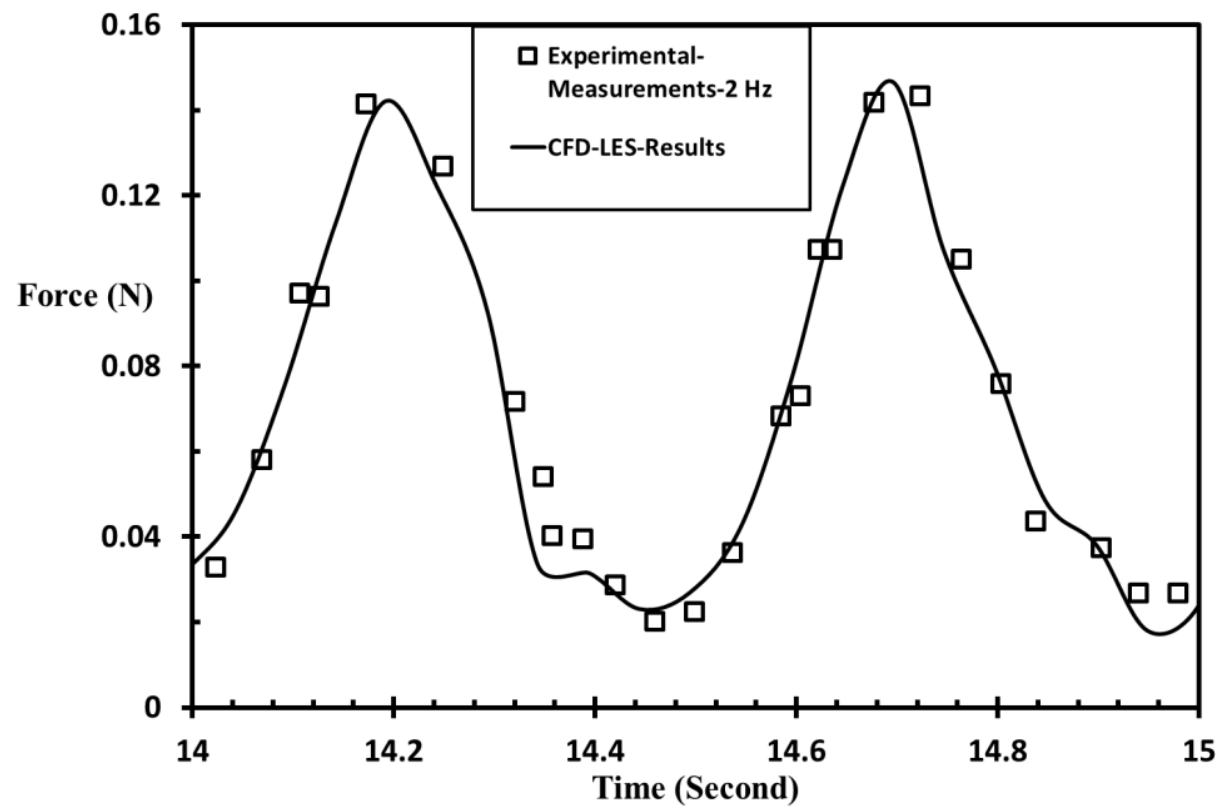

Figure 13 Measured unsteady in-line force $F_{D}$ from reference ((Nomura, Suzuki et al. 2003), (angle of attack= 0 degree) and $F_{D}$ calculated from the present CFD for frequency $2 \mathrm{~Hz}$ 


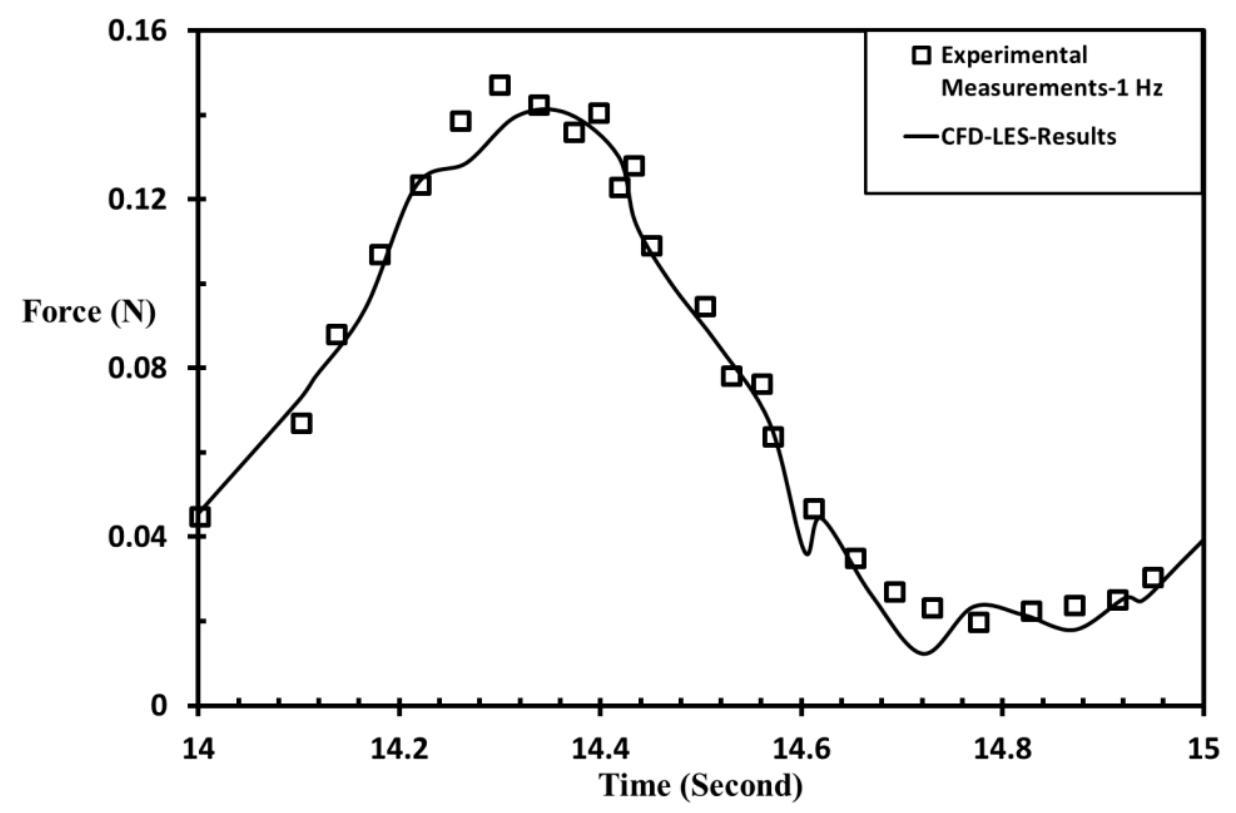

Figure 14 Measured unsteady in-line force $F_{D}$ from reference ((Nomura, Suzuki et al. 2003), (angle of attack= 0 degree) and $F_{D}$ calculated from the present CFD for frequency $1 \mathrm{~Hz}$.

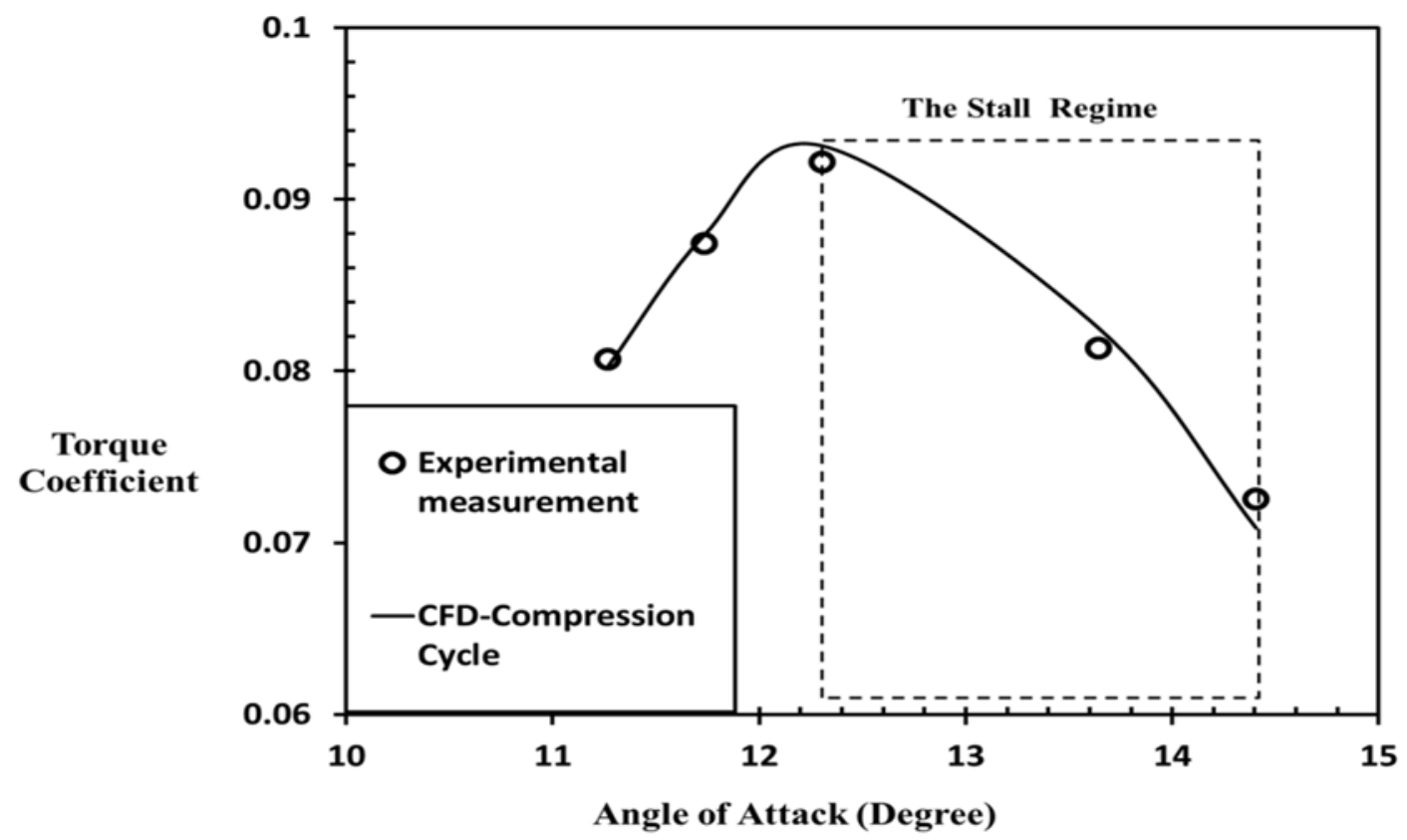

Figure 15 Measured torque coefficient from reference (Torresi, Camporeale et al. 2007, Torresi, Camporeale et al. 2007, Torresi, Camporeale et al. 2009) and calculated torque coefficient from CFD unsteady flow with sinusoidal inlet velocity 


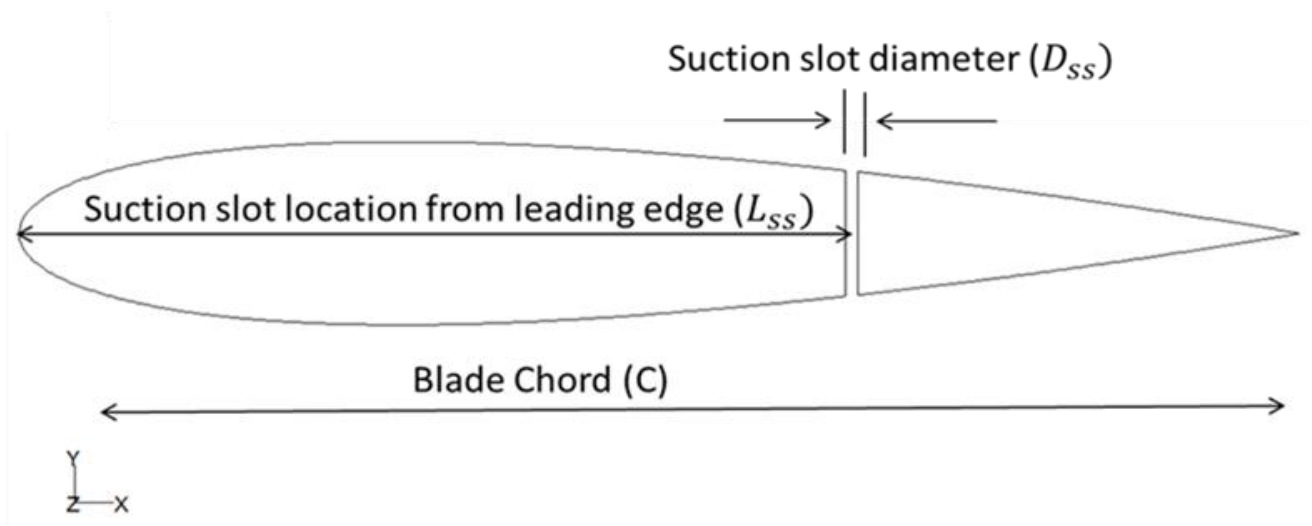

Figure 16 2D airfoil diagram with a slot
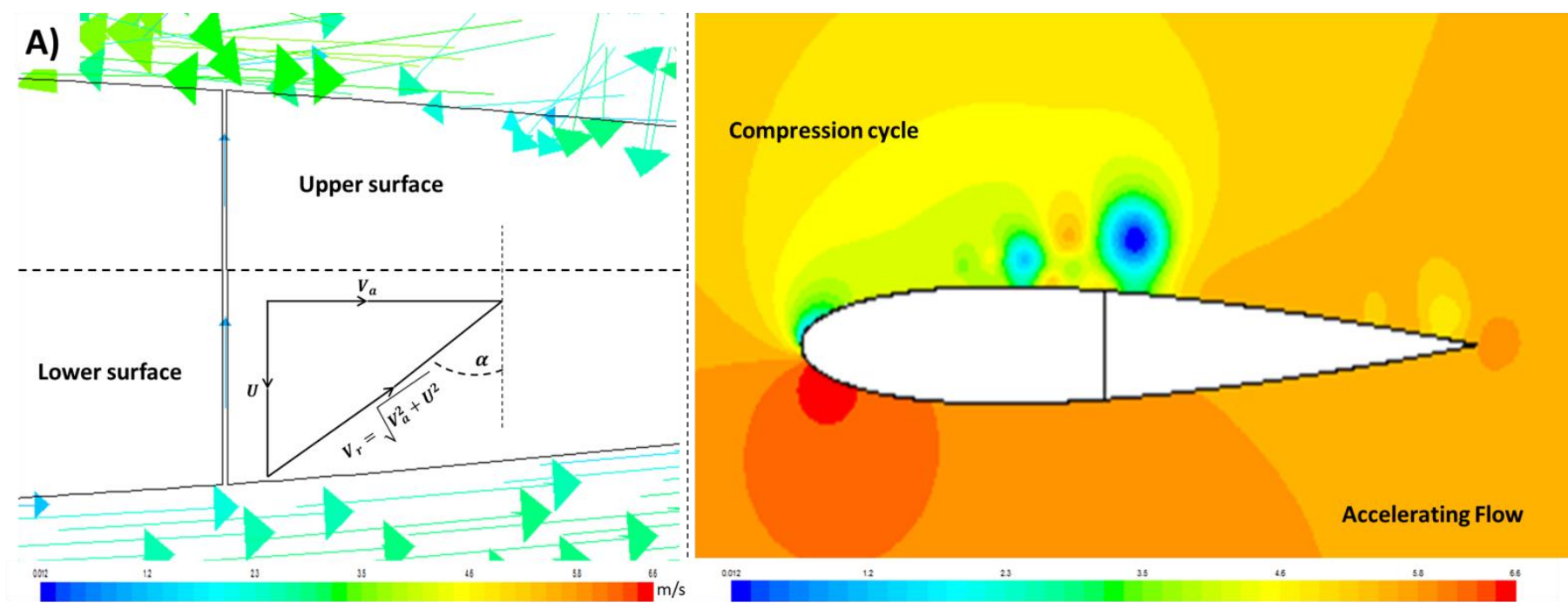


\section{B)}
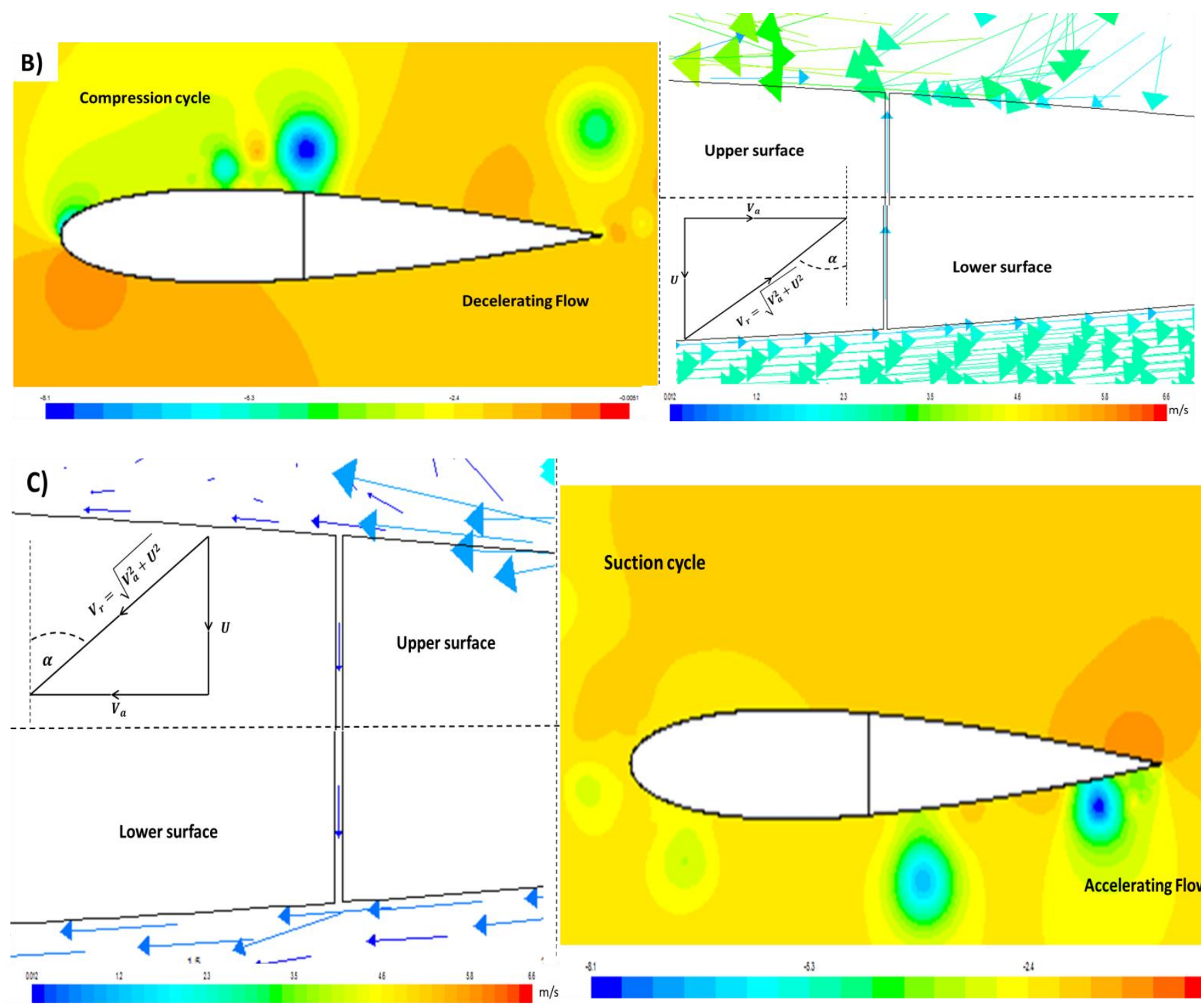

Suction cycle

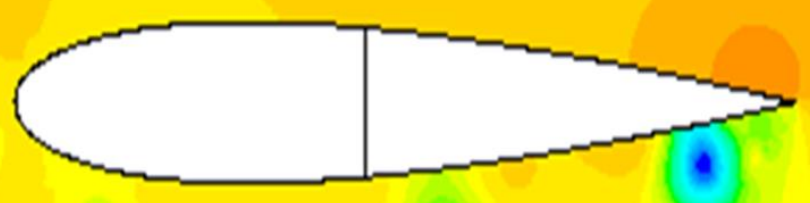

Accelerating Flow 

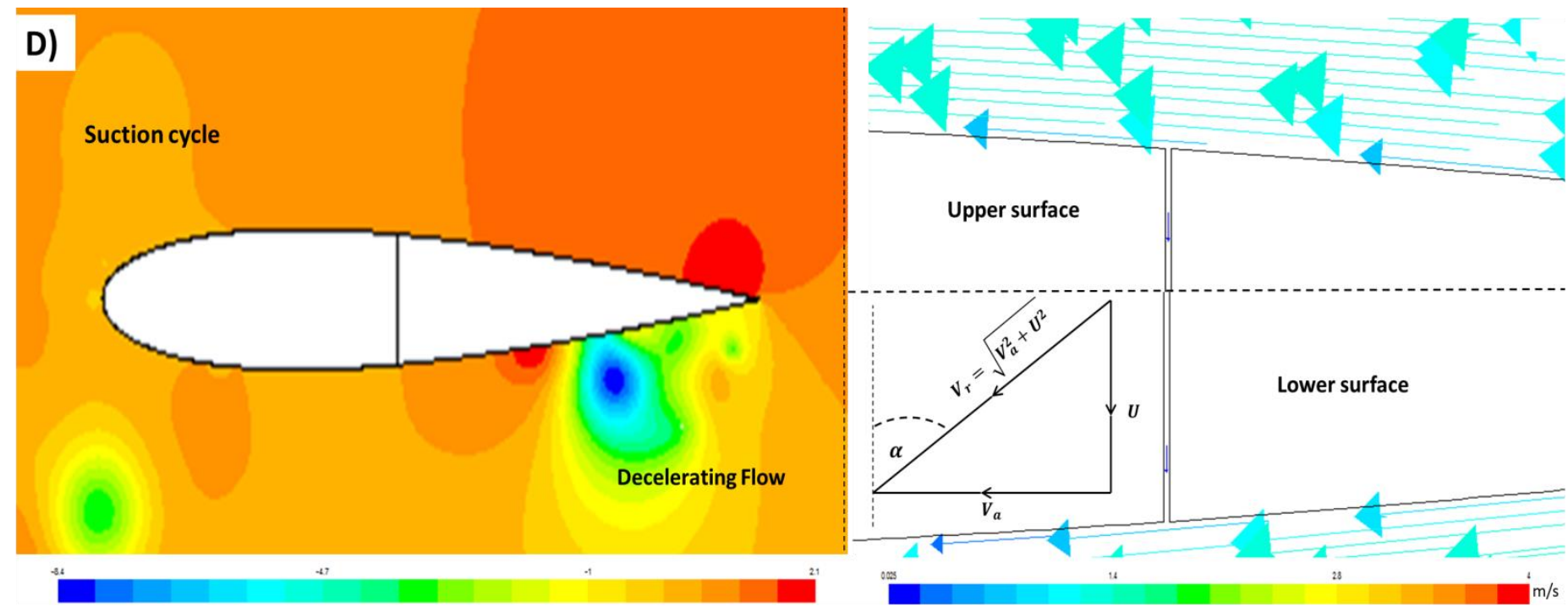

Figure 17 Factors affecting determination of the slot velocity direction for the Pressure distribution and Velocity vector direction A) Accelerating flow at compression cycle B) Decelerating flow at compression cycle C) Accelerating flow at suction cycle D) Decelerating flow at suction cycle

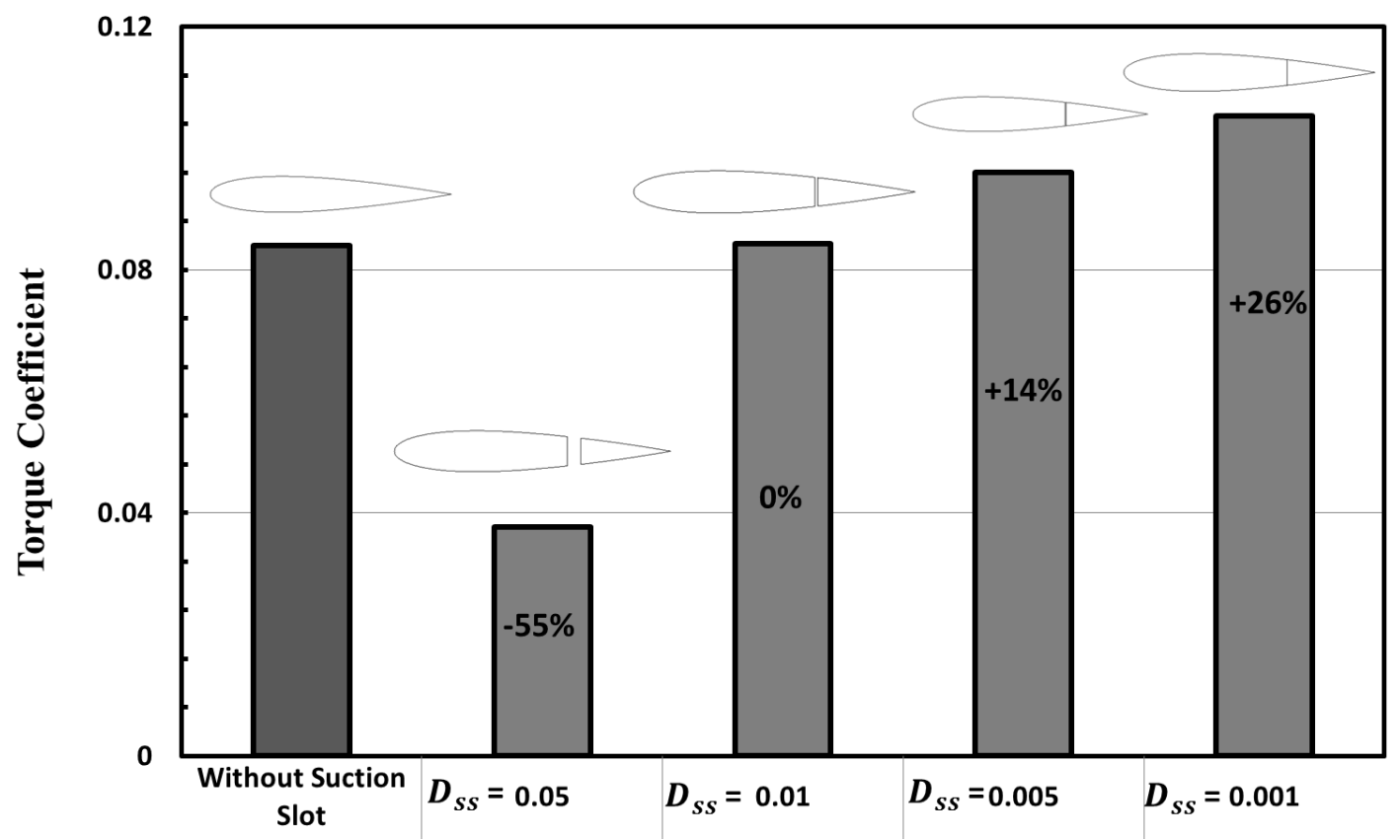

Figure 18 Torque coefficient for different $D_{s s}$ at stall angle 


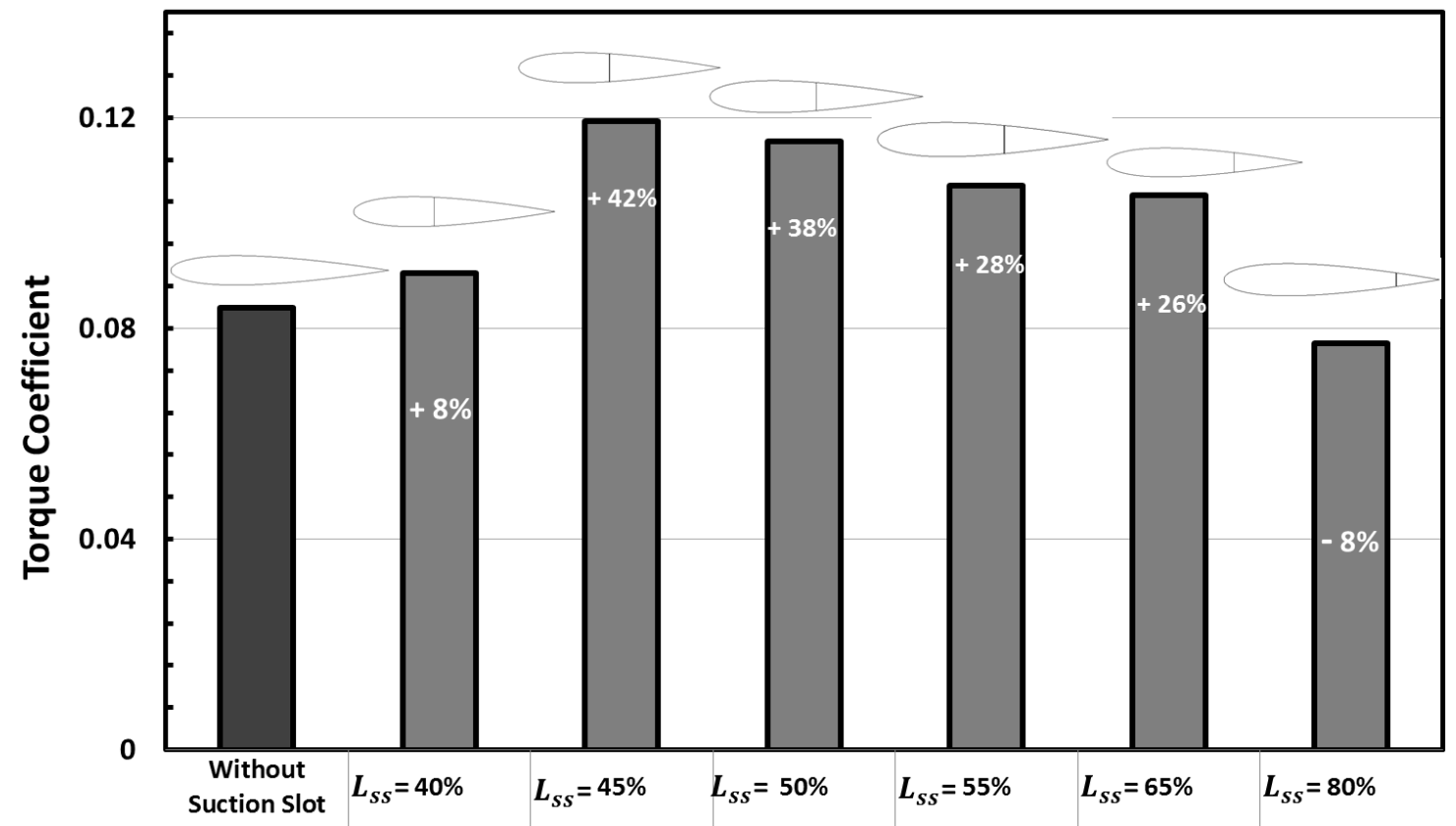

Figure 19 Torque coefficient for suction slots at different $L_{s s}$ at 13.64 degree

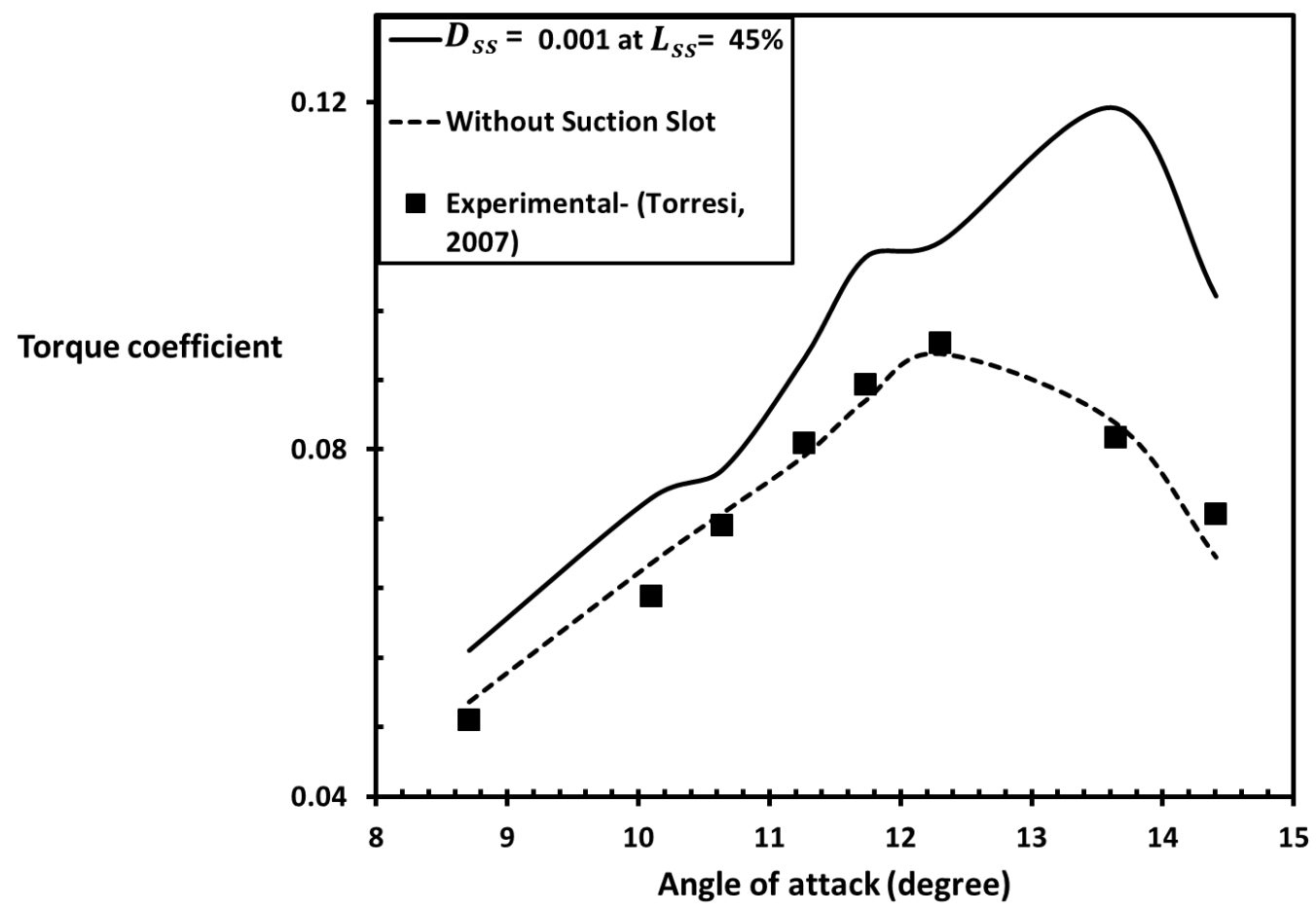

Figure 20 Suction slot with optimum $L_{s s}(45 \%)$ and optimum $D_{s s}(0.001 \mathrm{~m})$ at different angles of attack 


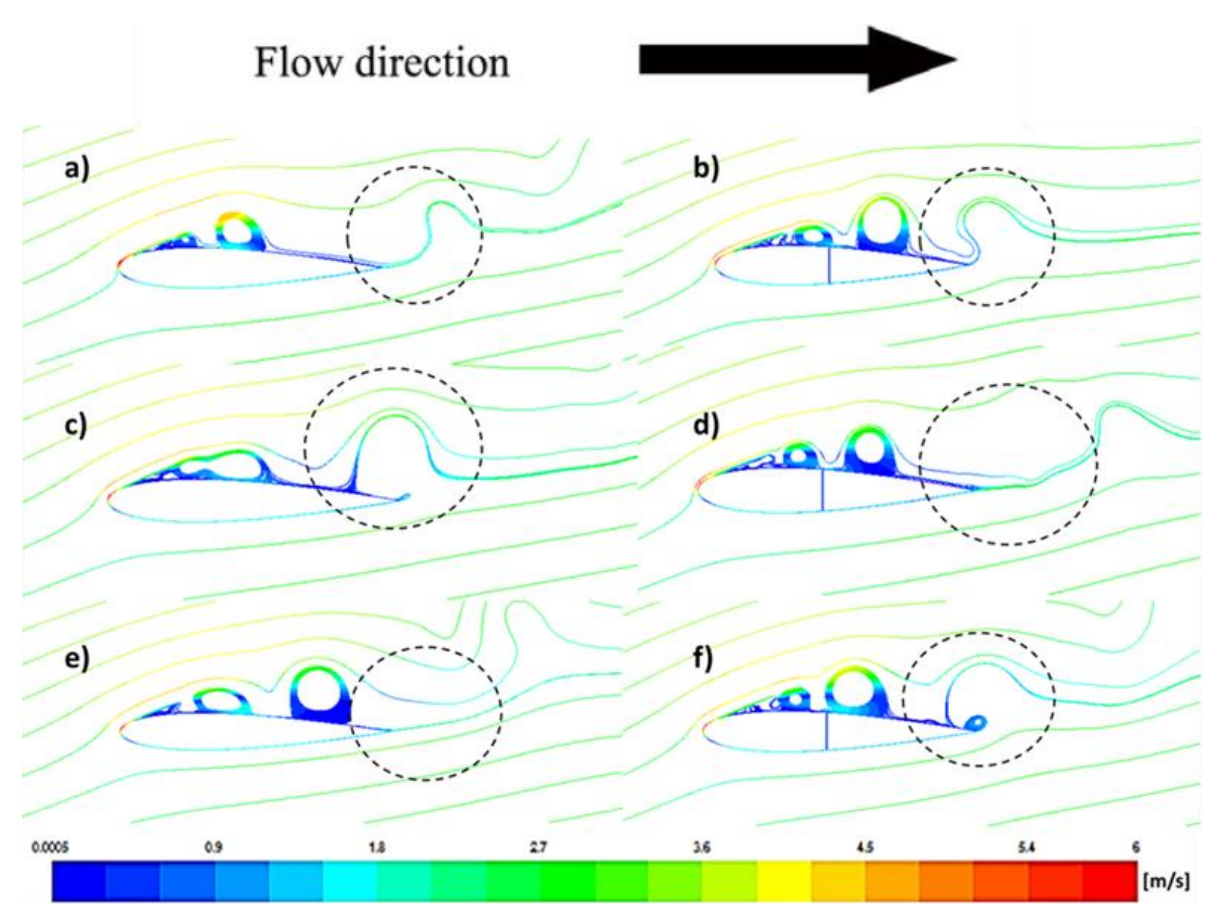

Figure 21 The Path-line for mean velocity magnitude at certain velocity equal to $2.92 \mathrm{~m} / \mathrm{s}$ unsteady input flow with non-oscillating velocity, a) and b) 12.3 degree, c) and d) 13.6 degree, e) and f) 14.4 degree

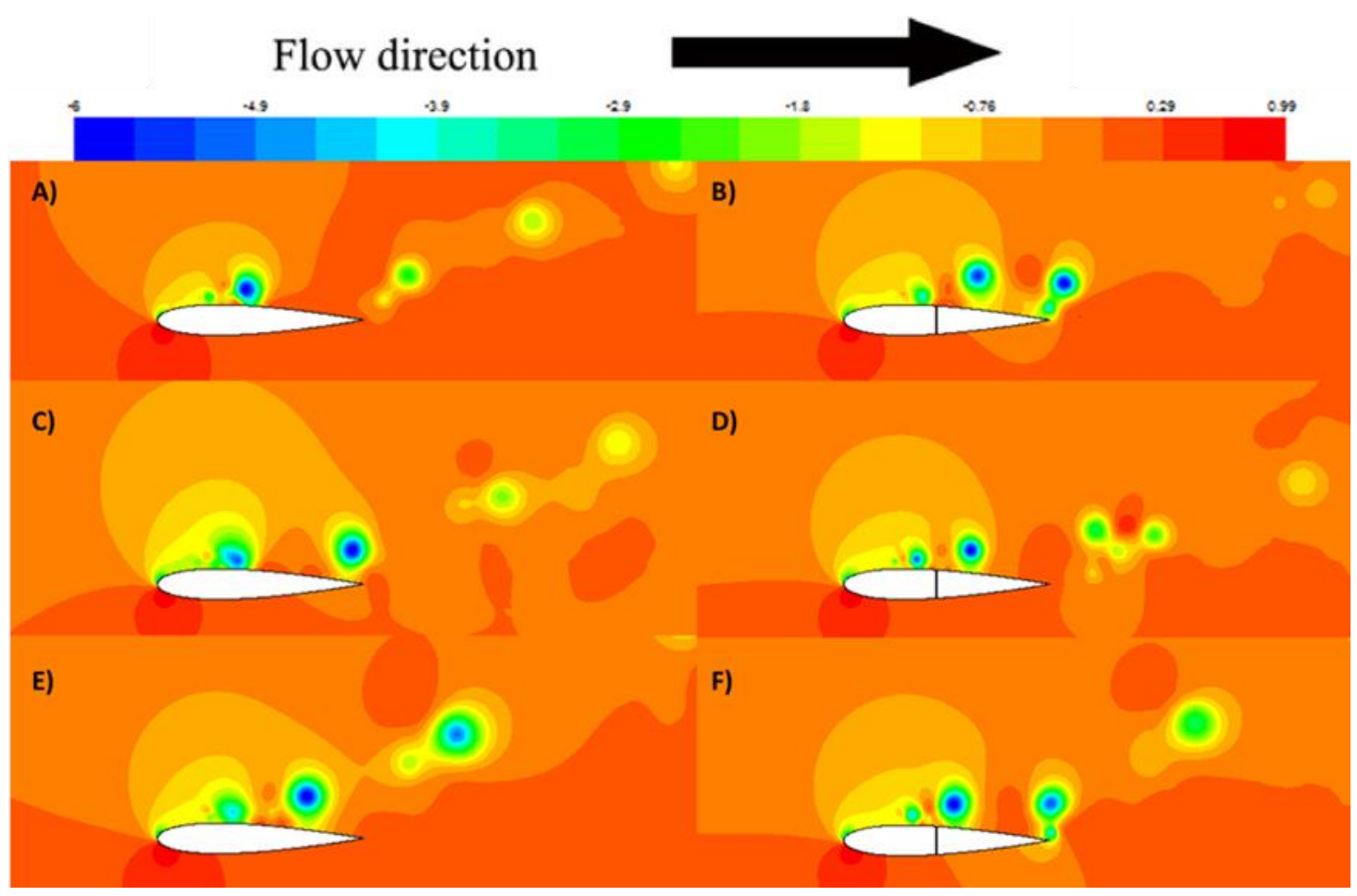

Figure 22 The pressure coefficient around the airfoil, unsteady input flow with non-oscillating velocity, A) and B) 12.3 degree, C) and D) 13.6 degree, E) and F) 14.4 degree 

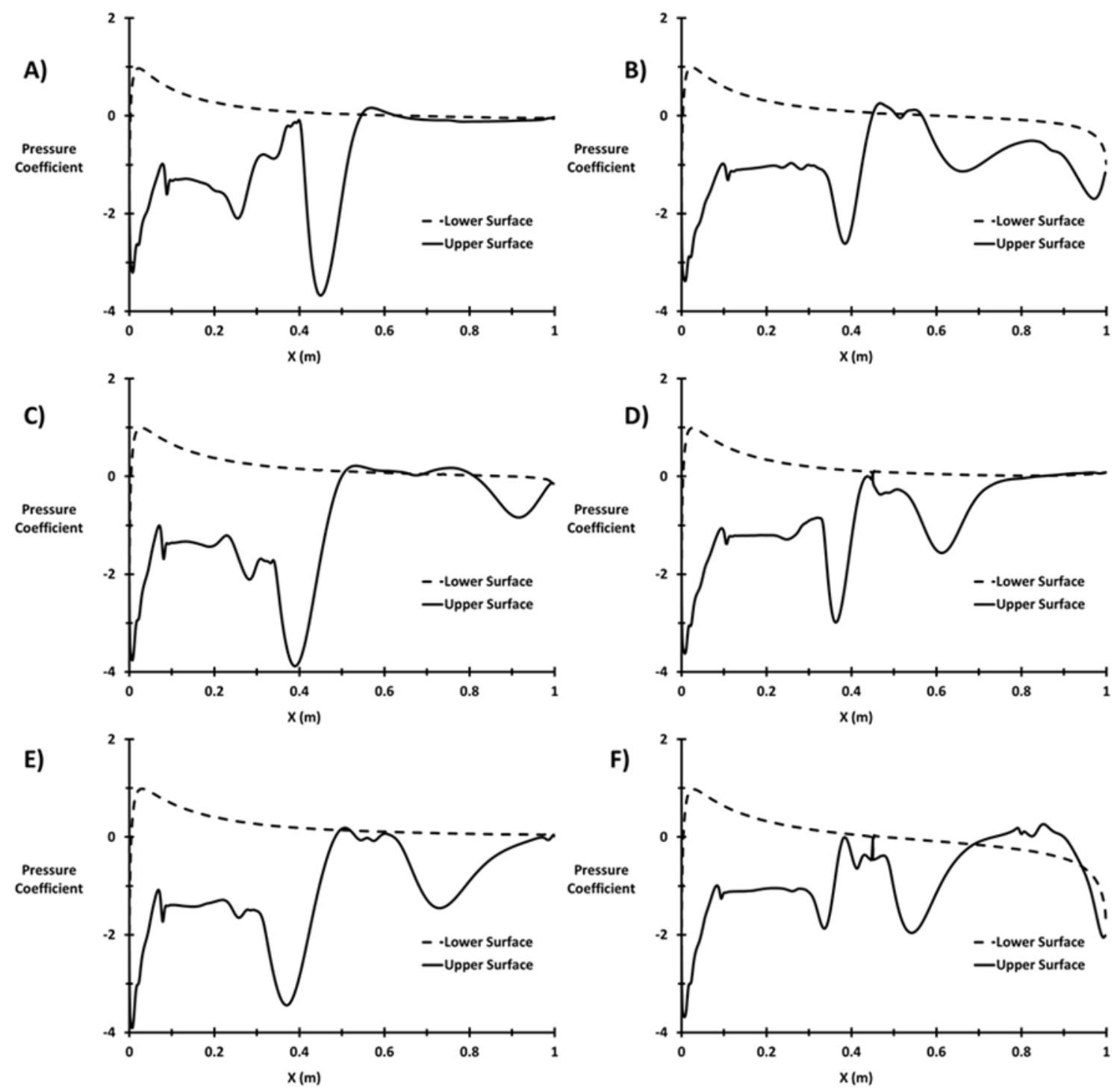

Figure 23 Pressure coefficient distribution on the upper and lower surface of the airfoil, A) and B) 12.3 degree, C) and D) 13.6 degree, E) and F) 14.4 degree 


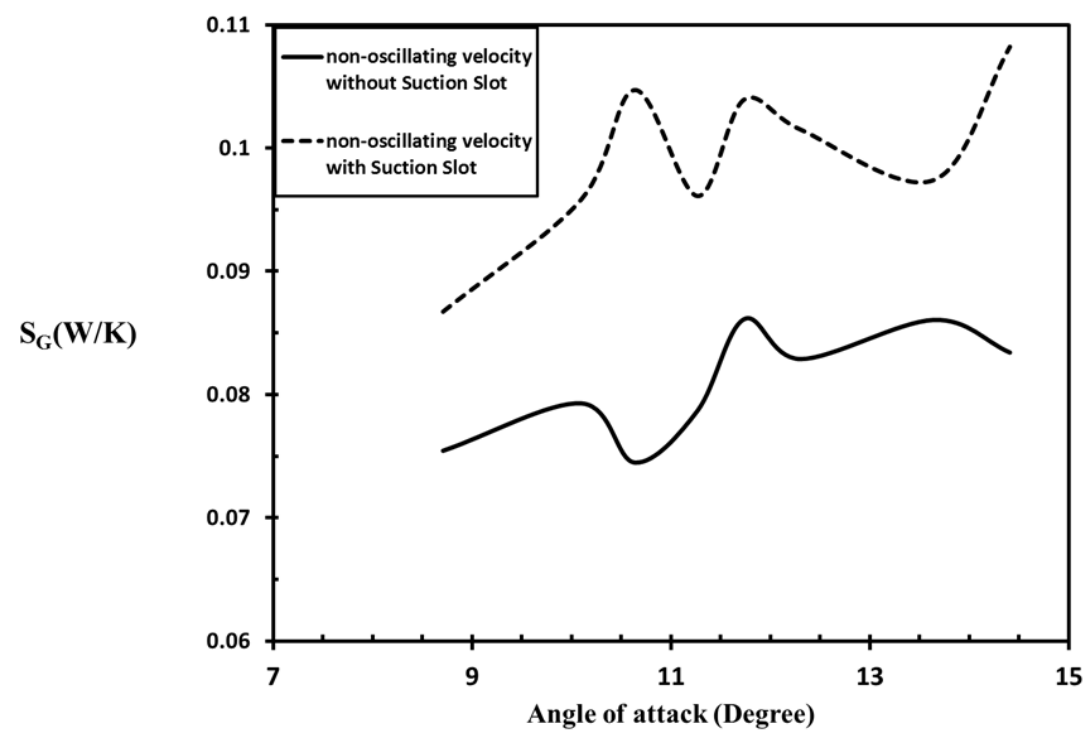

Figure 24 The effect of suction slot on the global entropy generation rate with different angle of attack

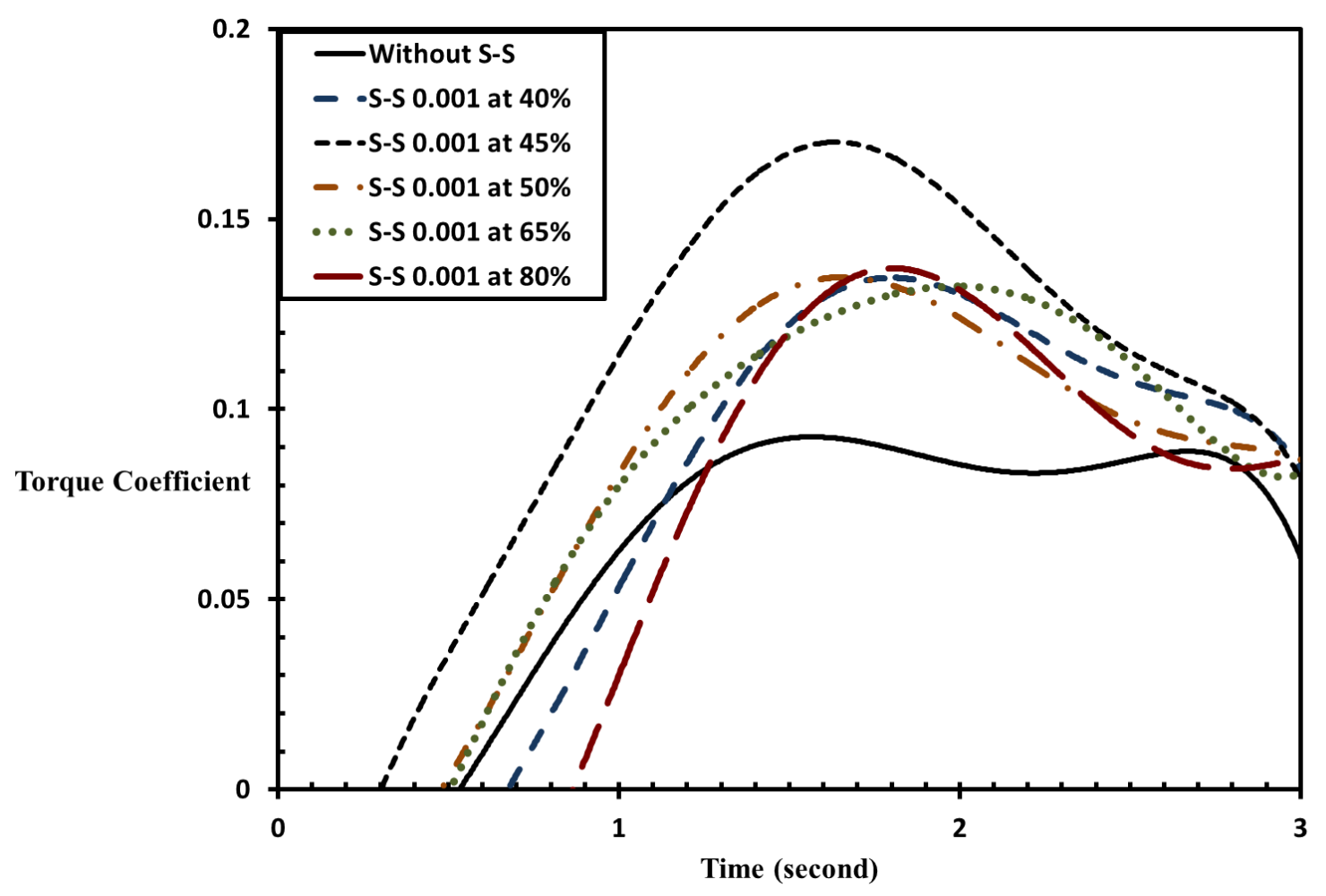

Figure 25 a) Suction slot with $D_{s s}$ equal to $0.001 \mathrm{~m}$ at different $L_{s s}$ for instantaneous torque coefficient at 13.6 degree under unsteady flow with sinusoidal inlet velocity 


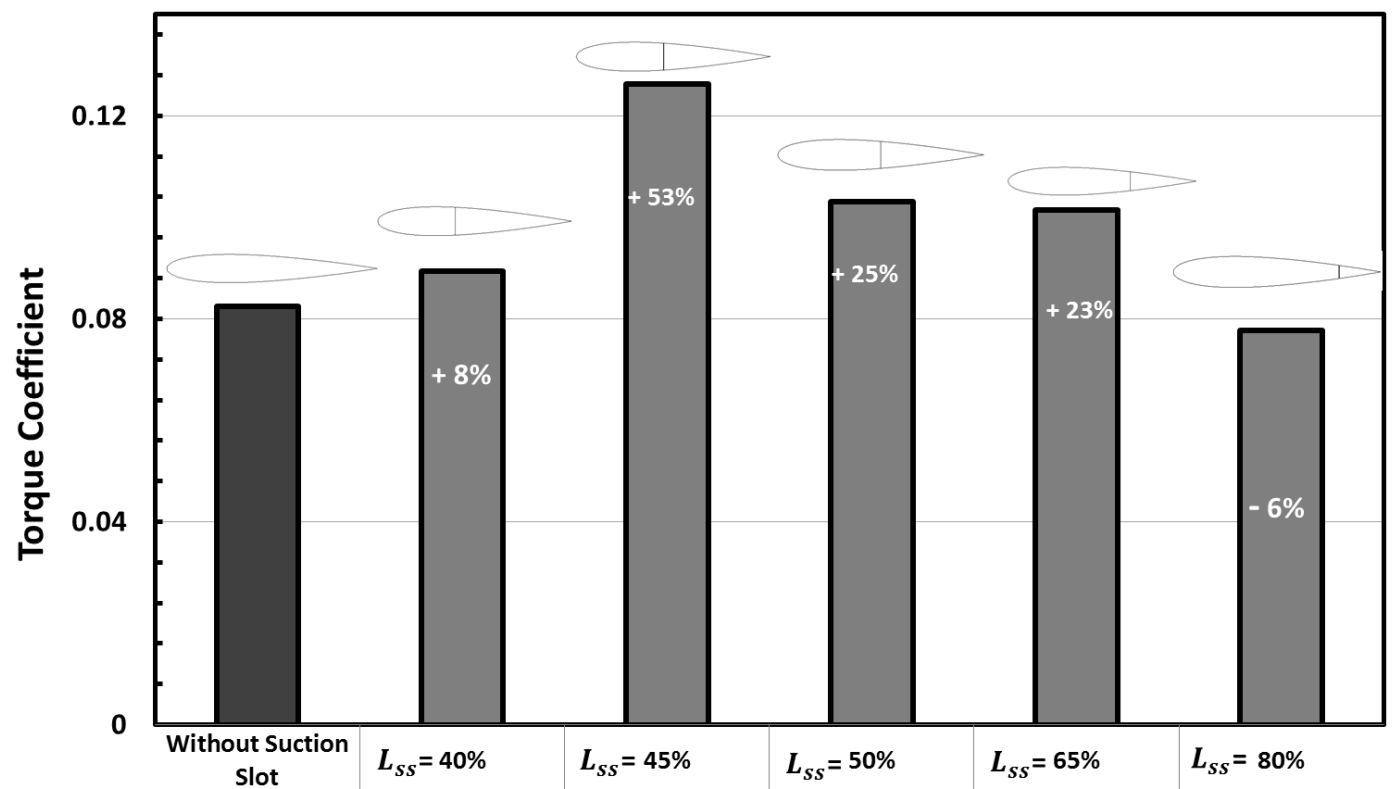

Figure $25 \mathrm{~b}$ ) Suction slot with $D_{s s}$ equal to $0.001 \mathrm{~m}$ at different $L_{s s}$ for average torque coefficient at 13.6 degree under unsteady flow with sinusoidal inlet velocity

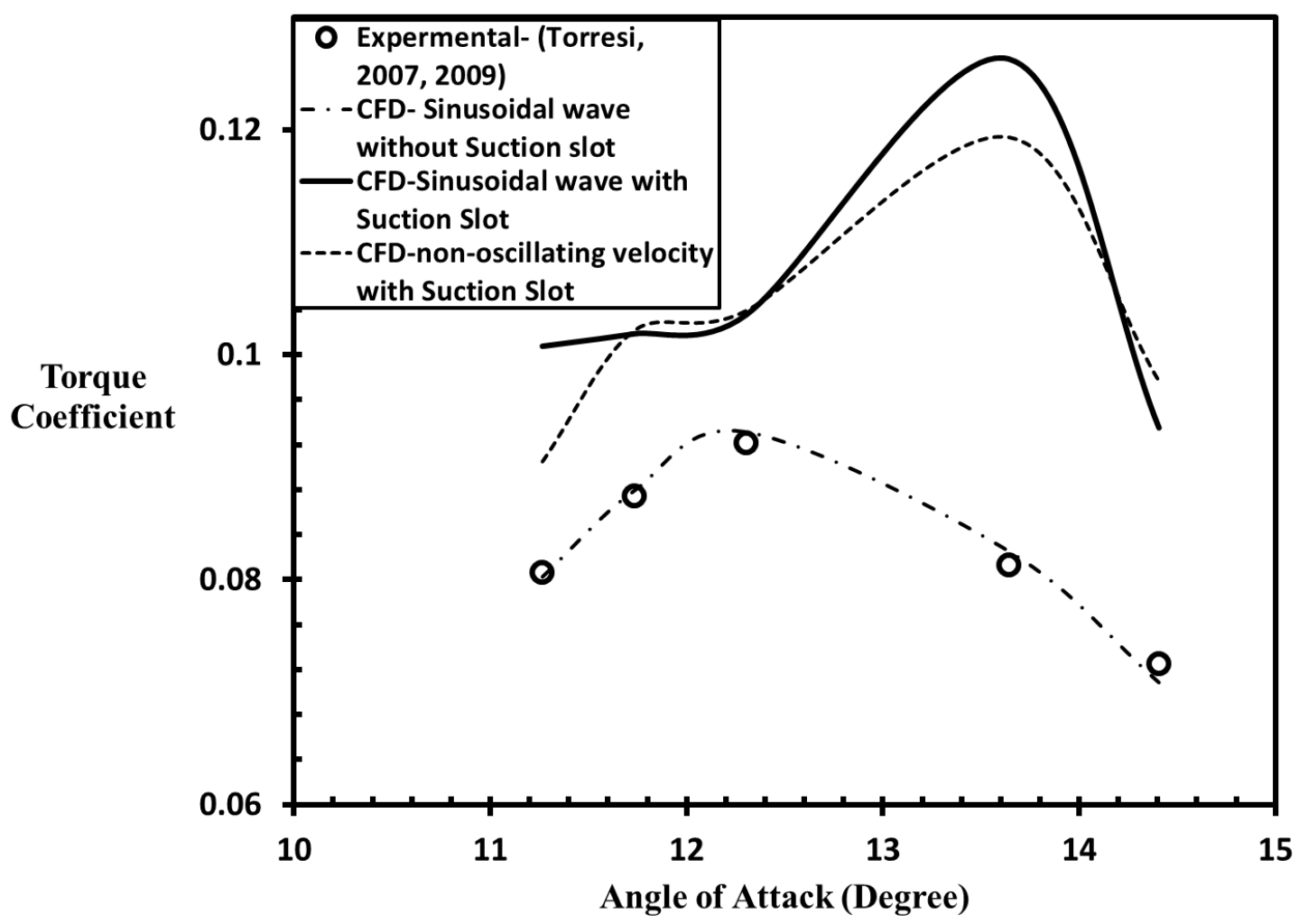

Figure 26 Suction slot with optimum $L_{s s}(45 \%)$ and optimum $D_{s s}(0.001 \mathrm{~m})$ at different angles of attack under unsteady flow with sinusoidal inlet velocity 


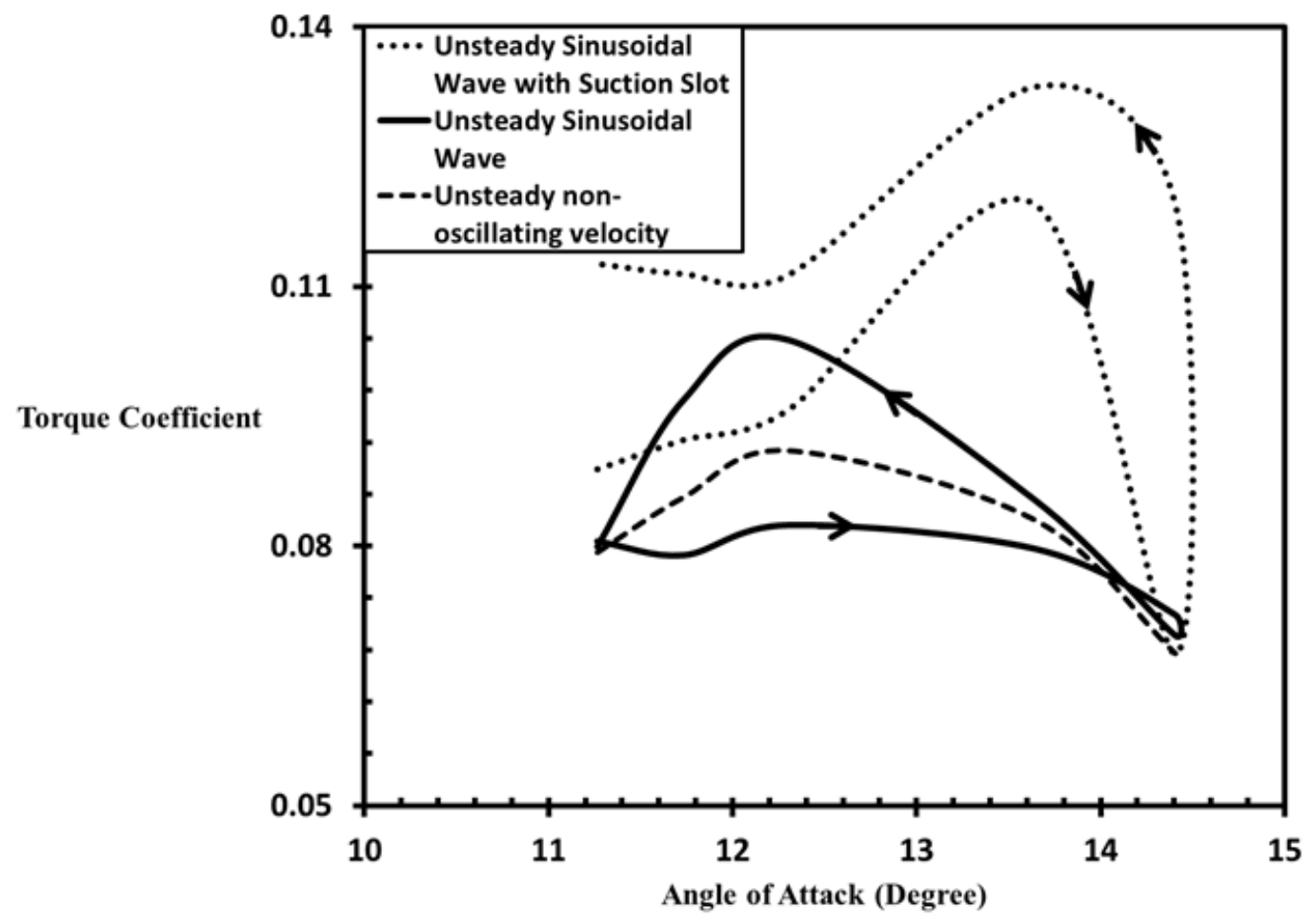

Figure 27 The hysteretic behavior due to unsteady flow with sinusoidal inlet velocity at different angles of attack with optimum $L_{s s}(45 \%)$ and optimum $D_{s s}(0.001 \mathrm{~m})$ 

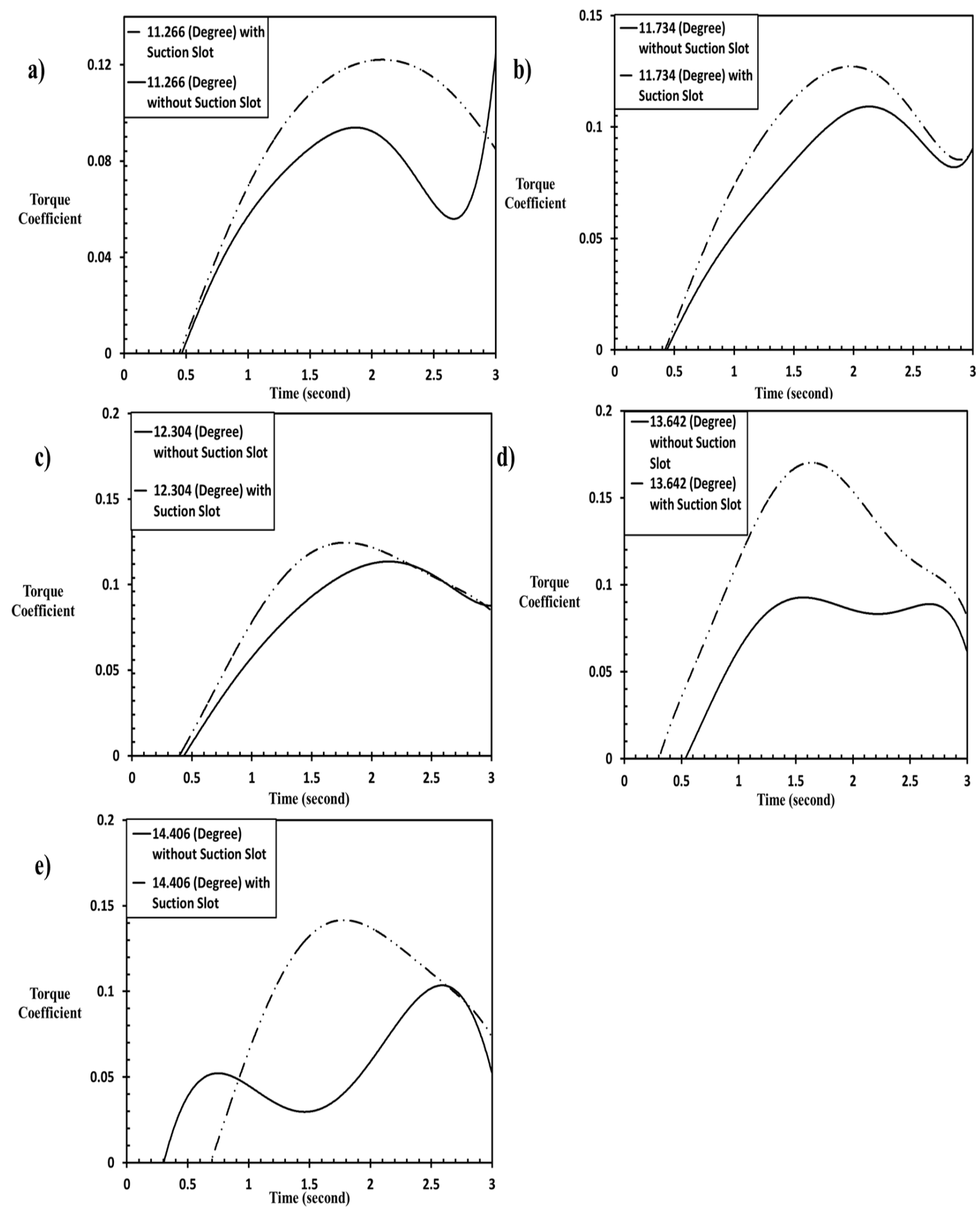

Figure 28 Torque coefficients at compression cycle for different angles of attack under unsteady flow with sinusoidal inlet velocity with optimum $L_{s s}(45 \%)$ and optimum $D_{s s}(0.001 \mathrm{~m})$, a) 11.3 degree, b) 11.7 degree, c) 12.3 degree, d) 13.6 degree, e) 14.4 degree 


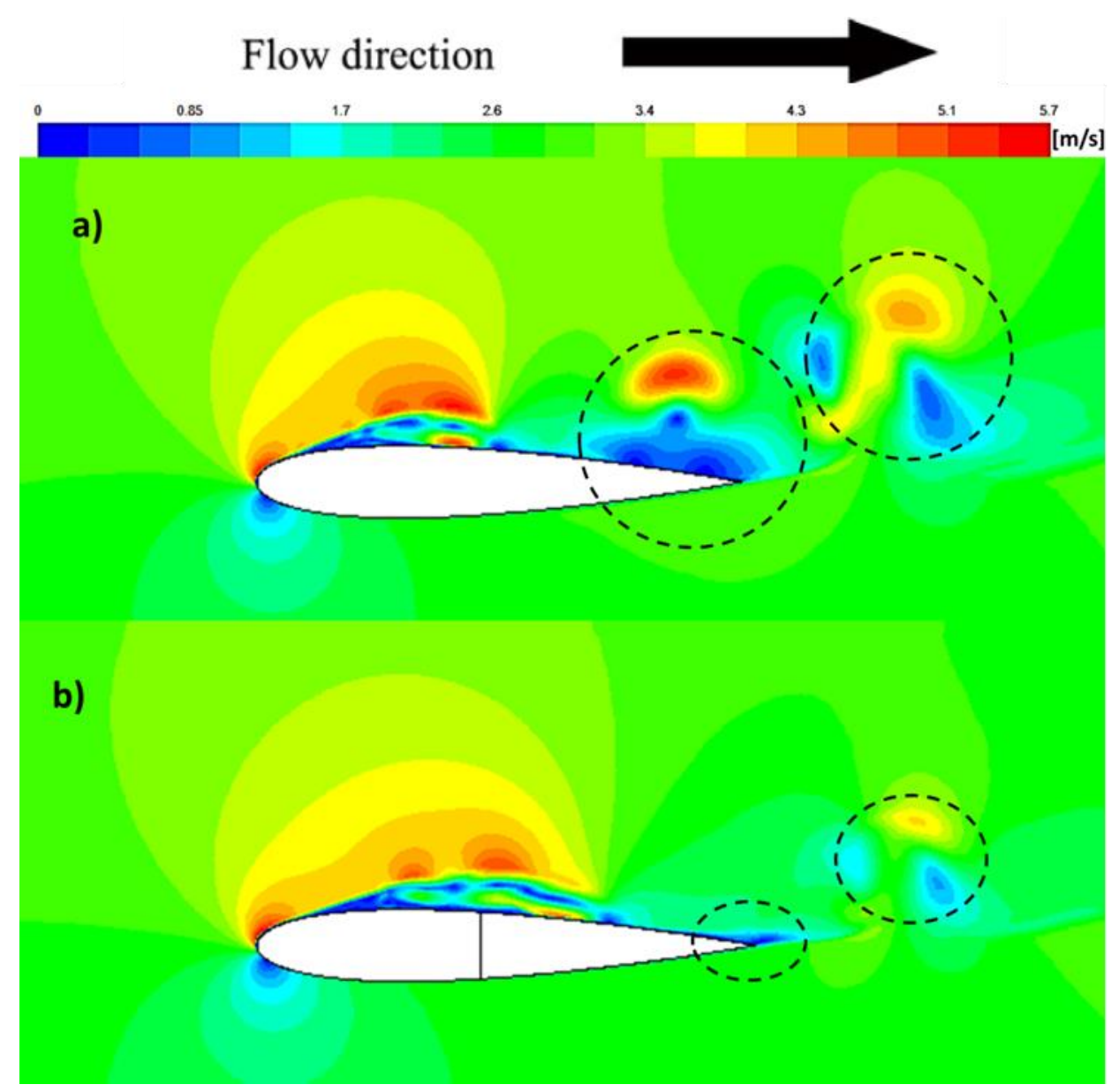

Figure 29 Velocity magnitude contours at maximum velocity equal to $2.92(\mathrm{~m} / \mathrm{s})$ for sinusoidal input flow, at 12.3 (Degree), Before the Stall 


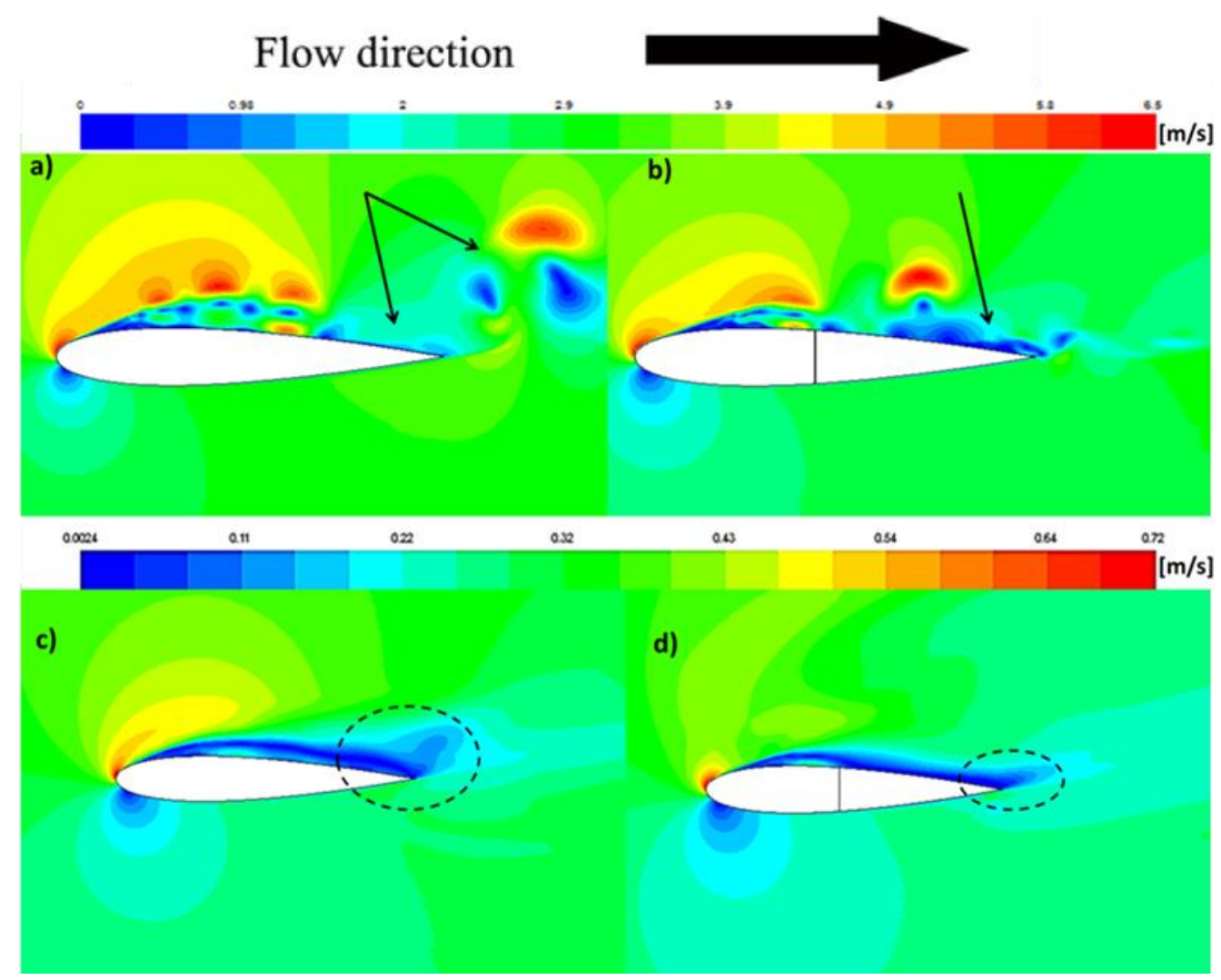

Figure 30 a) and b) velocity magnitude contours, c) and d) mean velocity magnitude contours, at maximum velocity equal to $2.92(\mathrm{~m} / \mathrm{s})$ for sinusoidal input flow, at13.6 (Degree), After the Stall 

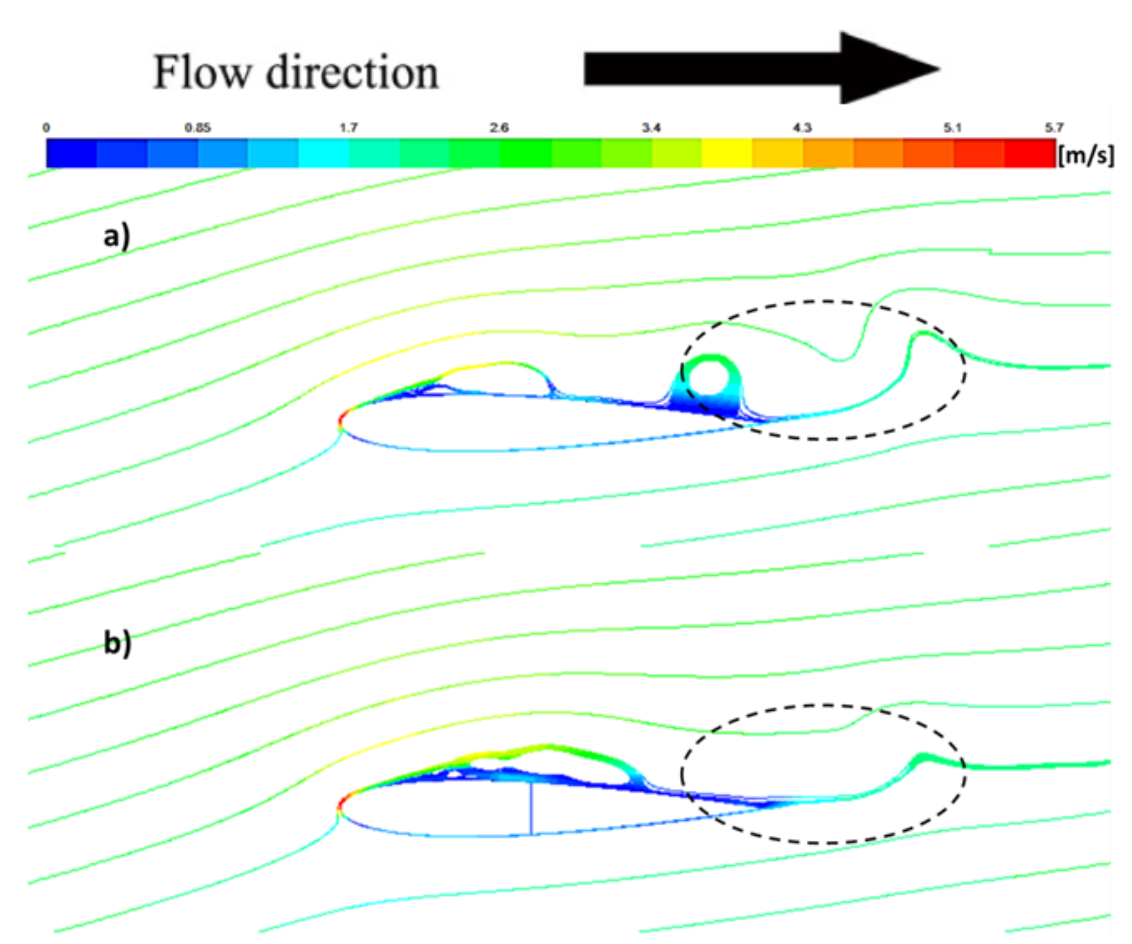

Figure 31 Path-line colored by mean velocity magnitude at maximum velocity equal to $2.92(\mathrm{~m} / \mathrm{s})$ for sinusoidal input flow, at 12.3 (Degree), Before the Stall
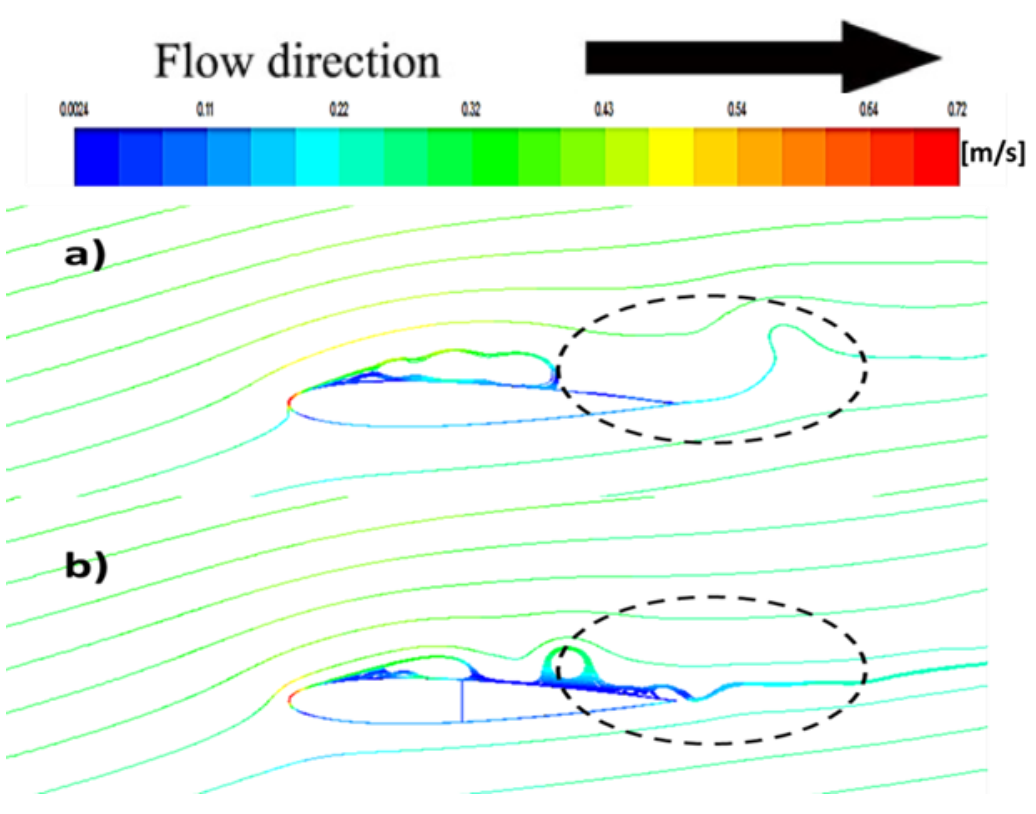

Figure 32 Path-line colored by mean velocity magnitude at maximum velocity equal to $2.92(\mathrm{~m} / \mathrm{s})$ for sinusoidal input flow, at 13.6 (Degree), After the Stall 

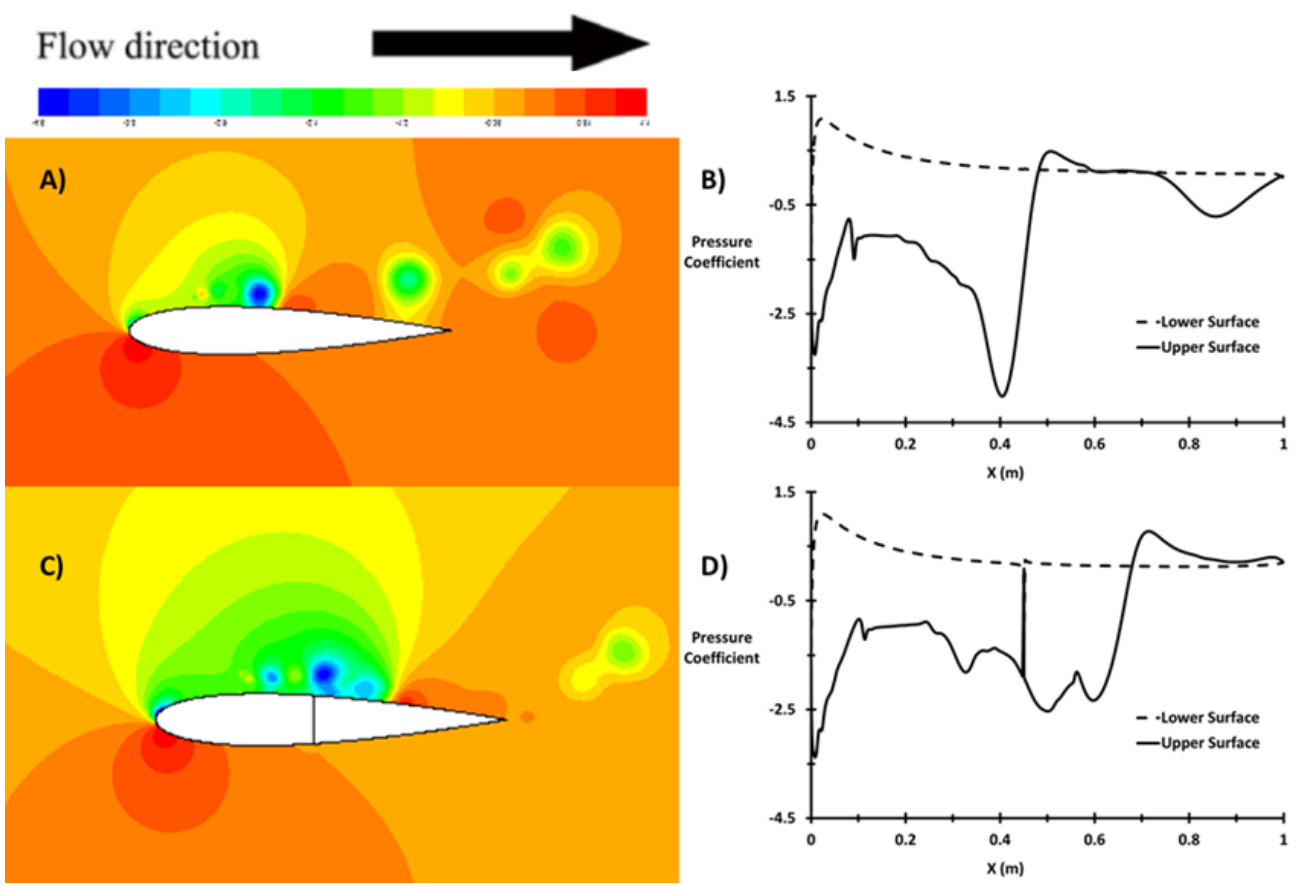

Figure 33 The pressure distribution at maximum velocity equal to $2.92(\mathrm{~m} / \mathrm{s})$ for sinusoidal input flow, at 12.3 (Degree), Before the Stall

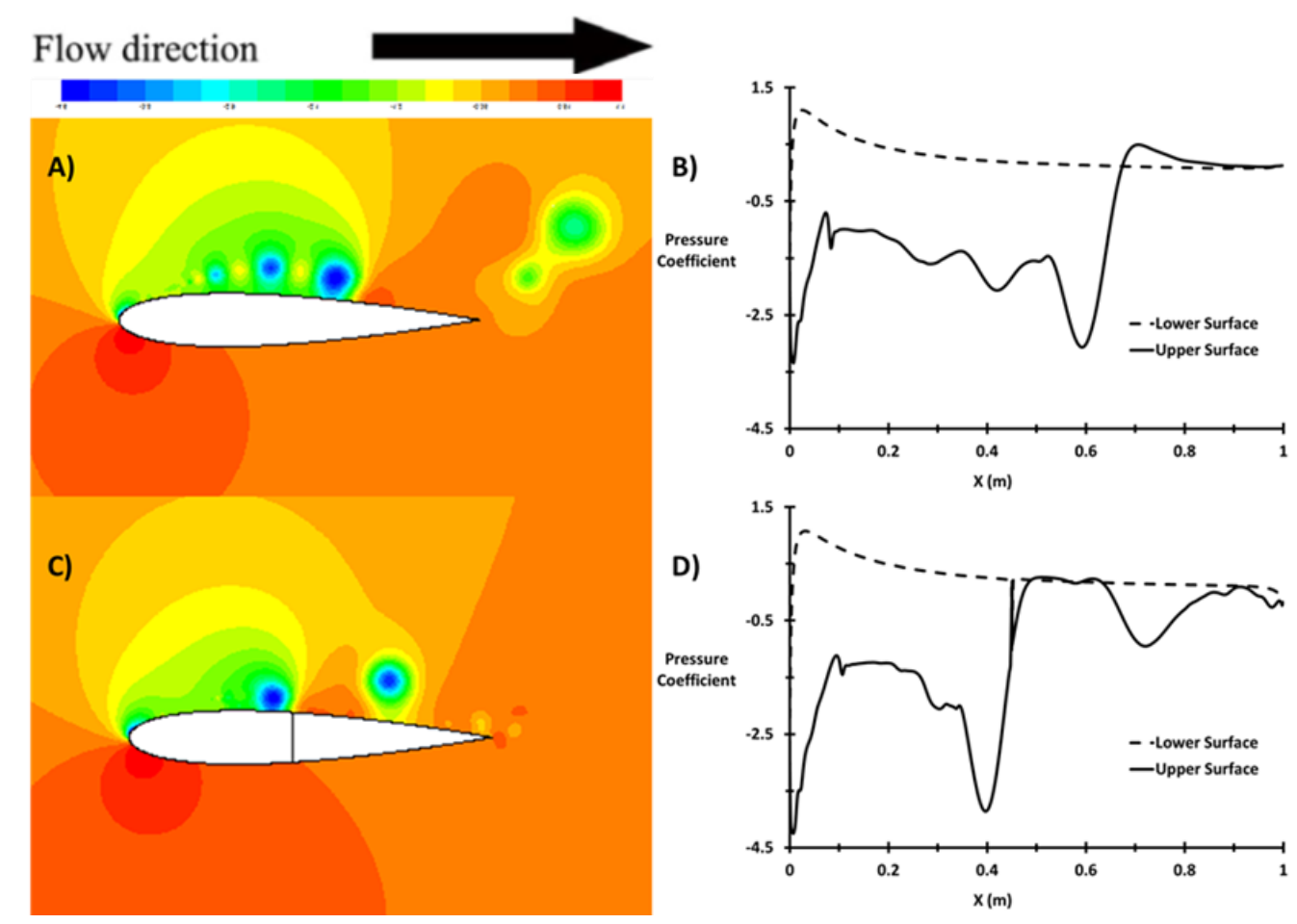

Figure 34 The pressure distribution at maximum velocity equal to $2.92(\mathrm{~m} / \mathrm{s})$ for sinusoidal input flow, at 13.6 (Degree), After the Stall 

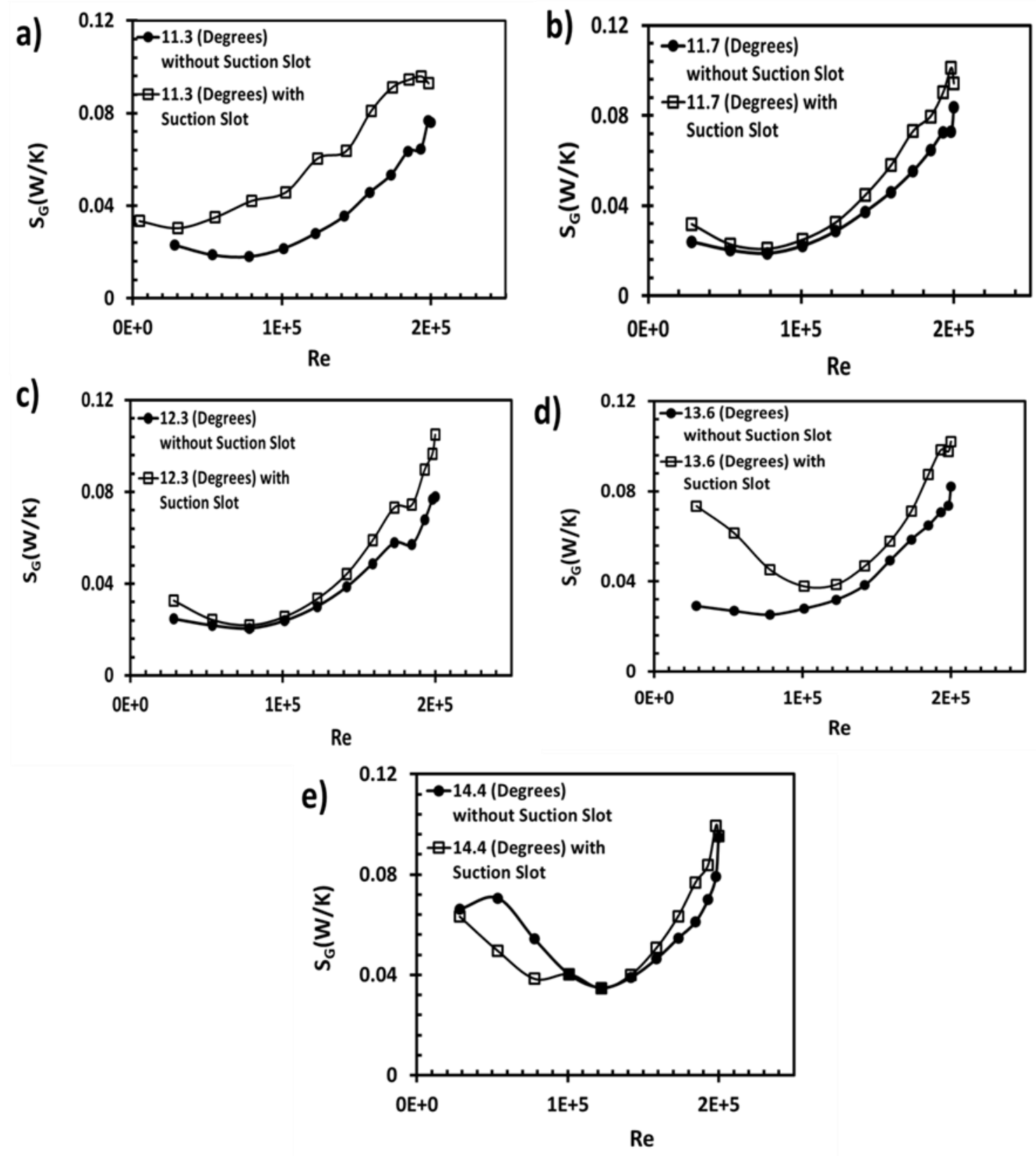

Figure 35 The global entropy generation rate variation with different Reynolds number at accelerating flow in compression cycle for different angles of attack with optimum $L_{s s}(45 \%)$ and optimum $D_{s s}(0.001 \mathrm{~m})$ 

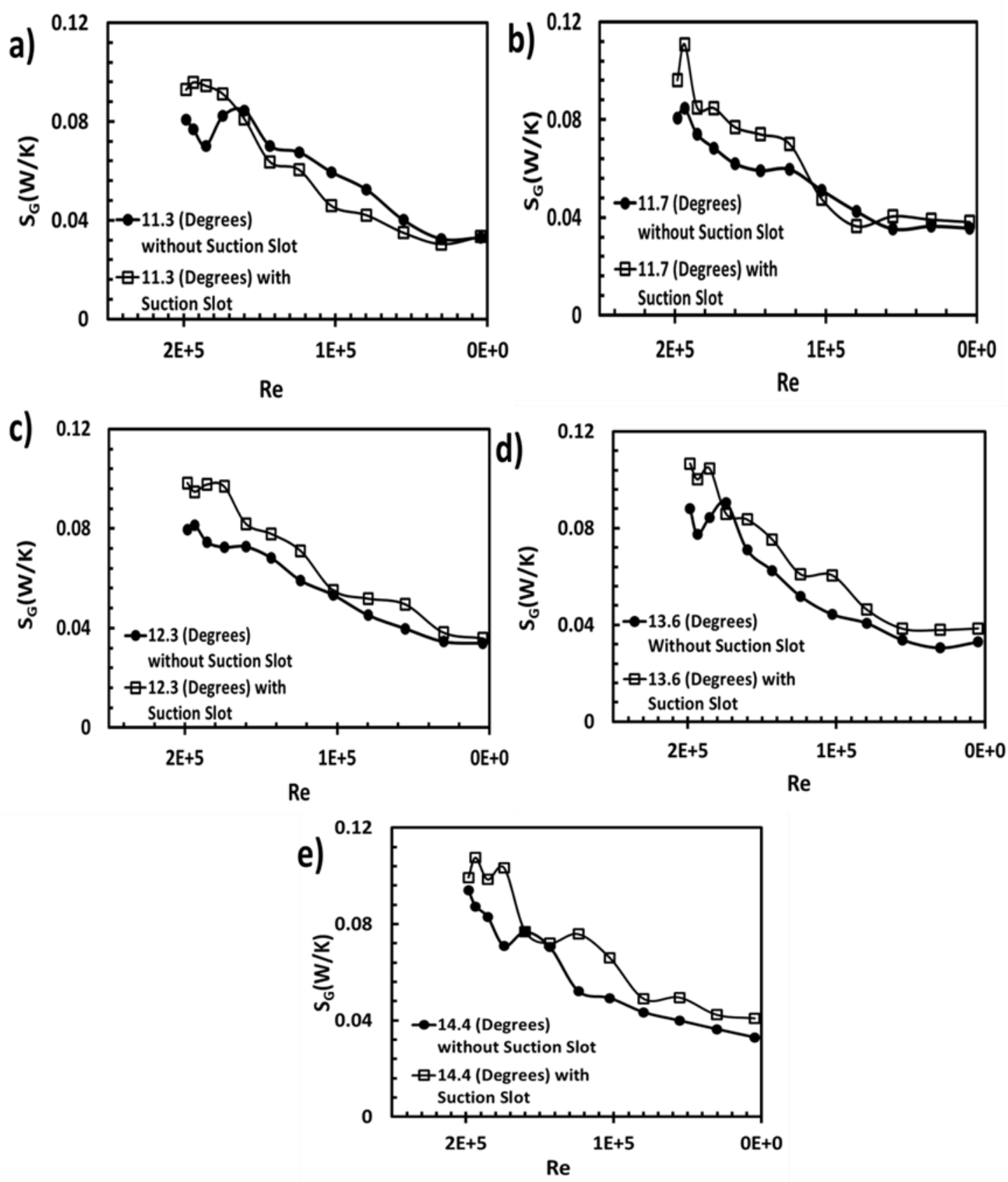

Figure 36 The global entropy generation rate variation with different Reynolds number at decelerating flow in compression cycle for different angles of attack with optimum $L_{s s}(45 \%)$ and optimum $D_{s s}(0.001 \mathrm{~m})$ 


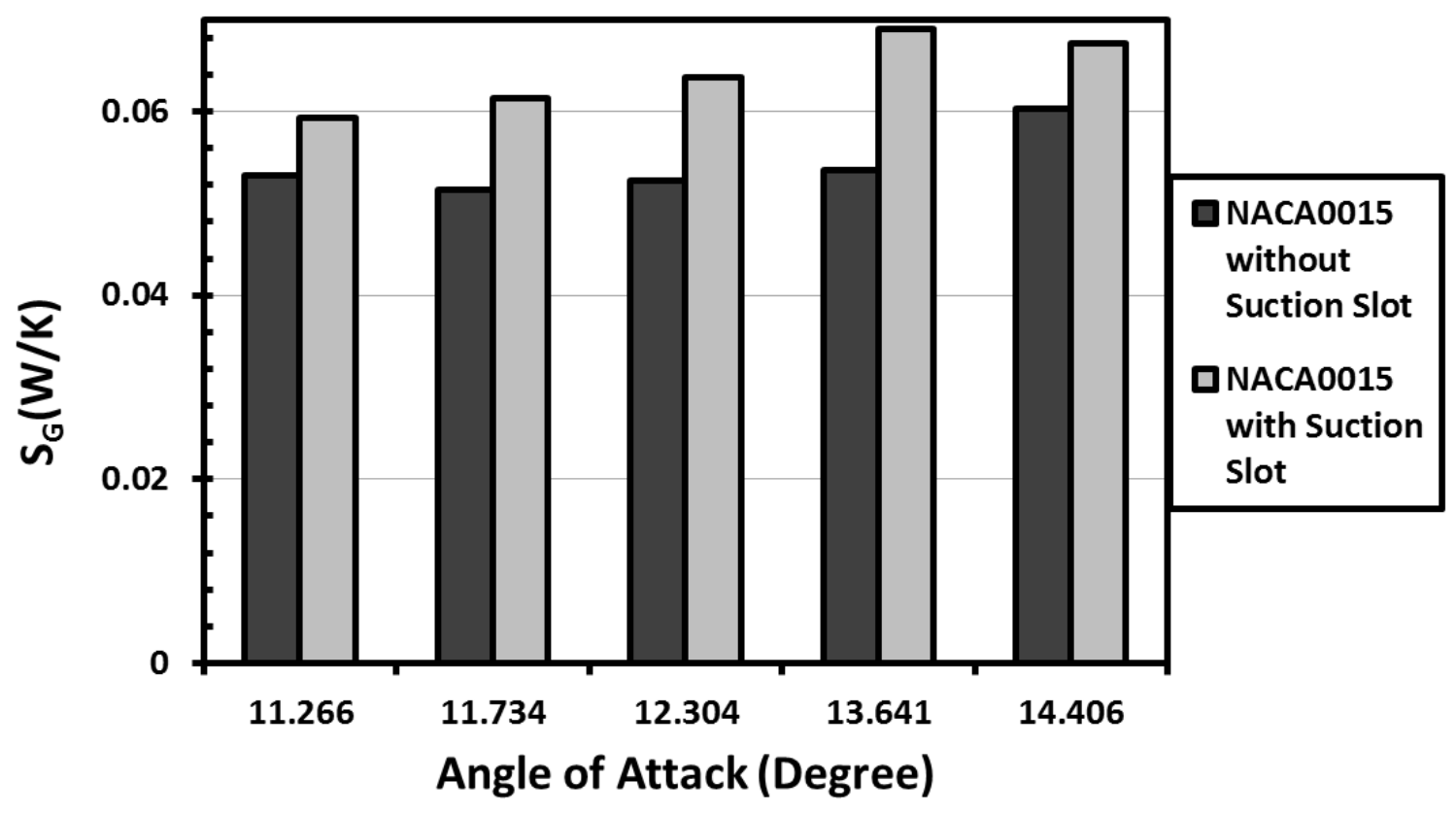

Figure 37 The global entropy generation rate in compression cycle for different angles of attack with optimum $L_{s s}(45 \%)$ and optimum $D_{s s}(0.001 \mathrm{~m})$

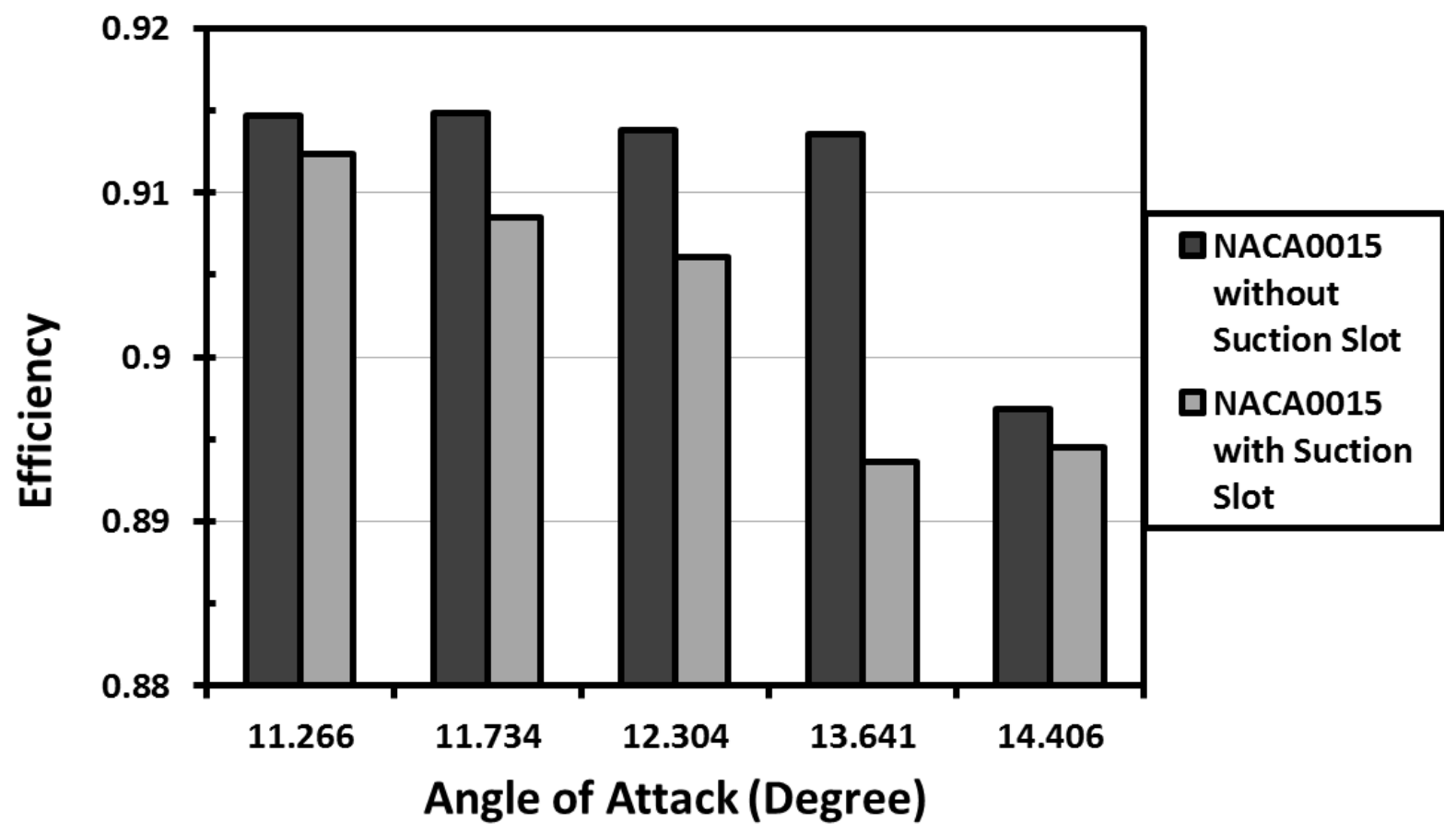

Figure 38 The second law efficiency in compression cycle for different angles of attack with optimum $L_{s s}$ $(45 \%)$ and optimum $D_{s s}(0.001 \mathrm{~m})$ 
Table 1 The error percentage between measured torque coefficient from reference (Torresi, Camporeale et al. 2007, Torresi, Camporeale et al. 2007, Torresi, Camporeale et al. 2009) and calculated torque coefficient from CFD under unsteady flow with non-oscillating velocity

\begin{tabular}{|c||c|c|c|c|c|c|c|c||}
\hline \multirow{2}{*}{ Torque Coefficient } & \multicolumn{7}{|c||}{ Angle of attack (Degree) } \\
\cline { 2 - 10 } & 8.709 & 10.097 & 10.639 & 11.266 & 11.734 & 12.304 & 13.642 & 14.406 \\
\hline Experimental & 0.0488 & 0.0631 & 0.0712 & 0.0807 & 0.0875 & 0.0922 & 0.0814 & 0.0725 \\
\hline CFD & 0.05092 & 0.06689 & 0.0726 & 0.0793 & 0.0856 & 0.091 & 0.083 & 0.0676 \\
\hline Error \% & 4 & 6 & 2 & -2 & -2 & -1 & 2 & -7 \\
\hline \hline
\end{tabular}

Table 2 The error percentage between measured $F_{D}$ from reference ((Nomura, Suzuki et al. 2003) and calculated $F_{D}$ from CFD under unsteady flow with sinusoidal inlet velocity

\begin{tabular}{|c|c|c|c|c|c|c|c|c|c|c|c|c|c|}
\hline \multicolumn{14}{|c|}{ Frequency $2 \mathrm{~Hz}$} \\
\hline \multirow{2}{*}{$F_{D} * 10^{-2}(\mathrm{~N})$} & \multicolumn{13}{|c|}{ Time (Second) } \\
\hline & $\overline{14.02}$ & 14.1 & $\overline{14.12}$ & 14.2 & 14.3 & 14.34 & 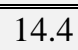 & 14.5 & 14.6 & 14.7 & 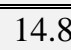 & 14.9 & $\overline{15}$ \\
\hline Experimental & 3.3 & 7.6 & 9.7 & 14.1 & 12.7 & 3.3 & 4 & 2.3 & 7.4 & 14.4 & 10.5 & 3.8 & 2.6 \\
\hline CFD & 3.7 & 7.6 & 9.6 & 14.2 & 12.3 & 3.4 & 3.3 & 2.6 & 7.6 & 14.6 & 10.7 & 3.7 & 2.4 \\
\hline Error \% & 11 & 1 & -1 & 1 & -4 & 1 & -17 & 17 & 4 & 1 & 2 & -2 & -11 \\
\hline \multicolumn{14}{|c|}{ Frequency $1 \mathrm{~Hz}$} \\
\hline Experimental & 4.4 & 6.8 & 12.4 & 13.8 & 14 & 12.7 & 10 & 7.6 & 4.6 & 2.7 & 2.3 & 2.5 & 2.9 \\
\hline CFD & 4.5 & 7.1 & 12.4 & 12.9 & 14 & 12.9 & 10.1 & 8.4 & 4.4 & 2.6 & 2.2 & 2.6 & 3.2 \\
\hline Error \% & 2 & 4 & 0 & -7 & 0 & 1 & 1 & 10 & -4 & 1 & -4 & 4 & 10 \\
\hline
\end{tabular}

Table 3 The error percentage between measured torque coefficient from reference (Torresi, Camporeale et al. 2007, Torresi, Camporeale et al. 2007, Torresi, Camporeale et al. 2009) and calculated torque coefficient from CFD under unsteady flow with sinusoidal inlet velocity

\begin{tabular}{|c|c|c|c|c|c|}
\hline \multirow{2}{*}{ Torque Coefficient } & \multicolumn{5}{|c|}{ Angle of attack (Degree) } \\
\cline { 2 - 6 } & 11.266 & 11.734 & 12.304 & 13.642 & 14.406 \\
\hline Experimental & 0.0807 & 0.0875 & 0.092 & 0.0814 & 0.0725 \\
\hline CFD & 0.0803 & 0.0879 & 0.0931 & 0.0825 & 0.0709 \\
\hline Error \% & -1 & 1 & 1 & 1 & -2 \\
\hline
\end{tabular}


Table 4 The improvement percentage between NACA0015 without suction slot and with suction slot at optimum $L_{s s}$ and $D_{s s}$ under unsteady flow with non-oscillating velocity

\begin{tabular}{|c|c|c|c|c|c|c|c|c|}
\hline \multirow{2}{*}{ Torque Coefficient } & \multicolumn{8}{|c|}{ Angle of attack (Degree) } \\
\hline & 8.709 & 10.097 & 10.639 & 11.266 & 11.734 & 12.304 & 13.642 & 14.406 \\
\hline Without Suction Slot & 0.0509 & 0.0669 & 0.0726 & 0.0793 & 0.0856 & 0.091 & 0.083 & 0.0676 \\
\hline$D_{s s}=0.001 \mathrm{~m}$ at $L_{s s}=45 \%$ & 0.0568 & 0.0744 & 0.0776 & 0.091 & 0.1022 & 0.104 & 0.119 & 0.0977 \\
\hline Improvement \% & 12 & 11 & 7 & 14 & 19 & 14 & 44 & 45 \\
\hline
\end{tabular}

Table 5 The improvement percentage between NACA0015 without suction slot and with suction slot at optimum $L_{s s}$ and $D_{s s}$ under unsteady flow with sinusoidal inlet velocity

\begin{tabular}{|c||c|c|c|c|c||}
\hline \hline \multirow{2}{*}{ Torque Coefficient } & \multicolumn{5}{|c|}{ Angle of attack (Degree) } \\
\cline { 2 - 7 } & 11.266 & 11.734 & 12.304 & 13.642 & 14.406 \\
\hline Without Suction Slot & 0.0803 & 0.0879 & 0.0931 & 0.0825 & 0.0709 \\
\hline $\boldsymbol{D}_{\boldsymbol{s s}}=\mathbf{0 . 0 0 1} \mathbf{m}$ at $\boldsymbol{L}_{\boldsymbol{s s}}=\mathbf{4 5} \%$ & 0.1008 & 0.1019 & 0.104 & 0.126 & 0.094 \\
\hline Improvement \% & 26 & 16 & 11 & 53 & 32 \\
\hline
\end{tabular}

